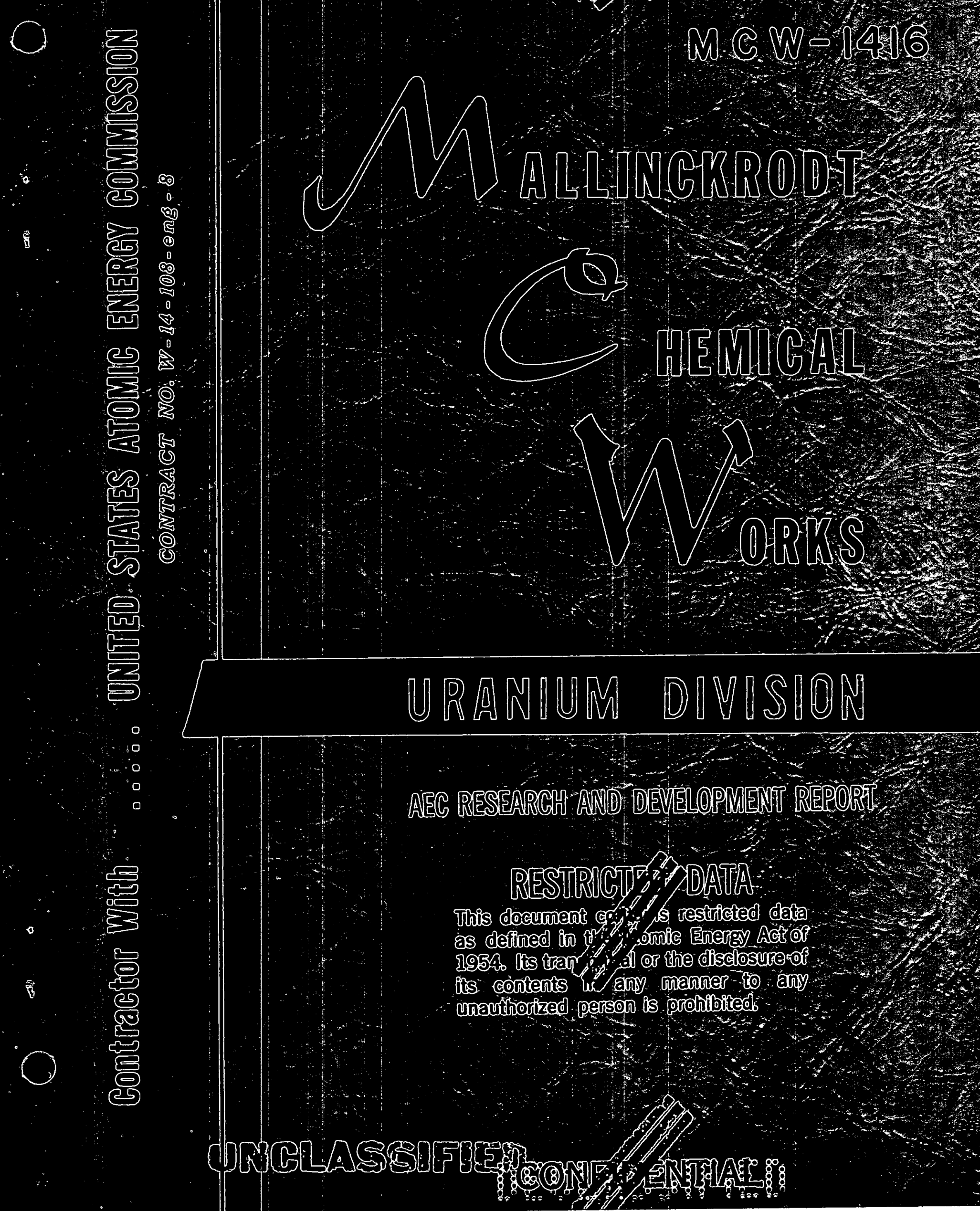




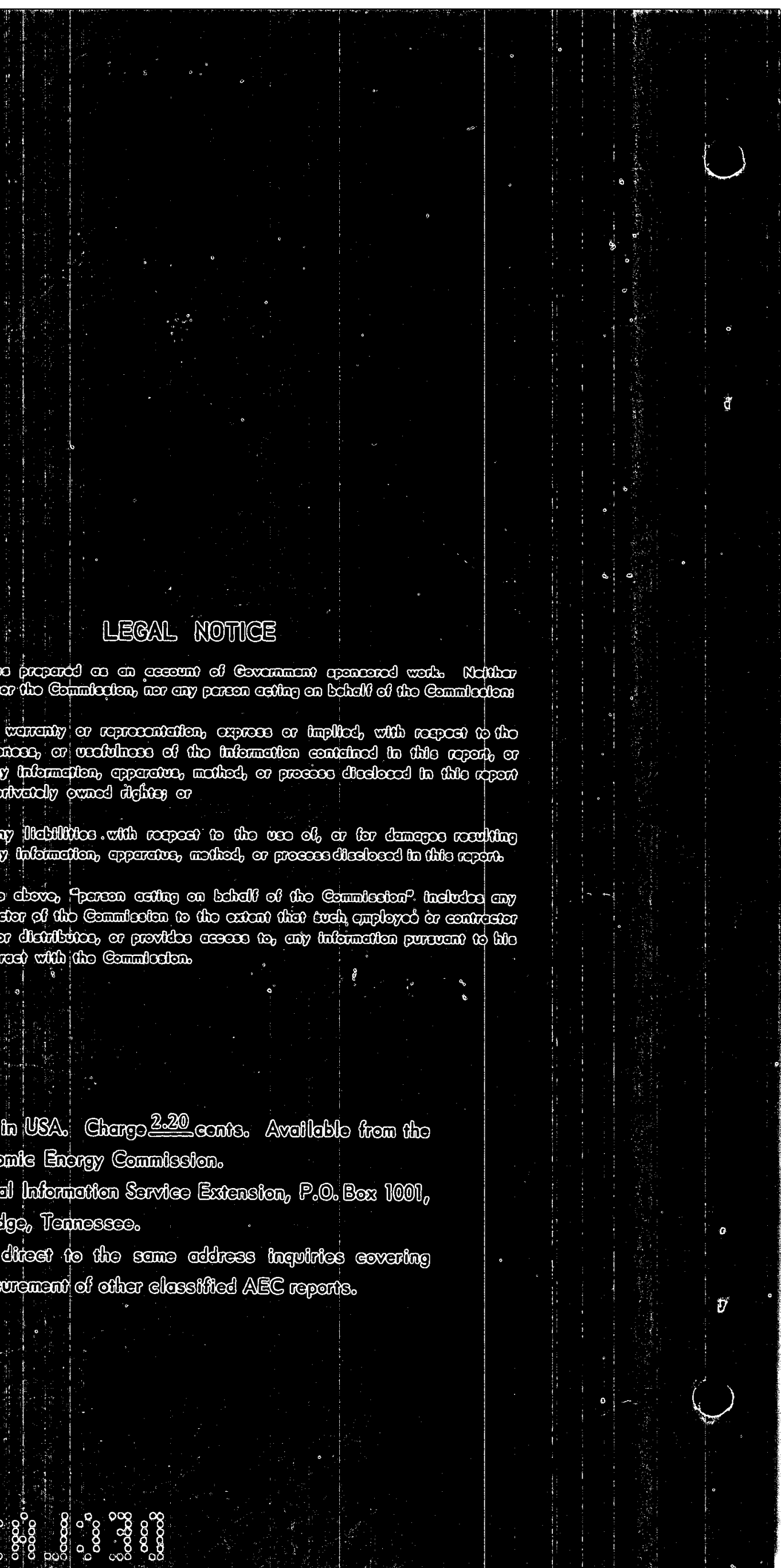


Date of Issue: August 1, 1958

Report Number: MCW-1416

Subject Category: Technology - Feed Materials

(M-3679, 22nd Ed.)

\section{PROCESS DEVELOPMENT QUARTERLY REPORT \\ PART II - PILOT PLANT WORK}

edited by John Nelson

The work reported berein was done under the general supervision of the following

Classification cancelled lor changed to UNCLASJIFIED

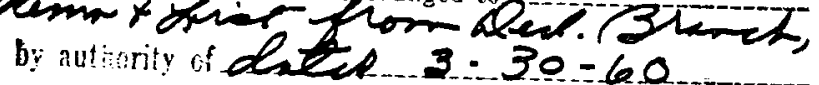

6:

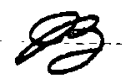

TE, dite $4-7-60$

N. E. Berry

Technical Director

A. E. Ruehle

Assistant Technical Ditector

R. M. Edwards

Manager, Process Development

C. Wuhlman, Jr.

Manager, Laboratory Development

\author{
J.A. Fellows \\ Manager, Metallurgical Development \\ J. U. Shepardson \\ Manager, Analytical Laboratory
}

E. I. Miller

Plant Manager, Operations Division

J. H. Yeager

Manager, Production Technology

This is a progress report on current work and is issued as promptly as possible at the end of the quarter. As a result, it is subject to inaccuracies.

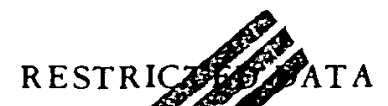

This document contains restricted data as in the Atomic Energy Act of 1954. Its transmittal or the disclosure of its contents in an to any unauthorized person is prohibited.

\section{Mallinckrodt Chemical Works}

St. Louis, Missouri

\section{UNCLASSIFIED}


• 
Report Number: $M C W-1416$

Date of Issue: August 1, 1958
Subject Category: Technology - Feed Materials

Tirle: PROCESS DEVELOPMENT QUARTERLY

REPORT, PART II - PILOT PLANT WORK

\section{External Distribution}

Aeroprojects, Inc.

1

Air Technical Intelligence Center

1

Allied Chemical and Dye Corporation

Argonne National Laboratory

Armed Forces Special Weapons Project, Sandia

Armed Forces Special Weapons Project, Washington

Atomic Energy Commission, Washington

Babcock and Wilcox Company (SOO-274)

Battelle Memorial Institute

Bridgeport Brass Company

Chicago Operations Office

Chicago Patent Group

Division of International Affairs (Pennington)

Division of Raw Materials, Washington

duPont Company, Aiken

Dr. M. H. Wahl

Mr. T. C. Evans

Dr. R. T. Huntoon

Fernald Area Office, Mr. C. L. Karl

General Electric Company, Richland

Dr. S. H. Bush

Dr. J. J. Cadwell

Mr. S. M. Gill

Mr. R. E. Olsen (3703 Building)

Dr. P. H. Reinker

Mr. K. V. Stave

Mr. F. W. Woodfield

Dr. L. P. Bupp and Dr. J. F. Music

Mr. J.. T. Stringer

Goodyear Atomic Corporation
2

1

1

2

1

1

1

1

1

1

1

2

1

.1

1

1

4

1

1

1

1

1

1

1

1

1

2 
Hanford Operations Office

lowa State College

Mound Laboratory

National Lead Company, Inc. (Winchester)

National Lead Company of Ohio

Dr. D. S. Arnold

Mr. C. E. Polson

Dr. C. E. Crompton

New Brunswick Area Office

New York Operations Office

Nuclear Metals, Inc.

Oak Ridge Operations Office

Patent Branch, Washington

Power Reactor Development Company

Union Carbide Nuclear Company (ORGDP)

Union Carbide Nuclear Company (ORNL)

Union Carbide Nuclear Company (Paducah Plant)

Vitro Engineering Division

Technical Information Service Extension, Oak Ridge
No. of Copies

1

1

1

1

3

1

1

1

1

1

1

1

1

1

6

4

1

1

40 
Report Number: MCW-1416

Date of Issue: August 1, 1958
Subject Category: Technology - Feed Materials Title: PROCESS DEVELOPMENT QUARTERLY REPORT, PART II - PILOT PLANT WORK

\section{Internal Distribution}

Dr. N. E. Berry

No. of Copies

Mr. B. J. Buntz

Mr. K. J. Caplan

Mr. F. R. Dowling

Mr. R. M. Edwards

Dr. P. J. Fain

Dr. R. H. Fariss

Dr. J. A. Fellows

Dr. C. D. Harrington

Mr. R. F. Hartmann

Dr. J. A. Kennelley

Mr. H. C. Kloepper

Mr. J. T. Krieg

Dr. C. W. Kuhlman

Mr. G. P. Lang

Dr. F. J. Ludwig

Metal Pilot Plant Files

Mr. E. I. Miller

Dr. J. P. Morgan

Dr. D. E. Morris

Mr. H. Myers

Mr. J.A. Nelson

Dr. N. F. Neumann

Mr.W. G. Petty

Dr. W. C. Philoon

Mr. R. D. Piper

Dr. W. Robertson

Mr. A. E. Ruehle

Mr. E. F. Sanders

Dr. J. U. Shepardson 
Internal Distribution (continued)

Mr. J。W. Stevenson

$\frac{\text { No. of Copies }}{1}$

Mr. E. K. Teter

Mr. H. E. Thayer

Mr. L. G. Weber

Mr. R. B. Wrinkle

Mr. J. H. Yeager

Dr.W. A. Ziegler

Technical Eibrary

Technical Editor

1

1

1

1

1

1

2

1

आTालिए। 


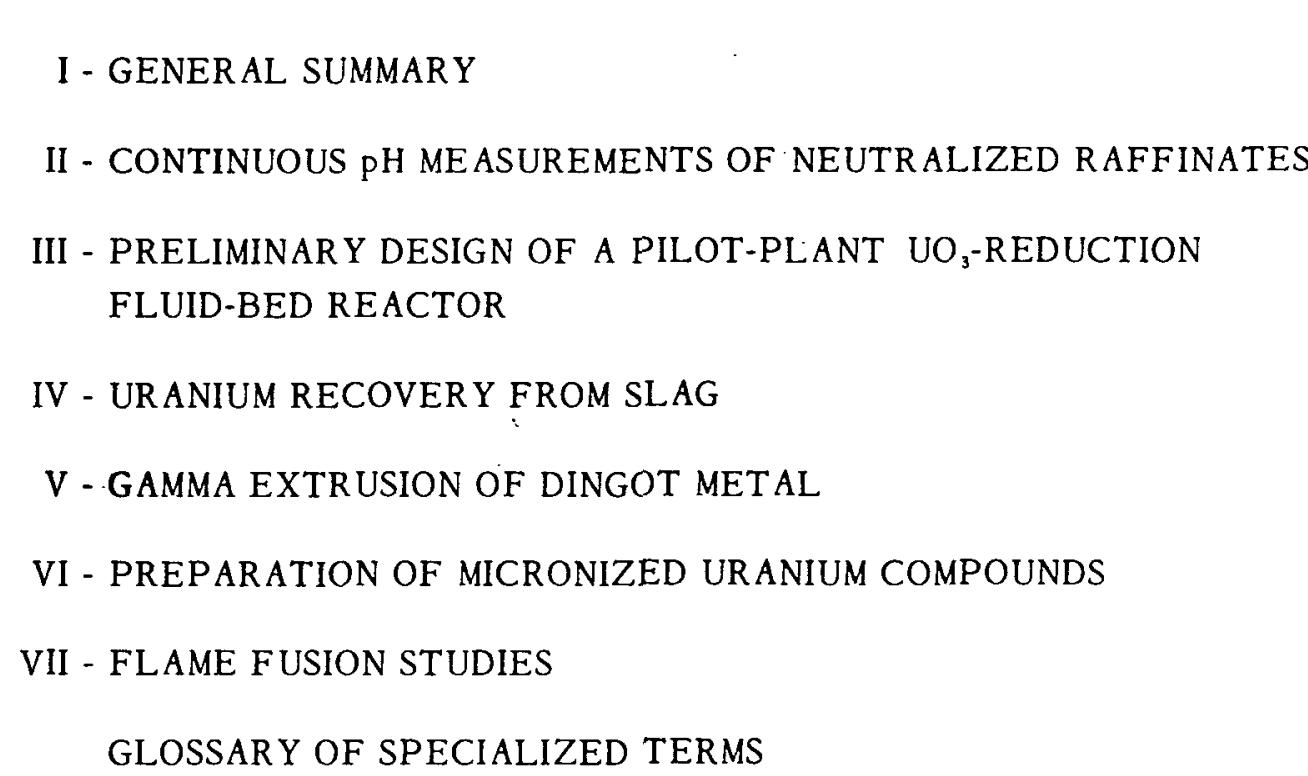

Page No.

9

11

17

27

37

81

93

103 
•

•

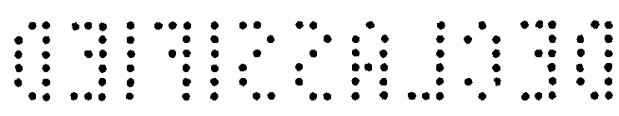




\section{GENERAL SUMMARY}

Work was continued during this quarter on the recovery of uranium from slag, the gamma extrusion of uranium, and on fuel element studies. The results of an investigation on automatic control of neutralization of raffinate, and of thepreliminary design of a pilot-plant $\mathrm{UO}_{3}$-reduction fluid-bed reactor are reported.

Specific studies are summarized as follows (Roman numeral refers to the section on which the summary is based):

II. Based on experimental studies in the pilot plant, a proposal is presented for the use of a $\mathrm{pH}$ meter to control automatically the addition of lime in the neutralization of raffinate.

III. Design calculations have been made for a continuous pilot-plant fluid-bed reduction reactor of tapering cross-sectional area to handle 50 pounds per hour of fluid-bed-denitrated $\mathrm{UO}_{3}$.

IV. Tests in an eight-inch-diameter screw reactor showed that the uranium content of MFL could be reduced to $0.15-0.20 \%$ by treatment with fluorine at elevated temperatures.

V. Evaluations at Bridgeport Brass Company of die materials for gamma extrusion of uranium have confirmed that sintered chromium carbide dies attain excellent die life and provide good extruded surfaces. Concave-faced graphite follower blocks have not improved the yield in gamma extrusion when used with flat-faced billers.

Studies conducted at Dow Chemical Company of special follower blocks confirm that contour, temperature, and material all require careful selection for achievement of optimum metal yields. Full-sized carbide dies have produced good extruded bar surfaces but require care in butt severance to avoid damage by shear blades. Separation of the butt without need for shears or saw has been shown to be feasitle by penetrating the butt with a circular punch slightly smaller than the die opening.

VI. WAPD-grade $\mathrm{UO}_{2}$ was ground to an average particle size of $0.8 \mathrm{micron}$ in an eight-inch-diameter Micronizer at production rates between 20 and 50 pounds per hour.

VII. Fusion in an atomic hydrogen arc shows promise as a method for growing single crystals of pure $\mathrm{UO}_{2}$ for fuel element use, employing either $\mathrm{UO}_{2}$ or $\mathrm{UO}_{3}$ powders as starting materials.

Laboratory work for this quarter has been reported in Part I as a separate volume. 
-

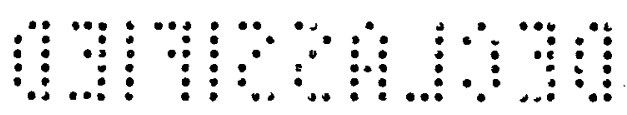

$\theta$ 
by

N. G. Holloway

\section{Summary}

A continuous $\mathrm{pH}$ monitor operated satisfactorily in neutralized raffinate slurry for a period of one month in the pilot plant. No evidence of electrode deterioration could be detected.

Introduction

Before the refinery raffinate is pumped to the disposal pits, it is neutralized with lime to minimize acid pollution of the countryside and to protect the quarter mile of carbon steel transfer line. At present the raffinate neutralization operation is controlled by means of samples analyzed in the laboratory. An instrument that would continuously monitor raffinate pH would (1) simplify refinery operations, (2) provide an automatic safeguard against inadvertent pumping of acid raffinate to the pits, and (3) minimize present excessive overneutralization of raffinate, with resultant lime cost savings.

This report describes pilot plant tests of a continuous pH monitor on neutralized plant raffinates.

Description of Materials and Equipment

A schematic flow diagram of the test stand is shown in Figure 1. Neutralized plant raffinate was pumped out of a hold cank through a cell containing the test electrodes and back again into the hold tank. The electrodes used in this test were standard Beckman electrodes; the glass electrode was Model No. 4990-80 and the reference electrode was Model No. 4970. For plant use a larger reference electrode, such as the Beckman No. 8970-90, is recommended with a No. $4990-83$ glass electrode. The meter used in this test was a Beckman Model $N$; however, in plant use a heavy-duty industrial type like the Beckman Model W meter would be used in conjunction with any standard recorder-controller

The vessel in which the electrodes were mounted was designed to minimize the problems of handling a slurry. In order to prevent build up of soiids in the chamber the botcom was sloped and the efluent discharged from the bottom at the lowest point. Raffinate was introduced into the chamber through the top at a point opposite to the discharge. The vessei was vented, and the discharge opening was slightly smaller than the inlet. The electrodes were mounted through the top of the chamber. By using this type of vessel the flow could be regulated to keep the chamber full under atmospheric pressure and to prevent scale formation on the electrodes. 


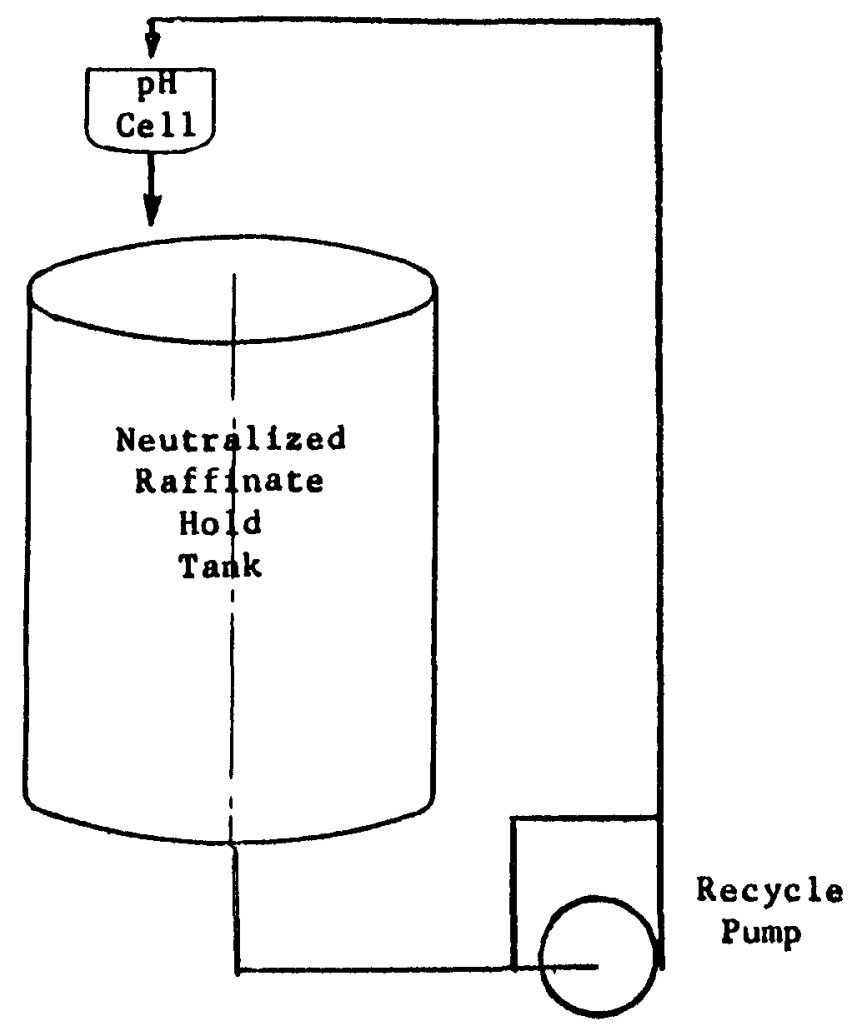

FIGURE 1

SCHEMATIC OF PH-METER TEST STAND IN THE PILOT PLANT

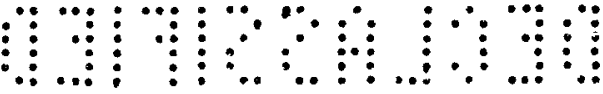


Experimental Procedure

Two battery-operated Beckman $\mathrm{pH}$ meters were used during the test. One was included in the continuous monitoring system and the other was kept in the pilot plant laboratory and used under carefully controlled conditions. The two instruments were standardized against the same buffer solution and checked for proper operation daily. Readings were made of the $\mathrm{pH}$ on the continuously measuring instrumeat hourly during the day shift and a sample of the material was taken at the same time for $\mathrm{pH}$ determination on the bench meter. During operation, raffinate flow past the electrodes was regulated at five $\mathrm{ft} / \mathrm{min}$ to prevent scaling. Erosion of the electrodes could not be detected at this flow rate. The electrodes of the continuous meter were in contact with stagnant raffinate each night to simulate refinery conditions while the electrodes of the bench meter were kept in distilled water.

Results and Discussion

A comparison of continuous versus "bench" $\mathrm{pH}$ measurements is shown in Table $\mathrm{I}$.

\begin{tabular}{|c|c|c|}
\hline \multirow[b]{2}{*}{$\begin{array}{c}\text { Continuous } \\
\text { Measurement } \mathrm{pH}\end{array}$} & pH of Refinery Raffinates ${ }^{a}$ & \multirow[b]{2}{*}{ Difference } \\
\hline & $\begin{array}{c}\text { Bench } \\
\text { Meter pH }\end{array}$ & \\
\hline 8.35 & 8.30 & +0.05 \\
\hline $8: 40$ & 8.25 & +0.15 \\
\hline 8.30 & 8.20 & +0.10 \\
\hline 8.30 & $8: 20$ & +0.10 \\
\hline 8.30 & 8.20 & +0.10 \\
\hline 8.20 & 8.15 & $\div 0.05$ \\
\hline 8.20 & 8.20 & 0.00 \\
\hline 8.25 & 8.15 & +0.10 \\
\hline $8: 25$ & $8: 40$ & -0.15 \\
\hline 8.25 & 8.65 & -0.40 \\
\hline 8.15 & 8.30 & -0.15 \\
\hline 8.20 & 8.20 & $0: 00$ \\
\hline 8.20 & 8.25 & -0.05 \\
\hline $8: 10$ & 8.20 & -0.10 \\
\hline 7.9 & 8.0 & -0.10 \\
\hline 7.8 & 8.0 & $-0: 20$ \\
\hline
\end{tabular}

These figures comprize a representative sample of the total data; one hundred and three measurements were made in all. 
As can be seen in the tabulated data, there is very little difference between the measurements obtained with the continuous monitor and the bench meter. The maximum deviation obtained was $0.4 \mathrm{pH}$ units. Statistical analysis of the data indicates that no real difference can be proven to exist between the two sets of data.

Conclusions and Suggestions

The $\mathrm{pH}$ of refinery raffinate can be monitored with a continuous measuring system, providing precautions are taken to prevent damage to the electrodes.

A suggested plant application of the continuous $\mathrm{pH}$ monitoring system is shown schematically in Figure 2. The control system is arranged so that the raffinate is continuously recycled through the neutralization tank during the addition of lime. After neutralization, the lime addition would be stopped and the raffinate pumped to the storage ponds automatically by closing the valve in the recycle line and opening the valve in the pump-out line.

Arrangements should be made to flush the measuring chamber and check the zero drift of the instrument periodically. 
FICURE 2

SCHEMAIIC OF SUGGSTED PH-RETER APPLICATION FOR RAFFINATE NEUTRALIZATION

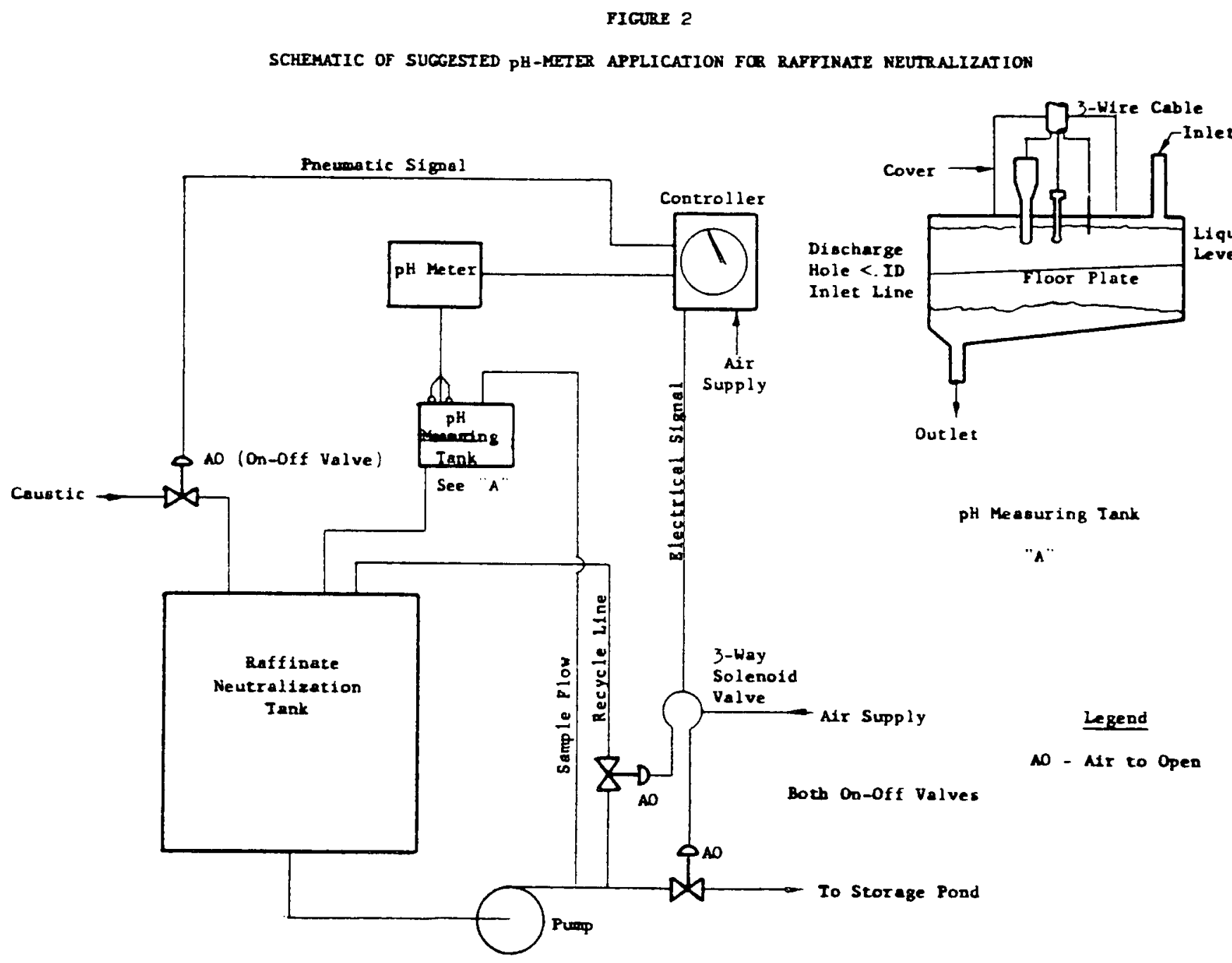




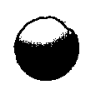


PRELIMINARY DESIGN OF A PILOT-PLANT
UO $_{3}$-REDUCTION FLUID-BED REACTOR

by

S. N. Robinson

W. J. S. Smith

B. E. Zimmerman

Summary

Calculations have been made for the design of a fluid-bed reactor for the continuous reduction of fluid-bed-denitrated $\mathrm{UO}_{3}$ to $\mathrm{UO}_{2}$ with cracked am monia. A bed of varying cross-section was chosen to permit approach to "piston" flow of solids. A bed with cylindrical sides containing a tapered mandrel was selected in preference to a bed with tapered sides because of ease of fabrication and greater flexibility.

For a processing rate of $50 \mathrm{lb} \mathrm{UO}_{3} / \mathrm{hr}$ with $\mathrm{UO}_{3}$ in the minus-35 to plus-65 mesh particle size range, a reactor shell 5 inches in diameter and $4.4 \mathrm{ft}$ tall was indicated. A tapered mandrel, 2.89 inches in diameter at the bottom and 0.63 inches in diameter at the top, is required.

\section{Introduction}

Currently there is a strong impetus for investigation of fluidized-bed techniques for the various gas-solids processes encountered in the uranium feed materials industry. Chief reasons for this impetus are that fiuid bedsare free of moving parts, are simple to construct and maintain, are virtually isothermai because of high vertical and horizontal heat transfer coefficients, permit easy handling of the solids, and provide the best possible gas-solids mass transfer. However, conventional fiuidized beds are also aimost perfect mixers. This fact, of course, means that for fluid beds used as reactors some of the solid particies are in the bed an insufficient time for complete reaction. To insure complete conversion, then, it becomes necessary to

1) build the teactor large enough to provide a long turnover time, which then assures that, say, $98 \%$ of the solids are present she required time for complete reaction, or,

2) cascade several reactors either vertically, so that the same gas fluidizes each stage, or horizontally, with paraliei gas flow.

Most uranium compounds have high bulk densities and consequently require high fluidizing gas rates. Because of this fact it is usualiy impractical to build long turnover-time reactors.

Horizontal multi-stage reactors exhibit the same large gas consumption (heretofore the exiting gas from one stage has not been used to fluidize another stage). Vertical stages offer economical gas 
consumption, but are difficult to design and operate because of the tendency of the gas to shortcircuit through the plate-to-plate downcomers.

To counter this disadvantage of the fluid bed, investigators at Y-12 have developed the taperedshell fluid bed. ${ }^{12}$ By providing a reactor cross-section which varies with the height of the bed, it has been possible to keep the fluidizing velocity approximately constant throughout the bed.

(In a cylindrical bed it will be recognized that friction losses cause a reduction in pressure and a consequent increase in velocity as the gas rises through the bed.) If the gas velocity is kept within a narrow range about that which defines incipient fluidization, turbulent mixing in the bed is virtually eliminated. The vertical solids movement closely approximates "piston" flow.

There are other advantages which the tapered bed has over a cylindrical bed. Solids elutriation is less, and greater height-to-diameter ratios can be employed without disastrous slugging in the upper portion of the bed.

However, the tapered shell is difficult to fabricate and lacks flexibility. If gas flow rate, particle size, or temperature are changed, the tapered bed no longer assures low solid mixing rates; turbulence in the bed will increase as the difference between design and operating conditions becomes greater.

As an alternative to the tapered shell, it is possible to use a tapered mandrel, installed in a cylindrical shell. This mandrel would be designed for constant gas velocity through the bed, and thus should duplicate the fluidization characteristics of the tapered shell.

The obvious advantage of the mandrel design is versatility, since replacement of a mandrel with one of different taper is easy. A mandrel should be inexpensive to fabricate. Further, a mandrel would offer an excellent method for internal cooling of the bed.

Preliminary Design Calculations and Discussion

Scoping calculations have been performed to determine the dimensions of a pilot plant fluid-bed reactor for the reduction of fluid-bed-denitrated $\mathrm{UO}_{3}$ according to the reaction $\mathrm{UO}_{3}+\mathrm{H}_{2} \rightarrow \mathrm{UO}_{3}+\mathrm{H}_{2} \mathrm{O}$. Results of these calculations are presented in this report.

Uranium Chemistry and Analytical Development Excerpts from Y-12 Plant Quarterly Report, First Fiscal Quarter, 1958. Union Carbide Nuclear Company, Y-B65-169 (November 22, 1957), p 8-10

2U Uranium Cbemistry and Analytical Development Excerpts from Y-12 Plant Quarterly Report, Second Fiscal Quarter, 1958, Union Carbide Nuclear Company, Y-B65-191 (February 26, 1958), p 15-18

3. $Y$-B 65.191 
For the first series of calculations, the results of which appear in Table I, it was desired to determine the degree of conversion occurring in a one- or two-stage cylindrical fluid bed. Perfect mixing was assumed, permitring the use of turnover-time distribution curves appearing in the literature." The reaction rate curve used for these and subsequent calculations was obtained by the thermobalance technique. ${ }^{5}$ It is presented in Figure 1.

\section{Table I}

Reduction of Fluid-Bed-Denitrated UO, in Multi-stage Cylindrical Fluid-Bed Reactors

\begin{tabular}{lcc} 
& Case I-A & Case I-B \\
\cline { 2 - 3 } Number of Stages & 1 & 2 \\
Feed Rate, Ib $\mathrm{NO}_{3} / \mathrm{hr}$ & 80 & 80 \\
Total Turnover Time, hr & 3 & 3 \\
Volume/Stage, cu ft ${ }^{a}$ & 1.2 & 0.6 \\
Reaction Temperature, ${ }^{\circ} \mathrm{F}$ & 1050 & 1050 \\
Average Total Conversion, \% & 73 & 84 \\
a Assuming $20 \%$ bed expansion and a bulk density of $237 \mathrm{lb} / \mathrm{cu} \mathrm{ft}$.
\end{tabular}

It can be seen that more than two stages would be needed for complete conversion of $80 \mathrm{lb}$ $\mathrm{UO}_{3} / \mathrm{hr}$, which is the anticipated production rate of the fluid-bed denitrator. In fact, ANL has found that for an average total turnover time of 2.6 hours four stages were necessary to produce $98 \% \mathrm{UO}_{2} \cdot{ }^{\circ}$ Of course, conversion could be increased by making each stage larger or by considerably reducing the feed rate, but for pilot plant purposes, neither alternative is desirable.

\footnotetext{
4 Perry, John H. (Editos), Cbemical Engineers ${ }^{j}$ Handbook, McGraw-Hill Book Company, Inc., New York (1950), Ed. 3, p 1230-1231

5: Ludwig, F. J., Mallinckrodt Chemical Works, Petsonal Communication

- Jonke, A. A., Cbemical Enginee:ing Division Summary Report, October, Noyember, and December, 1957, Argonne National Labozatory, ZANL.5820 (F ebruary, 1958), p 49-52
} 
TYPICAL REACTION RATE CURVE FOR REDUCTION OF FLUID-BED-DENITRATED VO ${ }_{3}^{a}$

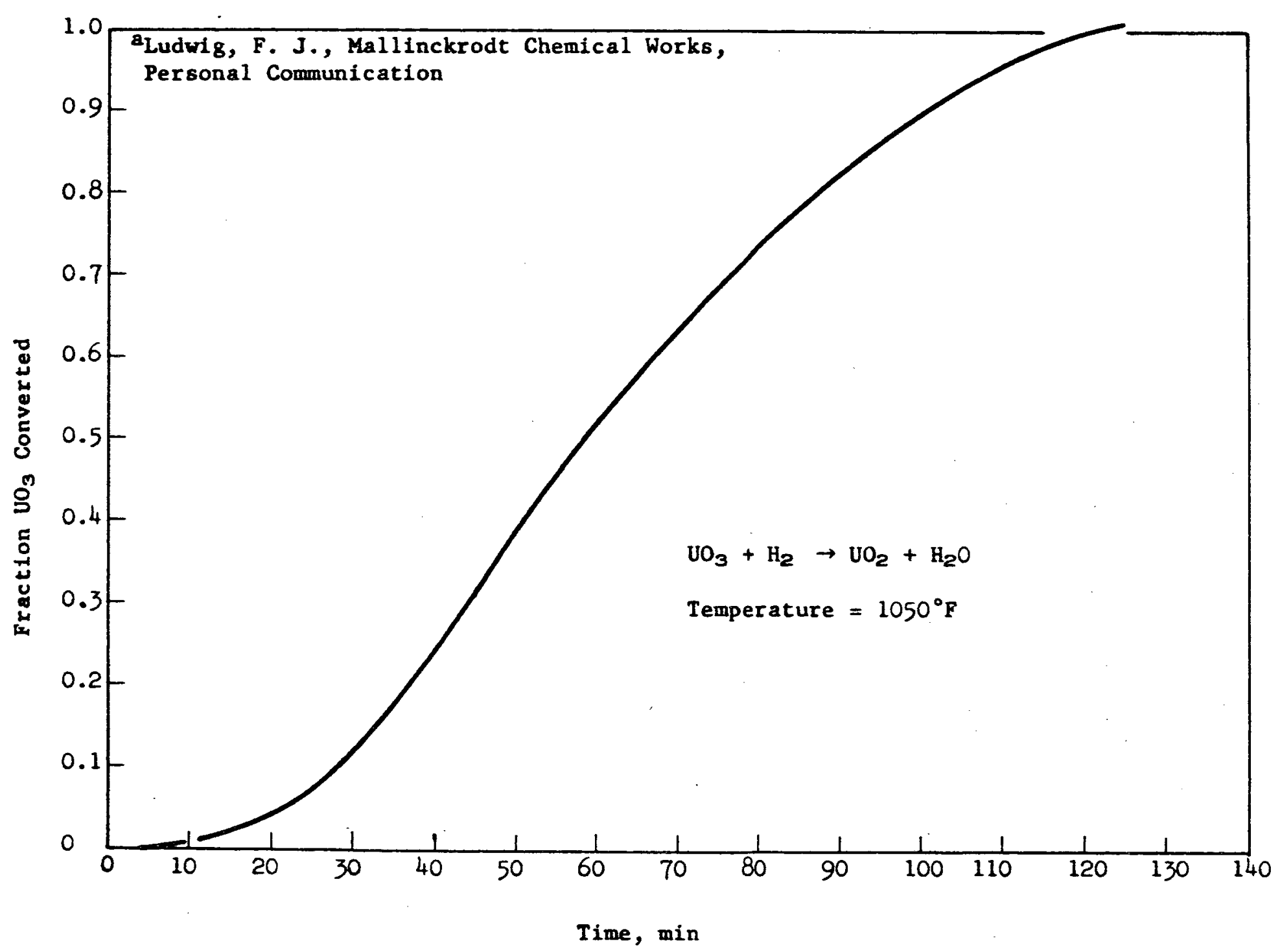

$\therefore \ldots:$

$\vdots \ldots . .:$

.......

…:

$\cdots$

$\because \because:$

$\because \because:$

$\ldots: .$.

$\vdots . . .$.

$\therefore$

$\vdots . . .: \vdots$

:....:

Time, min 
Calculations for a tapered-shell fluid-bed reduction reactor are presented in Table II. Again the basis was a productioncate of $80 \mathrm{lb} \mathrm{UO}_{3} / \mathrm{hr}$. A particle size range of -35 to $+65 \mathrm{mesh}$ was used, for which $237 \mathrm{lb} / \mathrm{cu}$ ft and 1.5 to $1.8 \mathrm{ft} / \mathrm{sec}$ are reasonable values of the fluidized density and fluidization velocity range, respectively. ${ }^{7}$ For these computations $1.8 \mathrm{ft} / \mathrm{sec}$ was assumed as the fluidizing velocity. Reaction temperature was set at $1050^{\circ} \mathrm{F}$. Total average turnover time was set at 2.5 hours. This value is higher than the 120 minutes needed for complete conversion because the tapered bed does not exhibit perfect "piston" flow; this value is also consistent with the Argonne data mentioned above.

\section{Table II}

Reduction of Fluid-Bed-Denitrated UO, in a Tapered Fluid-Bed Reactor

Bases for Calculated Data:

Feed Rate

Feed Particle Size

Superficial Fluidizing Velocity at Bed Conditions

Fluidized Density

Reaction Temperature

Turnover Time
$80 \mathrm{lb} \mathrm{UO}_{3} / \mathrm{hr}$

-35 to +65 mesh

$1.8 \mathrm{ft} / \mathrm{sec}$

$237 \mathrm{lb} / \mathrm{cu} \mathrm{ft}$ $1050^{\circ} \mathrm{F}$

$2.5 \mathrm{hr}$
Fluidizing Gas Flow, SCFH

Bottom Cone Diameter, in.

Top Cone Diameter, in.

Height of Bed, ft

$\Delta P$ Across Bed, psi
Case II-A 300

3.6

5.0

8.4

13.8
Case II-B

400

4.5

5.7

6.0

9.8
Case II- $\epsilon$ 500

5.2

6.4

4.6

7.6
Case II-D 700

6.6

7.6

3.1

5.1

7 Robinson, S. N., and Smith, W. J. S., Repo:t on Tripto Y.12, Mallinckrode Chemical Works, Project Memorandum 1017-P (June 18, 1958) 
The equations used to compute the size of the conical bed are straightiforward, although somewhat approximate. For a constant velocity at any point in the bed, the shell taper would be slightly parabolic. The simplification resulting from the assumption of a linear taper is accurate enough for scoping purposes, however. The equations are

1) $\mathrm{V}=$ volume of reactor $-\frac{\mathrm{R} \theta}{\rho_{\mathrm{S}}}-\frac{h}{3}\left(\mathrm{~S}_{\mathrm{B}}+\mathrm{S}_{\mathrm{T}}+\sqrt{\mathrm{S}_{\mathrm{B}} \mathrm{S}_{\mathrm{T}}}\right)$,

2) $S_{T}=\frac{Q}{3600} \times \frac{T_{R}}{492} \times \frac{14.7}{P_{T}} \times \frac{1}{U}$,

3) $S_{B}=\frac{Q}{3600} \times \frac{T_{B}}{492} \times \frac{14.7}{P_{T}} \times \frac{1}{U}$,

4) $P_{B}-P_{T}+\Delta P$,

5) $P-\frac{h \times \rho_{s}}{144}$,

where

$R$ - feed rate, $\mathrm{lb} \mathrm{UO}_{3} / \mathrm{hr}$,

$\theta$ - desired turnover time, hr,

$\rho_{s}$ - fluidized density, lb/cu ft,

h - height of reactor, $f t$,

$\mathrm{S}$ - free cross-sectional area, sq $\mathrm{ft}$,

Q - fluidizing gas flow, SCFH,

$T_{R}$ - temperature of bed, ${ }^{\circ} R$,

P - pressure, psia,

$\Delta P$ - pressure drop across bed, psi,

$\mathrm{U}$ - actual superficial fluidizing velocity at bed conditions, $\mathrm{ft} / \mathrm{sec}$,

Subscript B - bottom of bed,

Subscript $T=$ top of bed.

By setting $R-80, \theta=2.5, \rho_{B}-237, T_{R}-1510, P_{T}-15.7$, and $U=1.8$, the following final equations were evolved:

6) $S_{T}=4.45 \times 10^{-4} Q$,

7) $S_{B}=6.96 \times 10^{-3} \frac{Q}{P_{B}}$, 
8) $\Delta \mathrm{P}=1.646 \mathrm{~h}$,

9) $P_{B}=15.7+1.646 \mathrm{~h}$,

10) $\mathrm{S}_{\mathrm{B}}\left[15.7+\frac{4.165}{\mathrm{~S}_{\mathrm{B}}+4.45 \times 10^{-6} \mathrm{Q}+\sqrt{4.45 \times 10^{-4} \mathrm{~S}_{\mathrm{B}} \mathrm{Q}}}\right]=6.96 \times 10^{-9} \mathrm{Q}$.

For a given value of $Q$, equation 10 ) was solved by trial and error. The value of $S_{B}$ was then used to compute $b$ and $\Delta P$.

Case II-A was computed for a fluidizing gas flow of 300 SCFH, the maximum available supply rate. The shell for Case II-A is too small in average diameter for pilot plant studies, and is too tall, requiring an inlet gas pressure greater than that which is available.

The results of the calculations for a cylindrical shell containing a tapered mandrel are presented in Table III. 
Reduction of Fluid-Bed-Denitrated $\mathrm{UO}_{3}$ in a Cylindrical Fluid-Bed Reactor With Internal Tapered Mandrel

Bases for Calculated Data:

\section{Feed Particle Size}

Fluidizing Velocity at Bed Conditions

Fluidized Density

Reaction Temperature

Turnover Time

Feed Rate, $\mathrm{Ib} \mathrm{UO}_{3} / \mathrm{hr}$

Fluidizing Gas Flow, SCFH

Nominal Shell Diameter, in.

Actual Shell I.D., in.

Number of Mandrels

MandrelBottom Diameter, in.

MandrelTop Diameter, in.

Bed Height, $\mathrm{ft}$

$\Delta \mathrm{P}$ Across Bed, psi

\begin{tabular}{|c|c|c|c|}
\hline $\begin{array}{l}\text { Case } \\
\text { III-AA }\end{array}$ & $\begin{array}{l}\text { Case } \\
\text { III-B }\end{array}$ & $\begin{array}{l}\text { Case } \\
\text { III-C }\end{array}$ & $\begin{array}{l}\text { Case } \\
\text { III-D }\end{array}$ \\
\hline 80 & 80 & 80 & 80 \\
\hline 695 & 193 & 300 & 300 \\
\hline 10 & 4 & 6 & 5 \\
\hline 9.654 & 4.026 & 6.065 & 5.047 \\
\hline 1 & 1 & 1 & 1 \\
\hline 7.02 & 3.00 & 4.82 & 3.37 \\
\hline 5.87 & 0 & 3.42 & 0.63 \\
\hline 3.2 & 11.7 & 7.9 & 7.4 \\
\hline 5.2 & 19.3 & 12.9 & 12.2 \\
\hline
\end{tabular}

\begin{tabular}{lrrr}
-35 to +65 mesh & & \\
$1.75 \mathrm{ft} / \mathrm{sec}$ & & & \\
$237 \mathrm{lb} / \mathrm{cu} \mathrm{ft}$ & & & \\
$1050^{\circ} \mathrm{F}$ & & & \\
$2.5 \mathrm{hr}$ & & & \\
Case & Case & Case & Case \\
III-E & III-F & III-G & III-H \\
\cline { 5 - 5 } 80 & 80 & 50 & 35 \\
300 & 300 & 300 & 300 \\
5 & 5 & 5 & 5 \\
5.047 & 5.047 & 5.047 & 5.047 \\
4 & 8 & 1 & 1 \\
1.69 & 1.18 & 2.89 & 2.50 \\
0.30 & 0.21 & 0.63 & 0.63 \\
7.4 & 7.4 & 4.4 & 3.0 \\
12.2 & 12.2 & 7.2 & 4.9
\end{tabular}


For such a reactor system the free volume of the reactor becomes

11) $\mathrm{V}=\frac{\mathrm{R} \theta}{\rho_{\mathrm{S}}}=\mathrm{S}_{\mathrm{s}} \mathrm{h}-\frac{\mathrm{h}}{3}\left(\mathrm{~S}_{\mathrm{B}}^{\mathrm{e}}+\mathrm{S}_{\mathrm{T}}^{0}+\sqrt{\mathrm{S}_{\mathrm{B}}^{0} \mathrm{~S}_{\mathrm{T}}^{0}}\right)$,

where

$$
\begin{aligned}
& S_{s}=\text { cross-section of shell, sq } f t, \\
& S_{B}^{0}=S_{s}-S_{B}=\text { cross-section of mandrelat bottom, sq } f t, \\
& S_{T}^{E}=S_{S}-S_{T}=\text { cross-section of mandrelat zop, } s q f \varepsilon \text {, and }
\end{aligned}
$$

other: symbols are as defined above. Substitution of equations 6) and 7), which have been altered slightly for a fluidizing velocisy of $1.75 \mathrm{ft} / \mathrm{sec}$ instead of $1.8 \mathrm{ft} / \mathrm{sec}$, and equations 8 ) and 9) in equation 11) yields

$$
\text { 12) } \mathrm{S}_{\mathrm{B}}\left[15.7+. \frac{0.0520 \mathrm{R}}{\mathrm{S}_{\mathrm{s}}+\mathrm{S}_{\mathrm{B}}+4.58 \times 10^{-4} \mathrm{Q}-\sqrt{\left(\mathrm{S}_{\mathrm{s}}-\mathrm{S}_{\mathrm{B}}\right)\left(\mathrm{S}_{\mathrm{s}}-4.58 \times 10^{-76} \mathrm{Q}\right)}}\right]=7.16 \times 10^{-3} \mathrm{Q} \cdot
$$

For appropriate values of $S_{s}$, $Q$ and $R$, trial and error solution of equation. 12) provided the data of Table III. For Cases III-E and III-F, which represent use of mose than one mandreI, the sum of the individual mandrelcross-sectionai areas is $\mathrm{S}_{\mathrm{B}}^{0}$ or $\mathrm{S}_{\mathrm{T}}^{0}$.

Case III-A was calculated to determine the feasibility of using an existing reactor shell and was rejected because of the large fiuidizing gas rate tequired.

Case III-B was rejected because of excessive height.

Case III-C was less favorable than Case III-D because of a narrower annular space, which might result in less stable fluidization.

Cases III-D, - E, and - F were of interest, but were discarded in favor of Case III-G because the latter reactot has a larger bottom annular space, a lower pressure drop, and a shorter height

Case III-H was discarded because of the low production sate.

The chosen design, then, is Case III-G.

It was mentioned above that the taper of the cone should theoreticaily be curved. As a compromise between the fabrication expense of a theoretical taper, and the desire for the best approximation to it, a mandrel with several straight tapers will be fabricated. The mandreldimensions are presented in Table IV. The diameters were computed with equation 13), which was derived from the assumption that cross-sectional area multiplied by pressure equals a constant. 
13) $\mathrm{d}_{\mathrm{L}}^{0}=\left\{\mathrm{D}_{\mathrm{S}}^{2}\left[1-\frac{\mathrm{P}_{\mathrm{T}}}{\mathrm{P}_{\mathrm{T}}+\rho_{S} \mathrm{~L}}\right]+\left(\mathrm{d}_{\mathrm{T}}^{0}\right)^{2}\left[\frac{\mathrm{P}_{\mathrm{T}}}{\mathrm{P}_{\mathrm{T}}+\rho_{\mathrm{S}} \mathrm{L}}\right]\right\}^{1 / 2}$

where

$D_{S}=$ diameter of shell, inches,

$\mathrm{d}^{0}=$ diameter of mandrel, inches, with subscripts $L$ and $T$ denoting diameters at $L$ and the top, respectively, and

$L$ - distance measured from top of mandrel, inches,

$P_{T}=$ pressure at top of bed, psi,

$\rho_{s}=$ fluidized density, $\mathrm{lb} / \mathrm{cu}$ in.

Table IV

Dimensions of Tapered Mandrel

\begin{tabular}{cc}
$\begin{array}{c}\text { Distance } \\
\text { Down from Top } \\
\text { inches }\end{array}$ & $\begin{array}{c}\text { Diameter } \\
\text { of Mandrel } \\
\text { inches }\end{array}$ \\
\hline 0 & 0.63 \\
5 & 1.21 \\
11 & 1.61 \\
17 & 1.91 \\
23 & 2.14 \\
29 & 2.34 \\
35 & 2.50 \\
41 & 2.65 \\
47 & 2.77 \\
53 - Bottom & 2.89
\end{tabular}

A fluid-bed reduction reactor will be fabricated with a 5-inch-diameter cylindrical shell, a bed height of $4 \mathrm{ft}, 5$ in., and an internal mandrel with the dimensions listed in Table IV. With this basic equipment the feasibility of the cylindrical-shell, tapered-mandrel fluid-bed reactor will be investigated. 


\section{UR ANIUM RECOVERY FROM SLAG}

by

H. F. Plagens

E. F. Sanders

$\underline{\text { Summary }}$

Eight slag fluorination runs have been made in an eight-inch-diameter screw reactor. In general, the results indicate a final uranium content in fluorinated MFL of $0.15-0.20 \% \mathrm{U}$ regardless of the operating conditions or sieve fraction within the range tested. A slag feed rate of $100 \mathrm{lb} / \mathrm{hr}$ was attained with a retention time as low as one hour and a fluorine excess of 1.4 times theory.

Introduction

One of the products of the reaction between uranium tetrafluoride and magnesium is magnesium fluoride slag. This slag contains small amounts of metallic uranium and uranium oxides as a result of incomplete separation of uranium products from the slag during the reaction. In the dingot process a portion of this by-product slag is recycled for use as a refractory while the other portion is discarded; however, because of the value of the contained uranium, it is desirable to recover this uranium from this reject stream before it is discarded.

The general objective of this project is the establishment of a process for converting the contained metallic uranium and uranium oxides to uranium hexafluoride. In this process fluorine is continuously allowed to react with the contained metallic uranium according to the equation

$$
\mathrm{U}_{(\mathrm{s})}+3 \mathrm{~F}_{2(\mathrm{~g})}=U \mathrm{~F}_{\mathrm{i}(\mathrm{s})},
$$

and with other forms of uranium in accordance with similar equations. The gaseous uranium hexafluoride product is condensed from the off-gas stream and can either be used as feed material for the cascade or reduced to uranium tetrafluoride for conversion to uranium metal. This fluorination process has several significant advantages over the other techniques for recovering the uranium from slag. Some of these advantages are:

(1) the elimination of the usually required slag pretreatments;

(2) easy separation of the uranium from the slag since the uranium is removed in the vapor phase;

(3) the direct conversion of the uranium to a usable form thus eliminating the necessity for reprocessing, such as reintroduction into the refinery; and

(4) modest equipment requirements since the conversion and separation are done in one step. 
The immediate program is concentrated on the feasibility of recovering the uranium from slag in a screw reactor.

Experimental Equipment

The green salt reverter at the St. Louis Production Center was modified for this fluorination work. A sketch of the modified equipment is shown in Figure 1. The reactor consists of a ten-foot-long, eight-inch-diameter Inconel tube provided with a ten-foot-long ribbon type screw. The screw consists of three 1 -inch by ${ }^{3} / 16^{-i n c h}$ Hastelloy $\mathrm{C}$ ribbons connected by $\mathrm{Y}$-supports to a $1 / 2$-inch-diameter shaft, and was fabricated in five-foot sections, then butt-welded at the center. It is rotated by a variable speed drive and is free floating at the idle end. This reactor is enclosed in a $30 \mathrm{kw}$ electrical furnace divided into three zones of $10 \mathrm{kw}$ each. Slag is fed from a 300 -poundcapacity feed hopper, through a two-inch-diameter feed screw, to the drive end of the reactor. Fluorine, supplied in 400-psi cylinders, is fed through a modified Matheson Type 15A gas pressure regulator and a Pyrex rotameter, to the reactor countercurrent to the slag flow. The UF o produced and the off-gases are vented to the low-pressure scrubber system where they are neutralized with lime. The fluorinated slag is discharged into a receiving hopper, then emptied through a two-inchdiameter discharge screw and a cooling screw to a packaging station after each run. Nitrogen is available for purging the reactor and the fluorine manifold. The pressure at each end of the reactor is measured by means of a manometer filled with a fluorinated hydrocarbon oil. Each of the three electrical heating zones is controlied from a temperature indicator-controller with its thermocouple between the reactor tube and the furnace elements. Thermocouples are also provided on the reactor wall near each end of the tube and these temperatures are read on a temperature recorder.

Experimenta1 Procedure

The operating procedure was as follows: The slag feed hopper was filled with slag and enough slag was added to the receiving hopper to provide a gas seal. The empty reactor was purged with nitrogen and preheated to operating temperature. Fluorine flow was then started and, as soon as the reactor screw was rotaring, the slag feed was started. At the end of each run the slag feed and the reactor screw were stopped, the fluorine flow was cut off and the reactor purged with nitrogen for several hours. The slag in the receiving hopper was discharged to the packaging station leaving enough in the receiver to provide a seal for the next run.

Table I gives the operating data for the eight runs made in this reactor; the first six runs were made using normal MFL as feed and the last two runs were made using RMF dust. 
FIGURE 1

EXPERLIENTAL SLAG FLUORINATION REACTOR

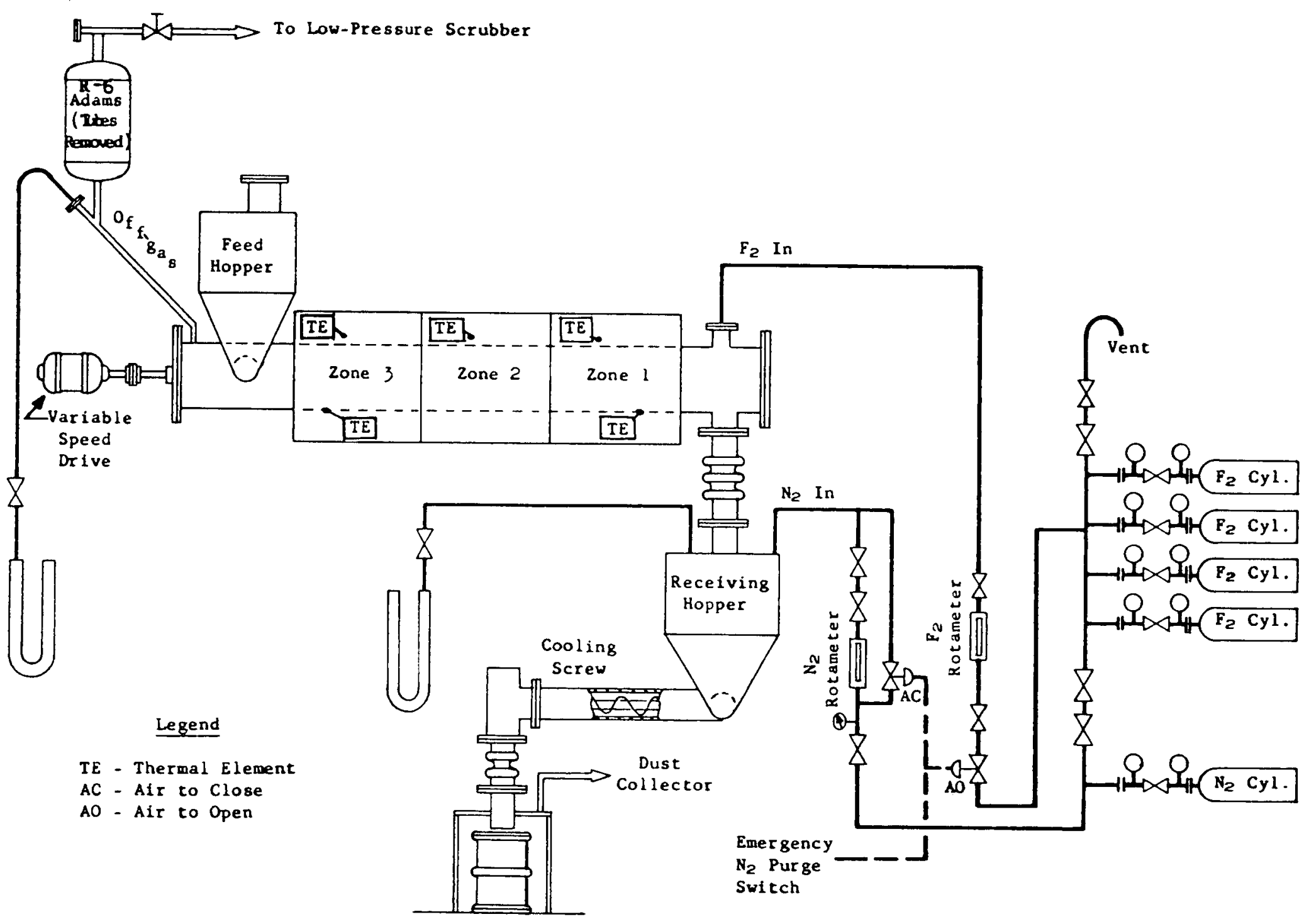


Table I

$\therefore: \cdots:$

$\vdots . . .:$ :

.......

...:.: :

......

$: \because:$

$: \because \because$

״.

¿....

$\therefore$

:...:

a...

\begin{tabular}{|c|c|c|c|c|c|c|c|c|c|}
\hline \multirow{2}{*}{ Condition } & \multirow[b]{2}{*}{ Run 1} & \multicolumn{4}{|c|}{ Operating Conditions for Slag Fluorination } & \multirow[b]{2}{*}{ Run $5 \mathbf{a}$} & \multirow[b]{2}{*}{ Run 6} & \multirow[b]{2}{*}{ Run 7} & \multirow[b]{2}{*}{ Run 8} \\
\hline & & Run 2 & Run 3 & Run 4 & Run 5 & & & & \\
\hline Slag Feed Rate, lb/hr & 15 & 25 & 40 & so & 50 & 100 & 100 & 100 & 100 \\
\hline$F_{2}$ Flow Rate, $1 b / h r$ & 1 & 1 & 1 & 1 & 1 & 1 & 1 & 2 & 1 \\
\hline \multicolumn{10}{|c|}{ Furnace Set Temperature } \\
\hline Zone $1,{ }^{\circ} \mathrm{F}$ & 900 & 900 & 890 & 1020 & 1020 & 1020 & 1020 & 1020 & 1040 \\
\hline Zone $2,{ }^{\circ} \mathrm{F}$ & 900 & 900 & 900 & 1050 & 1050 & 1050 & 1050 & 1050 & 1050 \\
\hline Zone $3,{ }^{\circ} \mathrm{F}$ & 900 & 960 & 970 & 1100 & 1130 & 1160 & 1150 & 1140 & 1120 \\
\hline \multicolumn{10}{|l|}{ Tube Temperature } \\
\hline Zone $1,{ }^{\circ} \mathrm{F}$ & 870 & 890 & 890 & 1010 & 1010 & 990 & 1000 & 990 & 1000 \\
\hline Zone $3,{ }^{\circ} \mathrm{F}$ & 810 & 850 & 840 & 960 & 1000 & 980 & 1010 & 990 & 1010 \\
\hline Screw Speed, rpm & 6 & 6 & 6 & 6 & 6 & 6 & 6 & 6 & 6 \\
\hline Run Duration, $\mathrm{hr}^{a}$ & 8.5 & 8.0 & 4.5 & 3 & 5.5 & 2.5 & 2.5 & 4.75 & 7 \\
\hline
\end{tabular}

${ }^{a}$ The total screw life consisted of the sum of the durations of the eight runs plus 6.5 bours. 
Results

The slag feed analyses are given in Table II and the fluorinated slag product analyses are given in Table III. Table IV shows the uranium content of fluorinated MFL at various slag feed rates and fluorine excesses. Table $V$ gives the uranium content of fluorinated MFL for various sieve fractions. Table VI gives the spectrographic analysis of a sample of powder taken from the off-gas header.

Table II

Slag Feed Analyses

\begin{tabular}{|c|c|c|}
\hline Component & MFL & RMF Dust \\
\hline Total U, \% & 1.50 & $2: 30$ \\
\hline $\mathrm{U}^{0}, \%$ & 0.50 & 0.50 \\
\hline Unoxidized $U, \%^{a}$ & 1.40 & 2.10 \\
\hline$U^{+\infty}, \%$ & 0.23 & 0.35 \\
\hline Free $\mathrm{Mg}, \%$ & 0.12 & 0.02 \\
\hline $\mathrm{MgO}, \%$ & 3.0 & - \\
\hline $\mathrm{H}_{2}\left(\right.$ a s $\mathrm{H}_{2} \mathrm{O}$ and $\left.\mathrm{HF}\right)$, ppm & 41 & 150 \\
\hline \multicolumn{3}{|l|}{ Sieve Fraction } \\
\hline$+20 \mathrm{Mesh}, \%$ & 0.1 & 1.0 \\
\hline-20 to $+40, \%$ & 1.1 & 1.0 \\
\hline-40 to $\div 80, \%$ & 12.9 & 0.6 \\
\hline-80 to $+100, \%$ & 7.0 & 0.4 \\
\hline-100 to $+200, \%$ & 21.0 & 3.4 \\
\hline-200 to $+325, \%$ & 12.3 & 6.5 \\
\hline$-325, \%$ & 45.6 & 87.0 \\
\hline
\end{tabular}

a The term "unoxidized $U "$ as used here denotes uranium with a valency of +4 or less. 
Fluorinated-Slag Product Analyses

$\therefore: .:$ :

$\vdots \ldots .: \vdots^{2}$

(n......

(...:.:

$\because \cdots$

$\because \because$

$\because \because$

$\because \because \cdots$

$\vdots \ldots$.

$\therefore \therefore$

$\vdots \ldots$

$\ldots \ldots:$

\begin{tabular}{|c|c|c|c|c|c|c|c|c|}
\hline Component & $\mathrm{Run} 1^{a}$ & $\operatorname{Run} 2^{a}$ & $\operatorname{Run} 3^{a}$ & Run $4^{a}$ & $\operatorname{Run} 5^{a}$ & $\operatorname{Run} 6^{a}$ & $\operatorname{Run} 7^{b}$ & $\operatorname{Run} 8^{b}$ \\
\hline Total U, \% & 0.15 & 0.20 & 0.19 & 0.16 & 2.8 & 0.14 & 1.5 & 1.8 \\
\hline $\mathrm{U}^{0}, \%$ & - & 0.014 & $<0.005$ & $<0.005$ & 0.04 & $<0.01$ & 0.05 & 0.01 \\
\hline Unoxidized $\mathrm{U}, \%^{\mathrm{c}}$ & - & 0.16 & 0.14 & $<0.1$ & 0.8 & 0.1 & 0.6 & 0.5 \\
\hline $\mathrm{U}^{+6}, \%$ & 0.09 & 0.06 & 0.02 & 0.01 & 2.23 & 0.03 & 0.96 & 1.41 \\
\hline Free $\mathrm{Mg}, \%$ & - & 0.12 & 0.04 & 0.14 & 0.02 & 0.04 & $<0.01$ & 0.01 \\
\hline $\mathrm{MgO}, \%$ & - & 2.6 & 2.6 & 2.5 & - & - & - & - \\
\hline \multicolumn{9}{|l|}{ Sieve Fraction } \\
\hline+20 Mesh, $\%$ & - & 0.4 & 0.5 & 0.4 & 0.3 & 0.5 & - & - \\
\hline-20 to $+40, \%$ & - & 1.1 & 0.8 & 1.6 & 1.3 & 1.2 & - & - \\
\hline-40 to $+80, \%$ & - & 12.5 & 9.9 & 15.6 & 13.6 & 13.7 & - & - \\
\hline-80 to $+100, \%$ & - & 7.4 & 7.1 & 8.0 & 6.8 & 7.1 & - & - \\
\hline-100 to $+200, \%$ & - & $23: 3$ & 28.4 & 22.4 & 21.6 & 24.9 & - & - \\
\hline-200 to $+325, \%$ & - & 13.5 & 15.0 & 12.8 & 13.1 & 16.3 & - & - \\
\hline$-325, \%$ & - & 41.8 & 38.4 & 39.2 & 43.3 & 36.2 & - & - \\
\hline
\end{tabular}

${ }^{a}$ Product resulting from fluorination of MFL.

${ }^{b}$ Product resulting from fluorination of RMF dust.

cThe term "unoxidized $U^{n}$ as used here denotes uranium with a valency of +4 or less. 
Table IV

\begin{tabular}{|c|c|c|c|c|}
\hline $\begin{array}{l}\text { Slag Feed Rate } \\
\mathrm{lb} / \mathrm{hr} \\
\end{array}$ & $F_{2}(x$ theory $)$ & $\begin{array}{c}\text { Total U } \\
\% \\
\end{array}$ & $\begin{array}{l}\mathrm{U}^{0} \\
\%\end{array}$ & $\begin{array}{c}\text { Unoxidized U } \\
\% \\
\end{array}$ \\
\hline 15 & 9.25 & 0.15 & - & - \\
\hline 25 & 5.55 & 0.20 & 0.014 & 0.16 \\
\hline 40 & 3.47 & 0.19 & $<0.005$ & 0.14 \\
\hline so & 2.78 & 0.16 & $<0.005$ & $<0.1$ \\
\hline 100 & 1.39 & 0.14 & $<0.01$ & 0.1 \\
\hline
\end{tabular}

a The term "unoxidized $U^{\prime \prime}$ as used here denotes uranium with a yalency of +4 or less.

Table V

Uranium Content of Fluorinated MFL versus Sieve Fraction

\begin{tabular}{|c|c|c|c|}
\hline Sieve Fraction & $\begin{array}{c}\text { Total U } \\
\% \\
\end{array}$ & $\begin{array}{l}\mathrm{U}^{0} \\
\%\end{array}$ & $\begin{array}{c}\text { Unoxidized U } \\
\%^{a} \\
\end{array}$ \\
\hline \multicolumn{4}{|c|}{ Run 4} \\
\hline+100 Mesh & 0.21 & $<0.01$ & 0.13 \\
\hline-100 to +200 & 0.21 & 0.01 & 0.20 \\
\hline-200 to +325 & 0.20 & 0.02 & 0.19 \\
\hline-325 & 0.21 & 0.02 & 0.22 \\
\hline \multicolumn{4}{|c|}{ Run 5} \\
\hline+100 Mesh & 1.0 & 0.1 & 0.94 \\
\hline-100 to $\div 200$ & 1.4 & 0.1 & 1.0 \\
\hline-200 to +325 & 1.8 & 0.04 & 1.3 \\
\hline-325 & 4.3 & $<0.01$ & 0.96 \\
\hline
\end{tabular}

"The term "unoxidized $U$ " as used here denotes uranium with a valency of +4 or less. 
Table.VI

Spectrographic Analysis of Powder from Off-Gas Header

\begin{tabular}{c} 
Constituent \\
\hline $\mathrm{Ni}$ \\
$\mathrm{Fe}$ \\
$\mathrm{Cr}$ \\
$\mathrm{Mo}$ \\
$\mathrm{W}$ \\
$\mathrm{Si}$ \\
$\mathrm{Mn}$ \\
$\mathrm{Mg}$ \\
$\mathrm{U}$ \\
$\mathrm{V}$
\end{tabular}

\begin{tabular}{l}
$\frac{1}{\text { Results }}$ \\
\hline Weak-Moderate \\
Weak-Moderate \\
Strong \\
Strong: \\
Moderate \\
Very, weak-Weak \\
$\quad$ - - : \\
Very strong \\
Very strong \\
Moderate-Strong
\end{tabular}

Composition of

Hastelloy C

The holdup in this reactor was measured after Run 6 and found to be 100 pounds of slag.

The Hastelloy C reactor screw was removed after 53 hours' operation at 6 rpm. At some point during this period the screw shaft was broken at the butt-weld as indicated by scale formation on each face of the break. There was only minor evidence of erosion or corrosion on the fivefoot section of the screw from the drive end to the butt-weld; however, the erosion or corrosion from the butt-weld to the powder discharge port was very severe.

Table VII gives the thicknesses of various disks cut from the reactor tube.: The original plate was one-quarter-inch plate but external gussets probably cut from the same plate measured 0.241 inches.

Table VII

Reactor Wall Thickness after 53 Hours: Operation

\begin{tabular}{ll}
\multicolumn{1}{c}{ Position } & \multicolumn{1}{c}{$\begin{array}{c}\text { Thickness } \\
\text { in. }\end{array}$} \\
\hline One Foot from Discharge End, Top & $0.200-0.206$ \\
One Foot from Discharge End, Bottom & $0.215-0.217$ \\
One Foot from Feed End, Top & $0.217-0.217$ \\
One Foot from Feed End, Bottom & $0.213-0.213$ \\
Discharge End by Flange & 0.220 \\
Feed End by Flange & 0.221
\end{tabular}


Discussion of Results

The results in Table III indicate a final uranium content in fluorinated MFL (Runs 1-6) of approximately $0.15-0.20 \% \mathrm{U}$. The results for the fluorinated RMF dust (Runs 7 and 8 ) are obscured by the formation of $\mathrm{UO}_{2} \mathrm{~F}_{2}$; however, the values for free uranium are consistent with those for the fluorinated MFL. These results also indicate that the metallic uranium is essentially completely fluorinated, the major portion of the uranium remaining in the slag being the oxides.

The magnesium and magnesium oxide analyses in Tables II and III indicate that these constituents are unreactive at these operating conditions. There are some anomalies in the data on magnesium but they are felt to be a result of sampling difficulties.

The screen analyses of the slag feed and the fluorinated slag do not indicate a significant change in the particie size distribution.

The results shown in Table IV indicate that there is no correlation between slag feed rate and uranium content of the fluorinated MFL. These results also indicate that successful conversion rates may be obtained at fluorine excesses as low as 1.4 times theory based on the total uranium content of the feed.

The results shown in Table $\mathrm{V}$ do not indicate a correlation between the particle size of the fluorinated slag and iss uranium content. The results for Run 5 are somewhat obscured by the formation of $\mathrm{UO}_{2} \mathrm{~F}_{2}$; however, the $\mathrm{U}^{0}$ results seem to substantiate the Run 4 results.

The retention time for $R$ un 6 is one hour, based on the feed rate and the measured holdup.

The severe deterioration of the zeactor screw is probably caused by the cyclical formation of a fluoride film on the metal and removai of this film by abrasion. If the shaft broke during an early run, the difference in the deterioracion of the two 5 -foot sections may be attributed to this fact. It is also conceivable that the ewo 5 -foot sections were fabricated from different meral heats. It is possible that by supporting both ends of the screw the deterioration may be considerably reduced at the discharge end.

Although there was little visable damage to the reactor tube, the corrosion rate, based on the measurements in Table VII, is quite high. The tesults in this table also indicate that the corrosion sate at the idle end may be substantially seduced by supporting the screw at this end. 
GAMMA EXTRUSION OF DINGOT METAL

by

T. N. Dean

W. E. Ellerman

\section{Summary}

Four gamma extrusion developmeat campaigns are reported, one from the program at BBC, Adrian, Michigan, and three from the program at Dow Chemical Co., Madison, Illinois.

A. Ninth Campaign at Adrian

1. No correlation was found between yields and follower block contour, using flat-end billets and contoured graphite follower blocks having respective contour depths of $2 \frac{1}{2}, 3$, and $3 \frac{1}{2}$ inches.

2. Chrome carbide was confirmed as an excellent die material. At the conclusion of this campaign, 47 rods had been extruded through the die employed and it was still usable.

B. Seventh Campaign at Dow

1. No correlation was found between yields and follower block contour, using contoured billets with contoured follower blocks having respective cone angles of $20^{\circ}, 25^{\circ}$, and $30^{\circ}$.

2. A siightly deleterious effect on rod surface quality was found in increasing the billet diametral upset from $3 / 4$ inch to $1 \frac{1}{2}$ inches in a 17 -inch-1D container liner.

3. An unusual flow pattern, similar to "reverse pipe," was revealed by radiographic inspection of a billet partially extruded with a uranium foilower block.

4. A five-inch-iong billet was pierced with 1200 tons of thrust, using a seven-inch-ID die, a $6^{15} / 10^{-i n c h-d i a m e t e r ~ p i e r c i n g ~ c a p ; ~ a n d ~ a ~} 6 \%$-inch-diameter mandrel.

5. Grade AGR graphite follower blocks were not found to be more effective than Grade CS 312 in crushing and thereby freeing rods from their butts.

6. A shear-type chrome carbide insert die produced rods of satisfactory surface quality, but was severely damaged by the action of the single-acting shear used to sever the butt. 
C. Eighth Campaign at Dow

1. Separation of rods from their butts by partial extrusion of copper, cast iron, and uranium follower blocks was not successful. The temperatures at which the copper and cast iron follower blocks were used were not high enough to impart sufficient malleability for extrusion, while the uranium follower block adhered firmly to the back end of the rod after extrusion.

2. A rod was separated from its butt by "punching," using a 2:6-inch-diameter mandrel without a piercing cap, and a seven-inch-ID die. A 1400-ton thrust was used in punching.

3. Two rods were separated from their butts by "punching" with a $6 \%$-inch-diameter mandrel without piercing caps, and a seven-inch-ID die. Respective thrusts of 1400 and 400 tons were used in the punching operation.

4. A billet composed of one-inch-thick slices welded together was extruded for a study of the flow pattern of gamma uranium by radiographic examination.

5. The chrome carbide insert die used was again damaged by the action of the shear.

D. Ninth Campaign at Dow

1. Six rods were separated from their butts by "punching," using punches of three diameters and both plugged and solid follower blocks. It was not necessary to move the punch through the die to effect the separation when sufficient follower block graphite preceded the punch.

2. Follower blocks weakened by having annular grooves machined in their back face were not effective in separating rods from their butts.

3. A tapered billet, approximating the shape expected in the Weldon Spring operation, was heated and extruded without incident.

4. Two flow-type chrome carbide insert dies were damaged during the punching operations because of punch misalignment, but produced rods of satisfactory surface quality.

II. Introduction

Gamma extrusion has been chosen as the primary forming operation to be used at the Weldon Spring plant in the preparation of dingots for rolling at NLO. ${ }^{1}$ Installation of the 1750 -ton press

1 Becker, R. W., Hansen, J. W., Schaffer, H. J., Hartmann, R. F., Process Development Quarterly Report, Part II. Mallinckrodt Chemical Works, MCW-1402 (May 1, 1957), D 133-150 
for extrusion of dingot size billets at Weldon Spring is nearing completion. Two paralled programs, differing in scale, to develop techniques for the operation of this press have been in progress and are now considered essentially complete.

A relatively small-scale program, utilizing $6: 3 / 16^{-i n c h-d i a m e t e r ~ b i l l e t s ~ m a c h i n e d ~ f r o m ~ f o r g e d ~}$ dingot stock, has been conducted at the Adrian, Mich., plant of the Bridgeport Brass Co. as a joint endeavor of $M C W$ and $B B C$. This program was designed for initial investigations of various factors for feasibility and scope. The ninth campaign of this program, conducted on February 26 and 27,1958 , is reported below.

A program on a scale comparable to that contemplated for Weldon Spring has been performed under the direct control of MCW at the Madison, Ill,; plant of the Dow Chemical Co. Most of the work in this program consisted of scaling up factors originally investigated at Adrian. The billets used in this program were $16 \frac{1}{4}$ inches in diameter and were machined from full size ascast dingots. Reported below are the seventh, eighth, and ninth campaigns of this program, conducted respectively on April 17 and 18, May 9, and June 7, 1958.

Most of the earlier work had been concentrated on improvement of yields. Extrusion with a minimum of lubrication was found to give improved rod surface quality, and convex billet back ends gave indications of reducing rod back-end losses attributable to "extrusion defect." However, the sealization that graphice follower blocks would not crush sufficiently to free the rods from their butts, under the pressure available on the Weldon Spring press, has revealed a problem of considerable importance.: Wiork at Adrian has continued toward the objective of improving yields, while work at Dow has been directed toward developing methods for freeing rods from their buts, as well as improving yields. For reasons involving both health problems and press configuration, neither a shear nor a saw has been incorporated in the design of the Weldon Spring press, and conventional methods of separating rods and butts are thus not available.

III. Ninth Campaign at BBC, Adrian

\section{A. Purpose}

The primary purpose of this campaign was to evaluate the effect on yieid of various depths of follower block contour between the $t$ wo-in. and $4 \frac{1}{2}$-in. depths employed in the eighth campaign." Also, an evaluation of the service life of a chrome carbide insert die was continued.

\footnotetext{
2 Dean, T. N., Ellerman, W. E., Schaffer, H. J., Process Developmeni Quaterty Report, Pait Il, Mallinckrodt Chemical Wöks, MCW.1413 (May 1, 1958), p 81-89

3 Dean, T. N., et al., MCW-1413, p $89-96$

4 Dean, T. N., et al., MCW-1413, p 62-72
} 
B. Experimental Work

1. General

Procedures were essentially the same as those employed in previous extrusions at Adrian, with the exception of those described below. Constant and variable extrusion conditions are listed in Tables I and II, respectively.

Table I

Constant Extrusion Conditions-Ninth Gamma Extrusion Campaign at BBC, Adrian, Mich.

Billet Temperature

Follower Block Temperature

Tool Oven and Container Temperature

Follower Block Material

Die Material

Die Design

Billet Diameter

Billet Length

Container Liner ID

Reduction Ratio $1900^{\circ} \mathrm{F}$

$1900^{\circ} \mathrm{F}$

$790^{\circ} \mathrm{F}$

CS 312 Graphite

All. Lud. Grade CA815 Chrome Carbide Insert (in A.I.S.I. H-21 Case, $R_{c}$ 46-50)

Shear Type, 3.475-in. ID, $\mathbb{1} / 3_{2}$-in. entrant radius, $1 / 8-i n$. land, $5^{\circ}$ relief angle, no offset relief

$6^{25 / 16}$ in.

$10^{5} / 16$ to $16^{\frac{1}{4}} \mathrm{in}$.

7.488 in.

4.6 to 1 


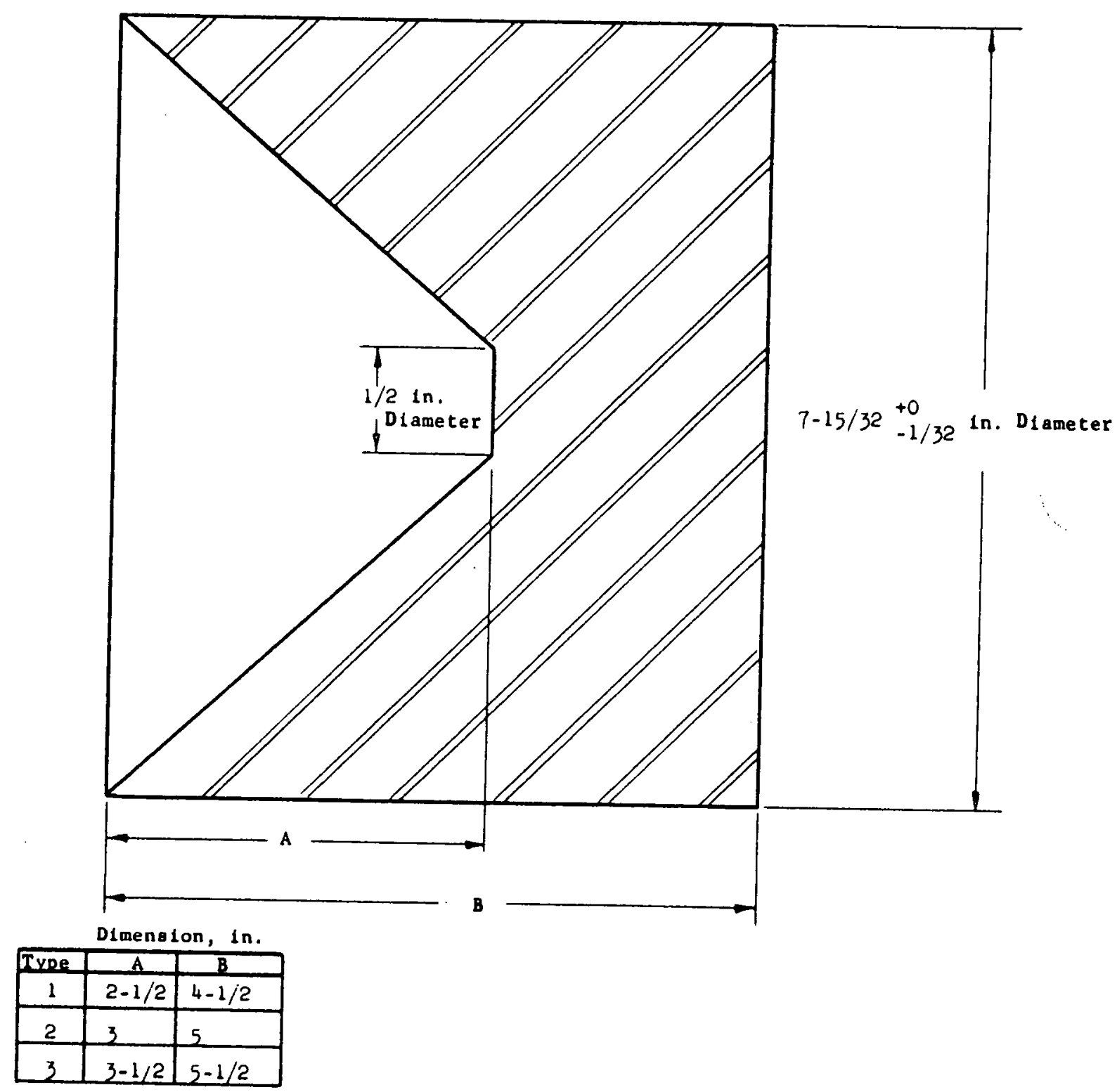

PIGURE 1

CONTOURED GAPHITE POLLOWER BLOCK

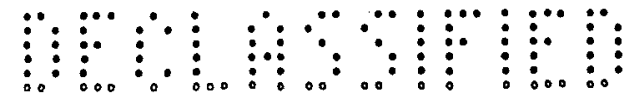


Extrusion Conditions and Yields for Individual Rods - Ninth Gamma Extrusion Campaign at $\mathrm{BBC}$, Adrian, Michigan

\section{:....:}

¿...:.

.......

$\ldots . . .:$

......

$: \because \bullet$

$: \because$ :

:....

$\vdots \ldots$

$\therefore \therefore$

!...:.:

:.....

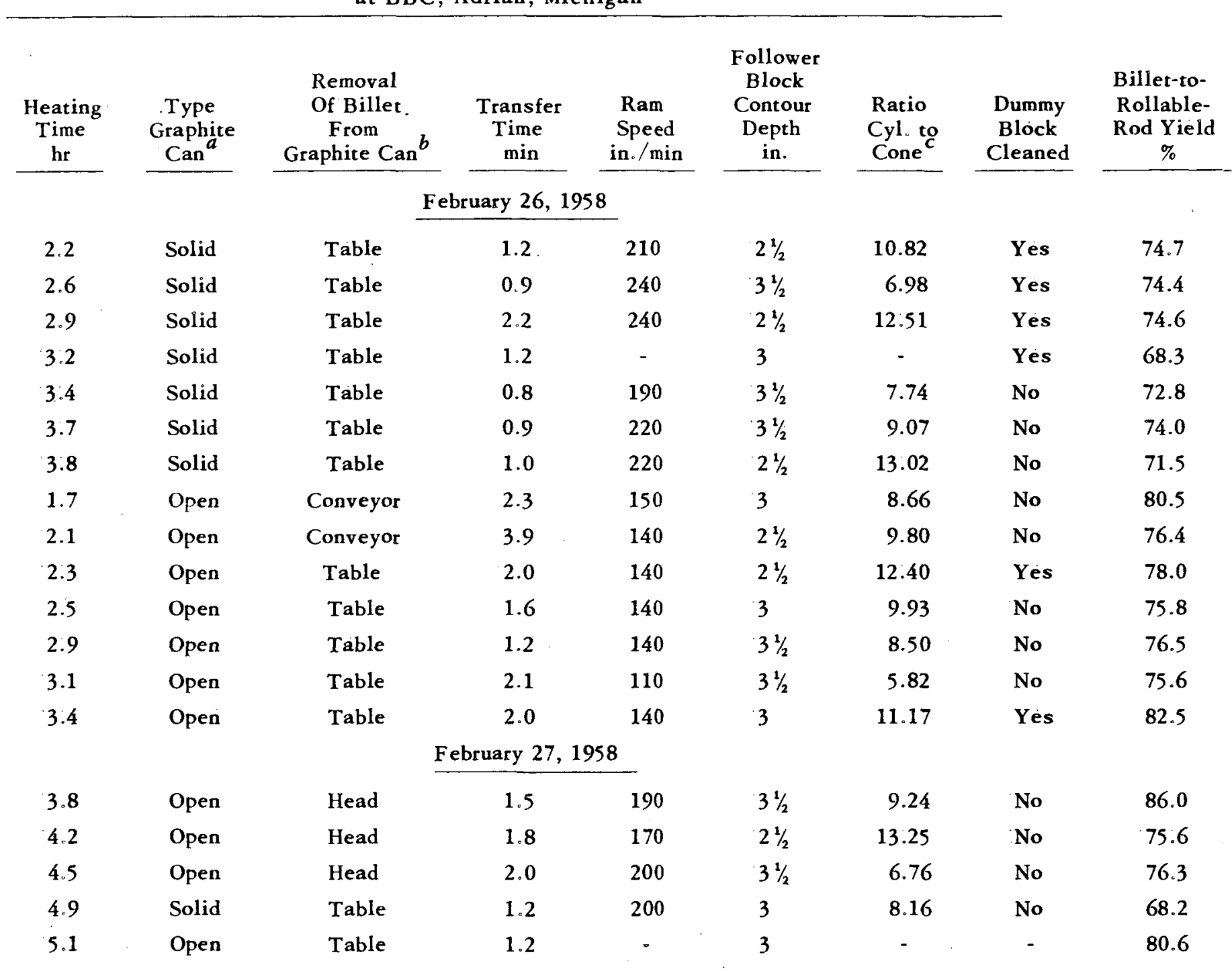


Table II (continued)

\begin{tabular}{|c|c|c|c|c|c|c|c|c|c|c|}
\hline $\begin{array}{l}\text { Billet } \\
\text { No. }\end{array}$ & $\begin{array}{c}\text { Billet } \\
\text { Weight } \\
\text { lb }\end{array}$ & $\begin{array}{c}\text { Heating } \\
\text { Time } \\
\text { hr }\end{array}$ & $\begin{array}{c}\text { Type } \\
\text { Graphite } \\
\text { Can }\end{array}$ & $\begin{array}{c}\text { Removal } \\
\text { Of Billet } \\
\text { From } \\
\text { Graphite Can }\end{array}$ & $\begin{array}{l}\text { Transfer } \\
\text { Time } \\
\text { min } \\
\end{array}$ & $\begin{array}{c}\text { Ram } \\
\text { Speed } \\
\text { in./min } \\
\end{array}$ & $\begin{array}{c}\text { Follower } \\
\text { Block } \\
\text { Contour } \\
\text { Depth } \\
\text { in. } \\
\end{array}$ & $\begin{array}{l}\text { Ratio } \\
\text { Cyl. to } \\
\text { Cone }\end{array}$ & $\begin{array}{l}\text { Dummy } \\
\text { Block } \\
\text { Cleaned }\end{array}$ & $\begin{array}{c}\text { Billet-to- } \\
\text { Rollable- } \\
\text { Rod Yield } \\
\%\end{array}$ \\
\hline \multicolumn{11}{|c|}{ F ebruary 27,1958} \\
\hline 20 & 331 & 5.4 & Solid & Table & 1.4 & 170 & $2 \frac{1}{2}$ & 11.24 & Yes & 78.5 \\
\hline 21 & 330 & 5.5 & Solid & Table & 1.3 & 170 & 3 & 9.65 & Yes & 79.2 \\
\hline 22 & 326 & 2.2 & Solid & Table & 1.0 & 220 & 3 & 9.01 & Yes & 74.5 \\
\hline 23 & 294 & 2.4 & Solid & Table & 1.2 & 220 & $3 \frac{1}{2}$ & 6.81 & Yes & 74.9 \\
\hline 24 & 369 & 3.1 & Open & Conveyor & 3.0 & 250 & 3 & 10.68 & Yes & 80.3 \\
\hline 25 & 378 & $3: 3$ & Open & Head & 1.7 & 250 & $31 / 2$ & 8.93 & Yès & $d$ \\
\hline 26 & 377 & 3.5 & Open & Head & 2.1 & 250 & $2 \frac{1}{2}$ & 12.92 & Yes & $d$ \\
\hline 27 & 416 & $3: 7$ & Open & Head & 1.4 & 200 & $21 / 2$ & 14.10 & Yes & 86.8 \\
\hline 28 & 410 & 3.8 & Open & Head & 1.5 & 230 & 3 & 11.56 & Yes & 83.6 \\
\hline
\end{tabular}

${ }^{a}$ Solid w solid on one end, slide fit disc closure on other end: Open - slide fit disc closure both ends.

${ }^{b}$ Table - can broken from billet on steel table in front of furnace; Conveyor - can broken from billet on roller conveyor; Head a billet pushed into container by ram from can on billet loading head.

${ }^{\prime}$ Ratio of volume of cylindrical portion of billet to truncated conical portion of billet after upsetting.

${ }^{d}$ Both rods stamped No. 25 
2. Billet Heating

The billets were encased in graphite cans and heated in a gas fired muffle furnace, as in the eighth campaign." Two types of cans were used. One type was of the same design as that used in the eighth campaign, having one end solid and the other closed by a plug. The other type was similar but the solid end was replaced by a $1 / 4$-inchthick slide-fit disc. The latter design was intended to permit transfer of a billet in its can to the loading head on the press, where the ram could push the billet directly from the can into the container liner, whereas the earlier design necessitated breaking of the can from the billet before transferring it to the press. Seven rods were transferred as planned in the open-end type can, but operational difficulties necessitated breaking eight other cans of this type from the billets either on the roller conveyor or on the table in front of the furnace. Insufficient allowance had been made for expansion of the billets in the solid-end type cans and all of these cans burst in the furnace, permitting some oxidation of the billets.

Plans had called for heating of the graphite follower blocks in the cans with the billets to minimize transfer time, but the cans were $n$ ot long enough for this in all cases, so the follower blocks were heated separately, although in the same furnace. The follower blocks are shown in Figure 1 .

3. Extrusion

The $1 / 4$-inch graphite disc forming the back end closure of the open-end cans was to be removed by stopping the forward movement of the ram just before the back end of the billet entered the container. This was accomplished in only two cases (Billets 17 and 27). In the other cases the disc entered the container with the billet and remained between the billet and contoured follower block during extrusion.

In every case, metal back-extruded past the graphite follower block and adhered to the face of the dummy block. This metal was permitted to remain on the face of the dummy block for 13 of the 28 extrusions (Table II), seriously interfering with the intended function of the contoured follower blocks.

The chrome carbide die used in this campaign had been used for extrusion of one EZ Hollow tube for NMI, five rods during the sixth gamma campaign, and 13 rods during the eighth gamma campaign.

5 Dean, T. N., et al., MCW-1413, p 64-65 


\section{Evaluation}

Evaluation of the rods was performed in the same manaer as the rods from previous Adrian campaigns.

C. Experimental Results

Yields for individual rods are listed in Table II. The relationship of the yields to the cylindrical-conical volume ratios of the billets heated in open-end cans is shown in Figure 2 .

The "reverse pipe" type of defect encountered in rods from the eighth gamma campaign at Adrian' was again the cause of high back-end losses and low yields. Surfaces of all of the rods were of acceptable quality for rolling.

The chrome carbide die used, while exhibiting myriad fine cracks, was still usable after this campaign. The die had been used for extrusion of a total of 47 rods at the completion of this campaign.

D. Discussion of Results

The yields obtained were, in general, much lower than desired and would not be acceptable for a manufacturing process.

A striking difference was noted between the yields for billets heated in open-end cans and those heated in solid-end cans. All of the former were above $75 \%$, while all but two of the latter were below $75 \%$. For this reason only yields for billets heated in open-end cans are included in Figure 2. The average of the yields for billets heated in open-end cans was $79.6 \%$, while for those heated in solid-end cans it was $73.8 \%$. Cropping losses were primarily responsible for the difference in average yields, being $14.9 \%$ and $20.8 \%$, respectively. There was no noticable difference in the pattern of the back-end defect (reverse pipe) for rods extruded from billets heated in either type of can, except that it extended further into those rods extruded from billets heated in solid-end cans. Since all of the solid-end cans ruptured during heating in the muffle furnace, there was undoubtedly a greater amount of oxide on the surface of the billets heated in these cans during extrusion. This oxide layer may have changed the flow pattern of the metal during extrusion, because of a change in friction between the billet and container liner, resulting in a greater than normal extrusion defect, or the oxide may have been enfolded during extrusion to form additional extrusion defect.

Dean, T. N., et al, MCW-1413, p 70 
No definite correlation was found between yields and depths of follower block contour or cylindrical-conical volume ratio. A greater effect from cleaning of the back extruded metal from the face of the dummy block is indicated in Figure 2.

Only five billets were handled in the preferred manner, i.e., heated in open-end cans and extruded with clean dummy blocks. Two of these were extruded with $2 \frac{1}{2}$-inch-deep follower blocks and three with $3 \frac{1}{2}$-inch-deep follower blocks, resulting in average yields of $82.4 \%$ and $82.1 \%$, respectively.

No consistent effect on yield was observed from the $1 / 4$-inch graphite discs between five of the billets and their follower blocks.

E. Conclusions

No correlation was found between yield and depth of contour, using contoured graphite follower blocks and flat back-end billets, and cylindrical-conical volume ratios between $5: 1$ and $15: 1$.

Investigation of shallower contours and greater ratios or contours of a modified design is suggested.

Chrome carbide was confirmed as an excellent die material.

IV. Seventh Campaign at Dow

A. Purpose

The various purposes of this campaign were as follows:

1. Investigate the effect on yield of various billet back end contours, using both contoured billets and contoured follower blocks.

2. Investigate the effect of two amounts of billet diametral upset on yield, and particularly on rod surface quality.

3. Investigate the flow characteristics of uranium in the gamma phase by partially extruding two billets.

4. Attempt to pierce a five-inch-long billet with a $6 \frac{15}{16}$-inch-diameter graphite piercing cap, a $6 \frac{7}{8}$-inch mandrel and a seven-inch die opening. This was intended to be a preliminary investigation of a possible method for freeing rods from their burts. 
5. Evaluate National Carbon Co. AGR Grade graphite as a follower block material.

6. Evaluate a seven-inch-ID shear-type chrome carbide insert die.

B. Experimental Work

1. General

Constant extrusion conditions and those for individual rods are shown in Tables III and IV, respectively. Truncated conical contours, designated by the angle at the base of the cone rather than by the depth of follower block contour, were machined on the back ends of the billets for follower block contour evaluation and for partial extrusion. AGR Grade graphite follower blocks of the design shown in Figure 3 were used for follower block contour evaluation. Uranium follower blocks, of the same design as figure 3 but with the same diameter as the billets, were used for partial extrusion to give as nearly as possible ideal flow conditions.

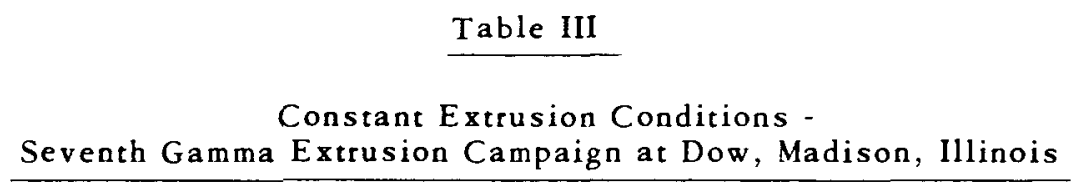

\section{Billet Temperature \\ Container Temperature \\ Tool Oven Temperature \\ Follower Block Material \\ Follower Block Design \\ Die Material \\ Billets 1-4 and 7-10 \\ Billet 6 \\ Die Design \\ Billets 1-4 and 7-10 \\ Billet 6}

Hot Follower Block Oven Temperature

Warm Follower Block Oven Temperature

Container Liner ID

Reduction Ratio $1850^{\circ} \mathrm{F}$

$890^{\circ} \mathrm{F}$

$900^{\circ} \mathrm{F}$

$1850^{\circ} \mathrm{F}$

$910^{\circ} \mathrm{F}$

Grade AGR Graphite

See Figure 3

All. Lud. Grade CA815

Chrome Carbide Insert (in A.I.S.I. H-13 Case, $50.54 \mathrm{R}_{c}$ )

A.I.S.I. $\mathrm{T} 1,50-54 \mathrm{R}_{\mathrm{C}}$

Shear Type, 7-in. ID, 1-in. land

Flow Type, 7 -in. ID, $3 / 4$-in. inlet radius, $3 / 4$-in. land

17 in.

5.9 to 1 
Extrusion Conditions for Individual Billets

Seventh Gamma Extrusion Campaign at Dow, Madison, Illinois

\begin{tabular}{|c|c|c|c|c|c|c|c|c|c|}
\hline \multirow{2}{*}{$\begin{array}{c}\text { Billet } \\
\text { No. }\end{array}$} & \multirow{2}{*}{$\begin{array}{c}\text { Dingot } \\
\text { No. } \\
\end{array}$} & \multicolumn{2}{|c|}{$\begin{array}{l}\text { Heating Time } \\
\text { min }\end{array}$} & \multirow{2}{*}{$\begin{array}{c}\text { Transfer } \\
\text { Time } \\
\text { min }\end{array}$} & \multirow{2}{*}{$\begin{array}{c}\text { Ram } \\
\text { Speed } \\
\text { in./min } \\
\end{array}$} & \multirow{2}{*}{$\begin{array}{c}\text { Final } \\
\text { Extrusion } \\
\text { Thrust } \\
\text { tons }\end{array}$} & \multirow{2}{*}{$\begin{array}{c}\text { Hot } \\
\text { Follower } \\
\text { Block } \\
\text { Angle } \\
\end{array}$} & \multirow{2}{*}{$\begin{array}{c}\text { Hot } \\
\text { Follower } \\
\text { Block } \\
\text { Material } \\
\end{array}$} & \multirow[b]{2}{*}{ Remarks } \\
\hline & & Heat & Soak & & & & & & \\
\hline 1 & 22126 & - & - & - & - & - & - & - & Melted billet \\
\hline 2 & 22140 & 47 & - & 9.0 & 56 & - & $30^{\circ}$ & Graphite & Partially melted billet \\
\hline 3 & $\begin{array}{l}21910+ \\
21978-1\end{array}$ & 33 & 11 & 4.2 & - & 780 & $30^{\circ}$ & Uranium & $\begin{array}{l}\text { Intentional partial } \\
\text { extrusion }\end{array}$ \\
\hline 4 & $\begin{array}{l}22151+ \\
23188^{-2}\end{array}$ & 27 & 13 & 3.0 & - & 390 & $30^{\circ}$ & Uranium & $\begin{array}{l}\text { Intentional partial } \\
\text { extrusion }\end{array}$ \\
\hline 5 & $21914-1$ & 34 & 11 & - & - & - & - & - & $\begin{array}{l}\text { Billet turned over } \\
\text { in grab }\end{array}$ \\
\hline 6 & 23188-1 & 37 & 12 & 19.7 & - & 1200 & - & - & Pierced \\
\hline 7 & 22148 & 46 & 10 & 7.9 & 39 & 1430 & $25^{\circ}$ & Graphite & - \\
\hline 8 & 22083 & 36 & 10 & 3.5 & 46 & 1170 & $20^{\circ}$ & Graphite & - \\
\hline 9 & 22141 & 43 & 15 & 4.3 & 51 & 1300 & $20^{\circ}$ & Graphite & - \\
\hline 10 & 22146 & 33 & 11 & 4.8 & 42 & 1300 & $30^{\circ}$ & Graphite & - \\
\hline
\end{tabular}


FIGURE 2

BILLET-TO-ROLLABLE-ROD YIELD VERSUS RATIOS OF CYLINDRICAL-TO-CONICAL VOLUMES OF BILLETS HEATED IN OPEN-END CANS, NINTH GAMMA EXTRUSION CAMPAIGN AT BBC IN ADRIAN, MICHIGAN

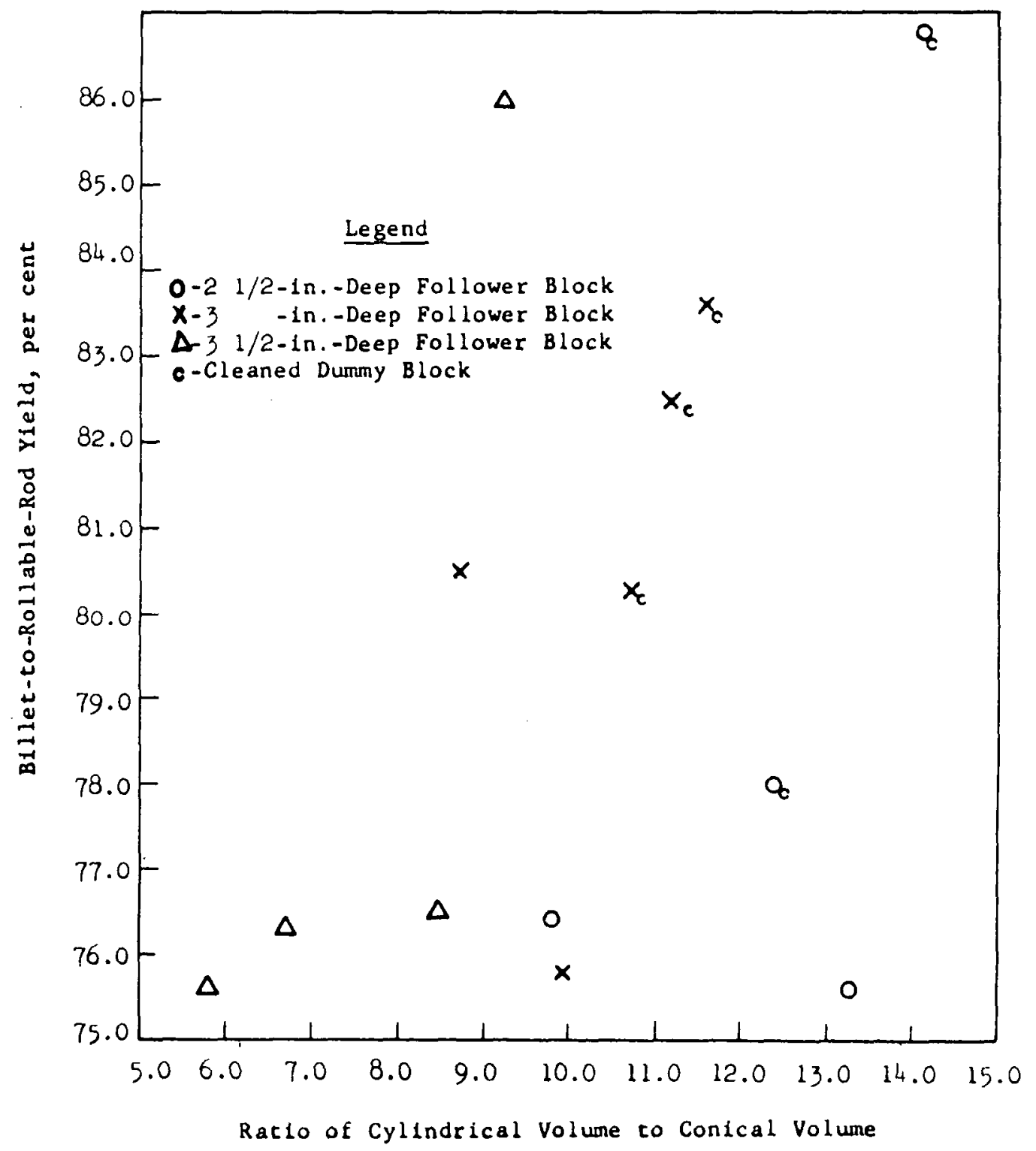

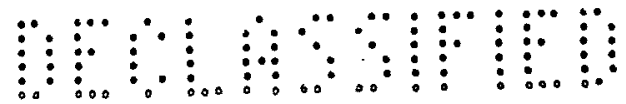


2. Billet Heating

When the power was turned on in the " $\mathrm{B}$ " coil, during the course of checking the control circuits prior to the start of the campaign, a short circuit between turns damaged the coil and precluded its use in this campaign.

Both coils had been modified before this campaign to improve their alignment in an effort to prevent short circuiting of the gap in the stainless steel liner. Also, a layer of Fiberfrax, a fibrous paper type insulation, was glued with waterglass to the inside of each liner to prevent contact of the billet with the liner. A piece of graphite 16 inches in diameter by 18 inches long was heated to $1750^{\circ} \mathrm{F}$ in the " $A$ " coil to dry out the Fiberfrax before heating a billet.

During heating of the first billet, part of the Fiberfrax in the "A" coil slid down and obstructed the view of the Rayotube. There was therefore no temperature control during the latter part of the heating of this billet and it was partially melted. The billet was placed in a steel box and covered with salt after removal from the coil, and the Fiberfrax was then completely removed from the coil liner. A small portion of the second billet heated was melted adjacent to the liner gap near the bottom, but the billet was extruded.

An attempt was made to use firebrick discs as stools to support the billets in the coils, in order to decrease heat loss from the billet and to prevent overheating of the bottom flux concentrator. These discs did not have sufficient strength to support the billets during lifting in the grab and their use was abandoned after the fourth billet.

The uranium follower blocks for use in the partial extrusions were placed on top of the billets in the coils and heated with the billets.

\section{Extrusion}

Handling of the hot graphite follower blocks, heated to $1850^{\circ} \mathrm{F}$ in an electric resistance furnace, again presented operational difficulties and resulted in long transfer times.

Two $16 \frac{1}{4}$-inch-diameter and three $15 \frac{1}{2}$-inch-diameter billets were extruded with contoured graphite follower blocks to determine the effect of degree of upset in the 17-inch-ID container liner.

The two billets partially extruded for study of flow characteristics were $15 \frac{1}{2}$ inches in diameter so that the maximum effect of upset in the 17-inch-ID liner would be observed. When the first of these had been inserted in the container, the ram was advanced until 
pressure was indicated on the gauge and then advanced eight inches more to extrude three-fourths of the billet: Theirod and butt were removed from the press intact and covered with salt. For the second billet, the ram was advanced only one inch after pressure was indicated on the gauge, with the result that only about six inches of rod was extruded. This billet was removed from the container in a box specially designed for this purpose and then covered with salt.

Since neither a shear nor a saw fits readily into the design of the press at Weldon Spring, and graphite follower blocks of the design and material used thus far have not crushed in the manner desired, the need for an alternate method for freeing rods from their butts arose. A method, termed "punching," was envisioned for this need which would consist of forcing a mandrel of slightly smaller diameter than the die through the butt, thus piercing a hole through the butt and pushing the back end of the rod through the die. As a preliminary investigation of this process, a short billet was pierced, or "punched," during this campaign. The five-inch-long billet for this "punching" experiment was inserted in the container, as shown in Figure 4, with a hollow graphite follower block behind it. A flat steel "pusher plate," screwed into the mandrel, was used to push the billet to within about one inch of the die. The ram was then withdrawn, the "pusher plate" removed, and the graphite piercing cap inserted in the mandrel. The ram was advanced until the front of the piercing mandrel was about one inch beyond the face of the die, piercing the billet as shown in Figure 4.

A shear-type chrome carbide insert die was used for all billets except the punching experiment. A steel flow-type die was used for this billet.

4. Product Evaluation

The rods extruded with contoured graphite follower blocks were washed free of salt, weighed, cropped, reweighed and examined visually for yield determination. One-inch: thick longitudinal slices, $90^{\circ}$ apart, were cut from the butts of the partially extruded billets, and radiographed. A number of one-inch-thick transverse slices, cut from the back end of the rod from the billet which was three-fourths extruded, were also radiographed.

\section{Experimental Results}

Yields for the rods extruded with contoured graphite follower blocks are listed in Table V. All of the surface area of these rods was of a quality satisfactory for rolling. However, the surfaces of the rods extruded from the $16 \frac{1}{2}$-inch-diameter billets were slightly superior to those extruded from the $15 \frac{1}{2}$-inch-diameter billets. The type of "reverse pipe" back-end defect encountered in rods extruded from flat back-end billets and contoured follower blocks in the sixth campaign was also evident in those rods from this campaign which had low yields. 
Losses and Yields - Seventh Gamma Extrusion Campaign at Dow, Madison, Illinois

$\therefore \cdots:$

¿....:

.

$\ldots$.

$\because$ :

$\because \because$

.....

$\vdots \ldots .$.

$\therefore \therefore$

¿....:

$\therefore .$.

\begin{tabular}{|c|c|c|c|c|c|c|c|c|c|}
\hline $\begin{array}{c}\text { Billet } \\
\text { No. }\end{array}$ & $\begin{array}{c}\text { Dingot } \\
\text { No. }\end{array}$ & $\begin{array}{l}\text { Billet } \\
\text { Weight } \\
\text { lb }\end{array}$ & $\begin{array}{c}\text { Billet } \\
\text { Diameter } \\
\text { in. }\end{array}$ & $\begin{array}{l}\text { Follower } \\
\text { Block } \\
\text { Angle }\end{array}$ & $\begin{array}{l}\text { Cylinder- } \\
\text { to-Cone } \\
\text { Ratio }\end{array}$ & $\begin{array}{c}\text { Butt and } \\
\text { Oxidation } \\
\text { Losses } \\
\%\end{array}$ & $\begin{array}{c}\text { Cropping } \\
\text { Losses } \\
\%\end{array}$ & $\begin{array}{c}\text { Total } \\
\text { Losses } \\
\%\end{array}$ & $\begin{array}{c}\text { Billet-to- } \\
\text { Rollable- } \\
\text { Rod Yield } \\
\%\end{array}$ \\
\hline 8 & 22083 & 2050 & $16 \frac{1}{4}$ & $20^{\circ}$ & 13.5 & 16.0 & 10.6 & 26.6 & 73.4 \\
\hline 9 & 22141 & 1765 & $15 \frac{1}{2}$ & $20^{\circ}$ & $13: 6$ & 15.1 & 1.5 & 16.6 & 83.4 \\
\hline 7 & 22148 & 1765 & $15^{1 / 2}$ & $25^{\circ}$ & 10.0 & 22.3 & 13.6 & 35.9 & 64.1 \\
\hline 10 & 22146 & 2045 & $16 \frac{1}{4}$ & $30^{\circ}$ & 8.2 & 15.4 & 1.6 & 17.0 & 83.0 \\
\hline 2 & 22140 & 1720 & $15^{1 / 2}$ & $30^{\circ}$ & 8.0 & 44.4 & 6.6 & 51.0 & $49.0^{b}$ \\
\hline
\end{tabular}



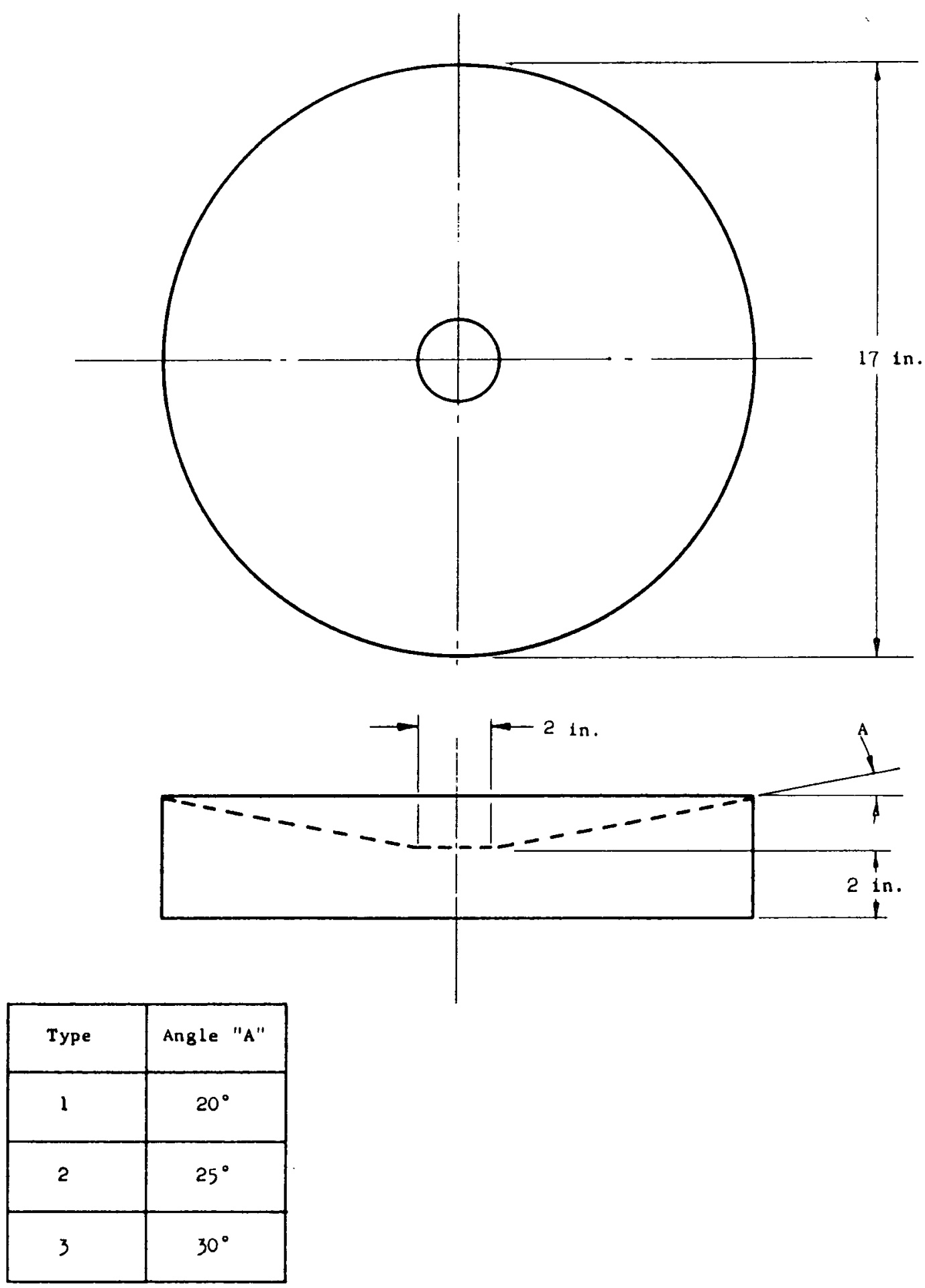

PIGURE 3

FOLLOWER BLOCK 
None of the graphite follower blocks crushed sufficiently to free the rods from their butts, and shearing, with the single-acting shear attached to the press, was necessary in every case. The behavior of the Grade AGR graphite as a follower block material was not found to be materially different from that of Grade CS 312.

In the punching experiment the piercing plug was not quite separated from the billet, as shown in Figure 5, but this was probably due to the graphite piercing cap crushing and flowing through the opening in the billet without pushing the plug free. A total thrust of 1200 tons was used in the piercing operation.

The uranium follower block used with the billet which was three-fourths extruded was pushed into the back end of the billet and metal was also back extruded around the follower block, as shown in Figure 6. An unusual flow pattern, shown in Figure 7 , was revealed by radiographic inspection.

The billet which had only one inch of its length extruded was not completely upset. It was barrel shaped and exhibited deep longitudinal fissures, apparently indicating that the billet was too cold and the surface was actually in the beta phase. The temperature record indicated that the Rayotube was not functioning properly during the heating of this billet, and the surface temperature of the billet just before it entered the container was below $1400^{\circ} \mathrm{F}$, which is the bottom of the range of the optical pyrometer used.

The chrome carbide die was damaged considerably during this campaign, evidently by the shearing operation, but enough of the land was intact around the entire ID for it still to be usable.

D. Discussion of Results

No correlation could be drawn between yield and follower block contour, or billet angles, for the billets extruded with contoured graphite follower blocks. This was probably due to the wide divergence in transfer times for these billets. The "reverse pipe" defect observed in the rods with low yields indicates that the cylinder-cone volume ratios on the billets used were too great.

The punching experiment was considered successful, in general. However, the amount of thrust required indicated that the full thrust of the Weldon Spring press would be required for punching. 


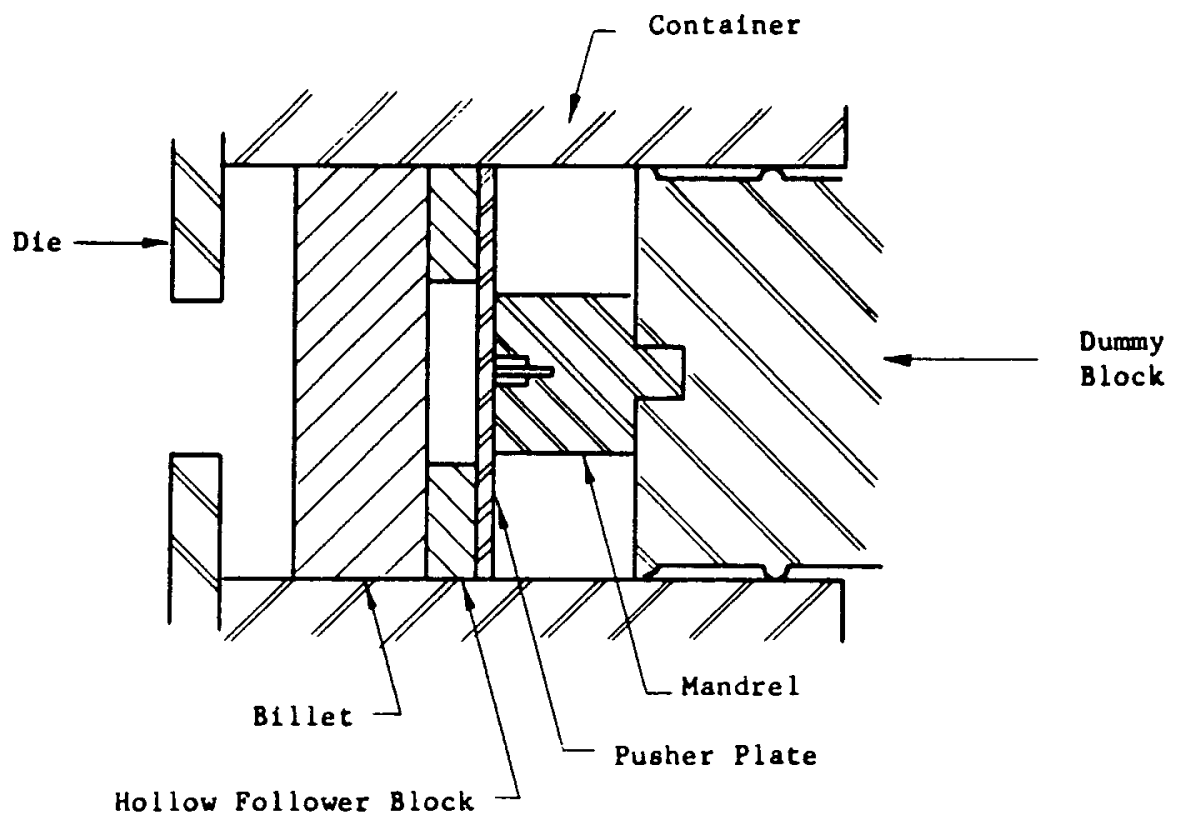

Inserting Billet Into Container

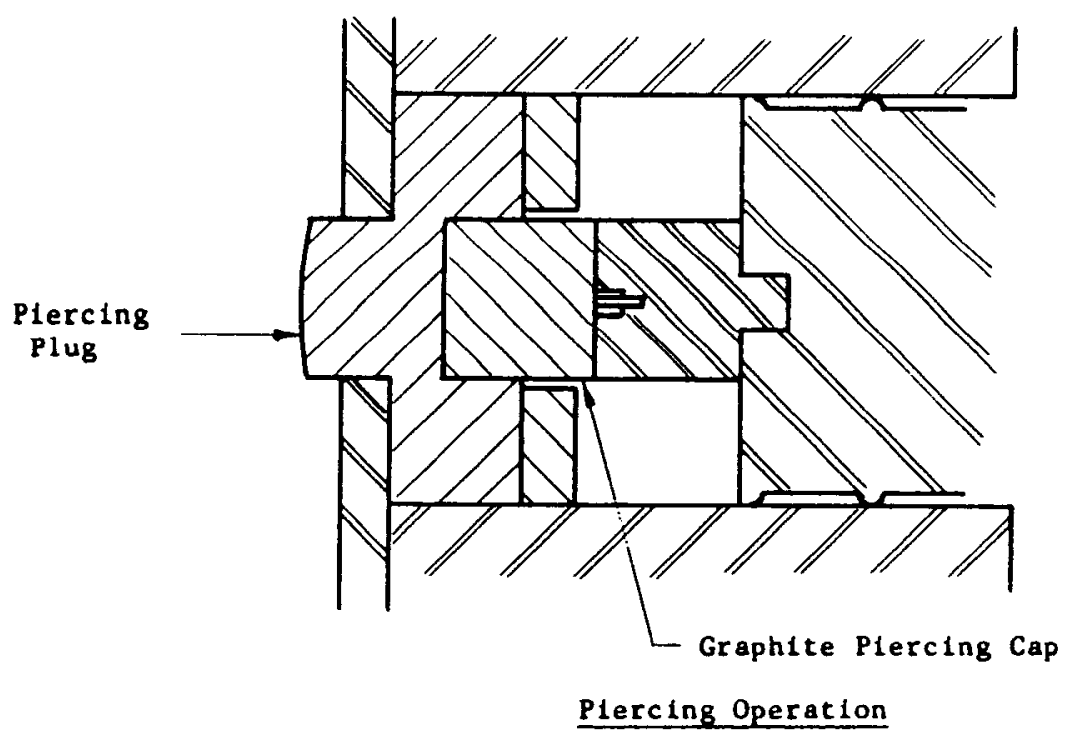

FIGURE 4

PUNCHING EXPERIMENT 


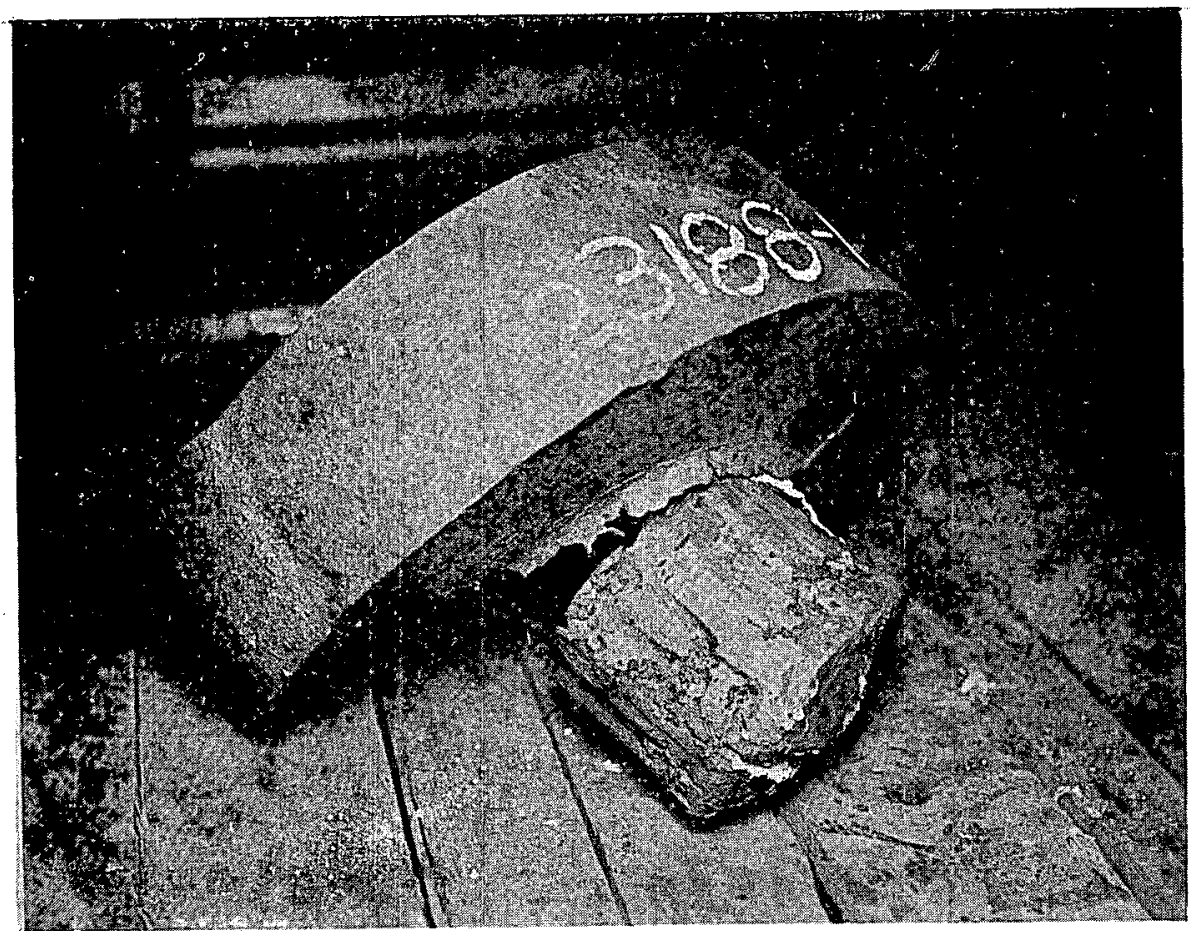

Figure 5

Pierced Billet from Punching Experiment, Billet No. 6, Seventh Campaign at Dow

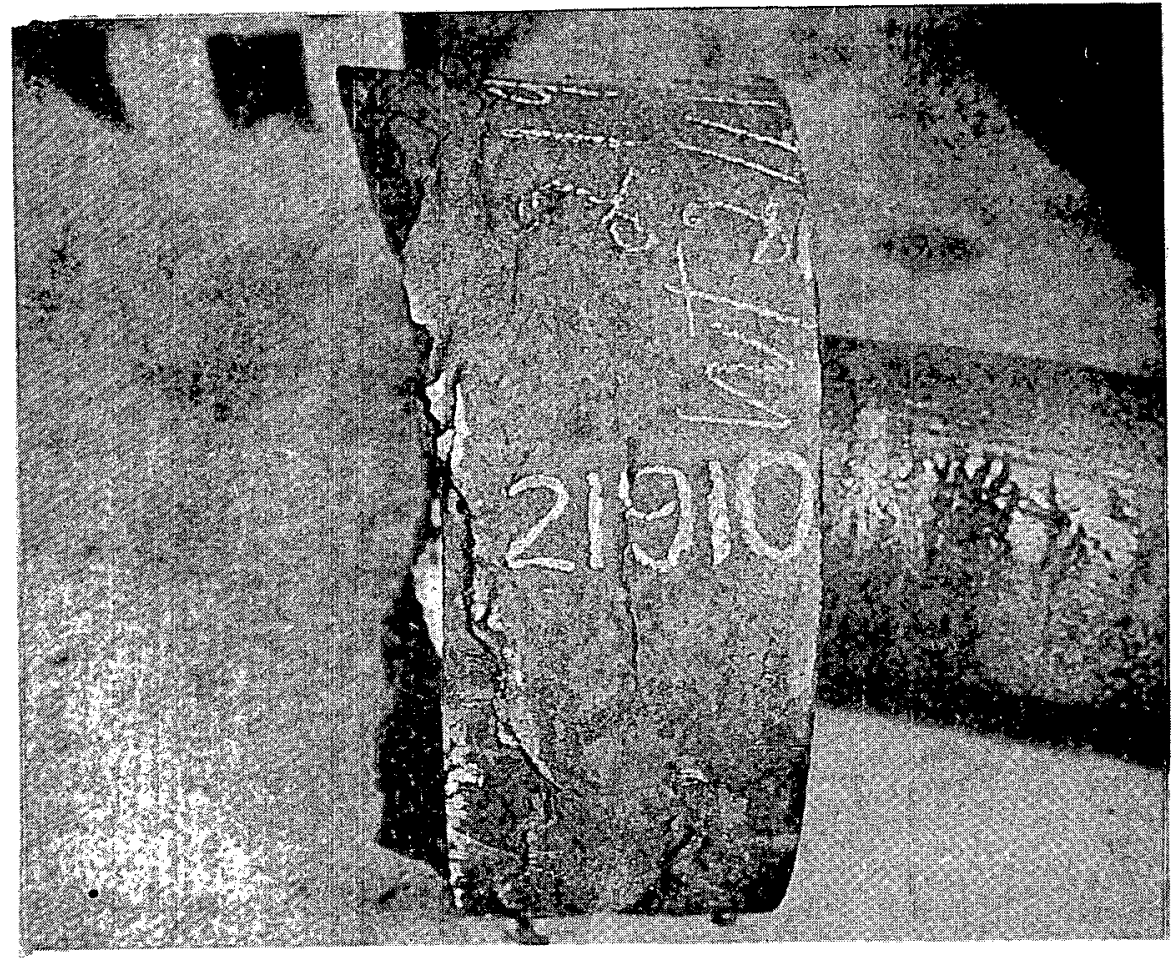

Figure 6

Butt from Partially Extruded Billet, Billet No. 4,

$\because \because \cdots: \cdots:$ : $\because$ : • seventh:Campaiga at Dow

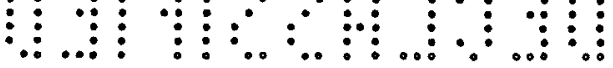



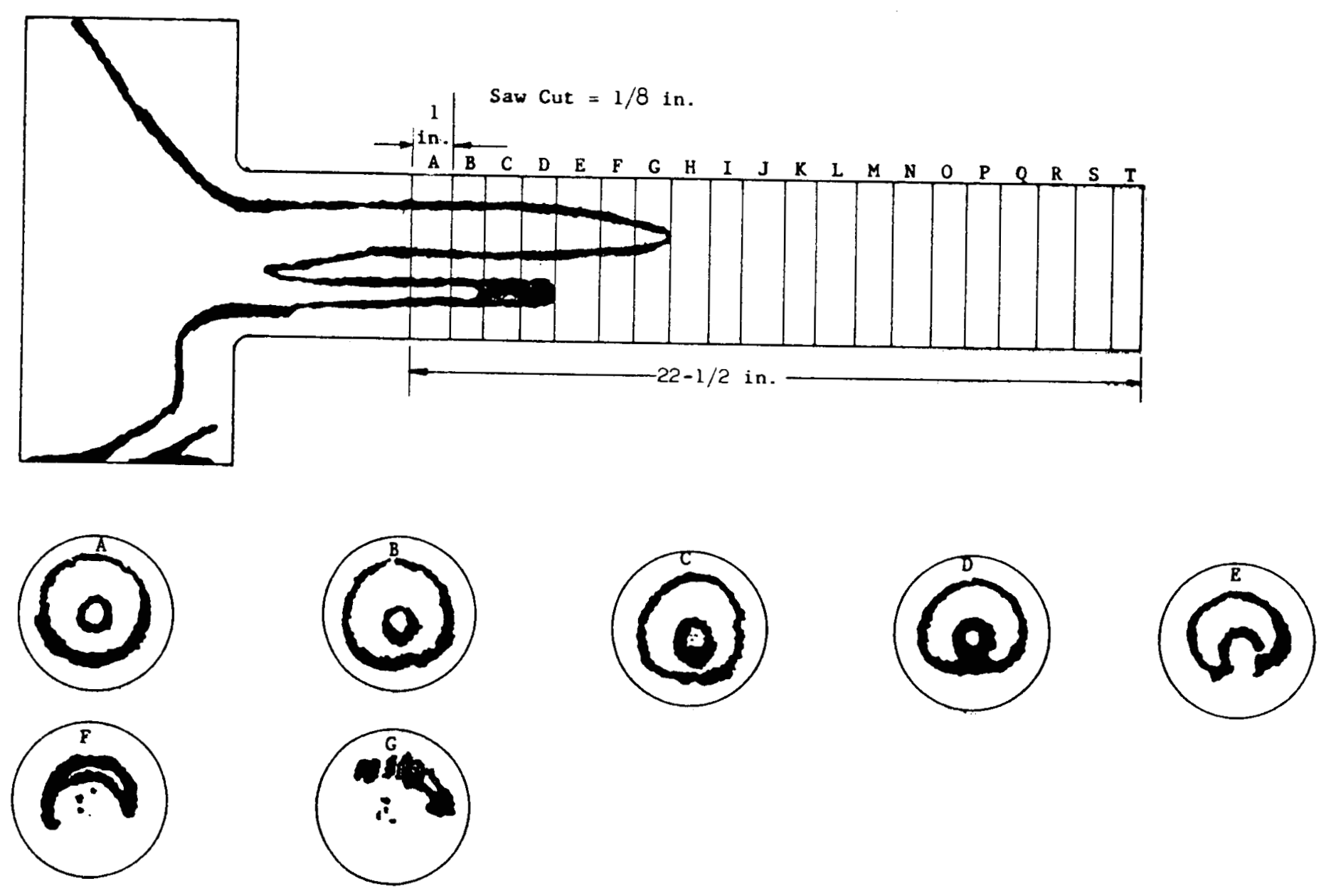

FIGURE 7

FLOW PATTERN FOR DINGOT NO. 21910 
The unusual flow pattern in the billet that was three-fourths extruded is not readily explained but may have been due to the interior of the billet and uranium follower block being hotter than the surface. This flow pattern was similar but not identical with that observed in rods extruded from flat-end billets with contoured graphite follower blocks. The information regarding flow available from the billet extruded only one inch could not be considered reliable because of the low billet temperature.

E. Conclusions

Further efforts toward increasing yields by the use of contoured billets and contoured follower blocks should be directed toward greater cylinder-cone volume ratios on the billets.

The punching process showed promise as a means of separating the rod from its butt, if the full capacity of the Weldon Spring press could be exerted on the mandrel.

Grade AGR graphite showed no more promise than Grade CS 312 as a follower block material that will crush and free a rod from its butt.

\section{Eighth Campaign at Dow}

\section{A. Purpose}

The primary purpose of this campaign was to develop a method for separating a rod from its butt without the use of a saw or shear. The two methods investigated were punching and the use of metal follower blocks. The reasoning behind the latter approach is:

(1) if the contour of a metal follower block is such that the interface between the back end of the rod and the follower block is flat after extrusion,

(2) if no welding takes place between the rod and the follower block, and

(3) if the follower block is partially extruded, then

(4) the rod would separate freely from the follower block and the resultant yield should be high.

Contoured copper, cast iron, and uranium follower blocks, having various contour depths, were used. 
The secondary purpose of this campaign was to investigate the flow characteristics of uranium during extrusion by extruding a billet composed of a series of one-inch-thick discs welded together.

B. Experimental Work

1. General

Procedures again corresponded generally to those of previous campaigns at Dow. Constant extrusion conditions are listed in Table VI and extrusion conditions for individual rods are listed in Table VII. 


\section{Constant Extrusion Conditions - Eighth Gamma Extrusion Campaign at Dow, Madison, Illinois}

Billet Temperature

Hot Follower Block. Temperature

Warm Follower Block Temperature

Tool Oven Temperature

Container Temperature

Die Material

Billets 6,7 and 10

All Other Billets

\section{Die Design}

Billets 6,7 and 10

All Other Billets $1850^{\circ} \mathrm{F}$

See Table VII

$900^{\circ} \mathrm{F}$

$890^{\circ} \cdot \mathrm{F}$

$850^{\circ} \mathrm{F}$
A.I.S.I. $T-1,50-54 R_{c}$

All. Lud. Grade CA815

Chrome Carbide Insert

(in A.I.S.I. H-13 Case, 50-54 Rc)

Flow Type, $3 / 4-$ in. inlet radius, $3 / 4-i n$. land

Shear Type, 1-in. land. 
Table VII

Extrusion Conditions for Individual Rods

Eighth Gamma Extrusion Campaign at Dow, Madison, Illinois

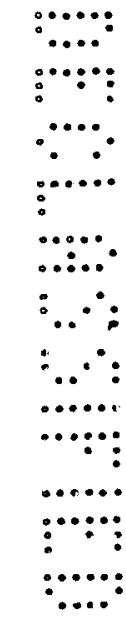

\begin{tabular}{|c|c|c|c|c|c|c|}
\hline $\begin{array}{l}\text { Heating } \\
\text { Time } \\
\text { (Including) } \\
\left(\begin{array}{l}\text { Soak }) \\
\text { min }\end{array}\right.\end{array}$ & $\begin{array}{c}\text { Transfer } \\
\text { Time } \\
\text { min }\end{array}$ & $\begin{array}{c}\text { Ram } \\
\text { Speed } \\
\text { in. } / \mathrm{min}\end{array}$ & $\begin{array}{c}\text { Final } \\
\text { Extrusion } \\
\text { Thrust } \\
\text { tons }\end{array}$ & $\begin{array}{c}\text { Hot } \\
\text { Follower } \\
\text { Block } \\
\text { Angle }\end{array}$ & $\begin{array}{l}\text { Hot } \\
\text { Follower } \\
\text { Block } \\
\text { Material }\end{array}$ & $\begin{array}{l}\text { Hot } \\
\text { Follower } \\
\text { Block } \\
\text { Temp. } \\
{ }^{0} \mathrm{~F}\end{array}$ \\
\hline 52 & 9.1 & 79 & 1430 & $20^{\circ}$ & Copper & 1250 \\
\hline 48 & 7.0 & 56 & 1430 & Flat & Copper & 1420 \\
\hline 46 & 4.3 & 60 & 1430 & $20^{\circ}$ & Copper & 1420 \\
\hline 44 & 4.6 & 54 & 1430 & Flat & Copper & " 1450 \\
\hline 48 & 4.4 & 56 & 1430 & $16.7^{\circ}$ & Cast iron & 1620 \\
\hline 45 & 5.1 & 49 & 1430 & Flat & Graphite $^{a}$ & 1600 \\
\hline 50 & 4.3 & 52 & 1430 & $10^{\circ}$ & Graphite & 1790 \\
\hline 48 & 3.6 & 58 & 1430 & $21.8^{0}$ & Cast iron & 1800 \\
\hline 49 & 3.7 & 55 & 1430 & $20^{\circ}$ & Uranium $^{c}$ & $c$ \\
\hline 48 & 4.9 & 48 & 1430 & $10^{\circ}$ & Graphite & 1800 \\
\hline 47 & 3.6 & 50 & 3900 & Flat & Graphite & 1800 \\
\hline
\end{tabular}

${ }^{a}$ Two-in.-thick, 2.6-in.-diameter plug.

${ }^{b}$ Seven-in.-diameter plug.

${ }^{C}$ Uranium follower block heated in coil with billet; two-in.-thick, flat graphite follower block at $1800^{\circ} \mathrm{F}$ behind uranium follower block. 
2. Billet Heating

No difficulties were encountered in billet heating during this campaign. However, only one coil was used as the one damaged during the seventh campaign had not yet been repaired.

3. Extrusion

The follower blocksfor Billets 1, 3, 5 and 8 were of the design shown in Figure 3, except for the angle on the cast iron follower blocks. They were cast to shape and the periphery was machined to insure rotundity. The respective angles on the cast iron follower blocks corresponded to contour depths of $2 \frac{1}{2}$ inches and 3 inches. The graphite follower blocks used for Billets 7 and 10 were of the design shown in Figure 8 , and that for Billet 6 was of the same design but flat with a 2.6-inch-diameter hole and plug. The flat copper follower blocks used with Billets 2 and 4 were five inches thick. Angles to correspond to the follower block angles were machined on one end of all of the billets used with contoured follower blocks.

Follower block handling was improved in this campaign by picking up the follower blocks, from a holding fixture, with the billet grab. Previous practice had been to place them behind the billet on the loading head at the press, after the billet had been placed on the head. This improvement resulted in generally shorter and more uniform transfer times.

After extrusion of Billet 6 with an articulated dummy block of the type usually used at Dow, the ram was withdrawn. A separate dummy block having a 2.6 -inch-diameter piercing mandrel attached was placed on the billet loading head and pushed into the container by the articulated dummy block. The ram was advanced until the front end of the mandrel was about 16 inches beyond the face of the die. The mandrel pushed the graphite plug out of the follower block and pushed on the back end of the rod until it was freed from its butt.

The same type of operation was performed on Billets 7 and 10 except that a $67 / 8$-inch mandrel was used and the ram movement during the punching operation was stopped when the end of the mandrel was about two inches beyond the face of the die. A thrust of approximately 1400 tons was used in the punching operation on Billet 7 . An attempt was made to stop the advance of the ram when the thrust had reached 250 tons on Billet 10 , in order to simulate the thrust conditions of punching with the piercing ram of the Weldon Spring press. However, the inertia of the massive crosshead of the 5500-ton press used carried the ram forward until a thrust of 


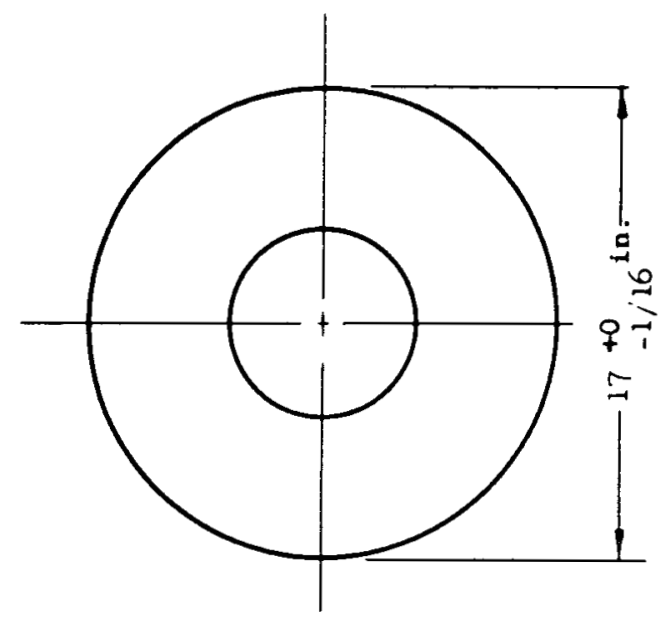

Follower Block

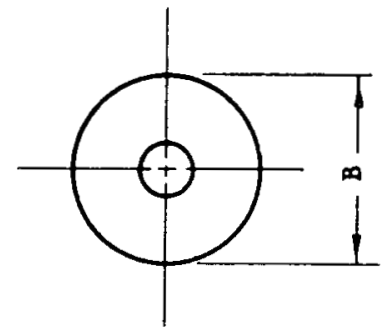

Pollower Block Plug
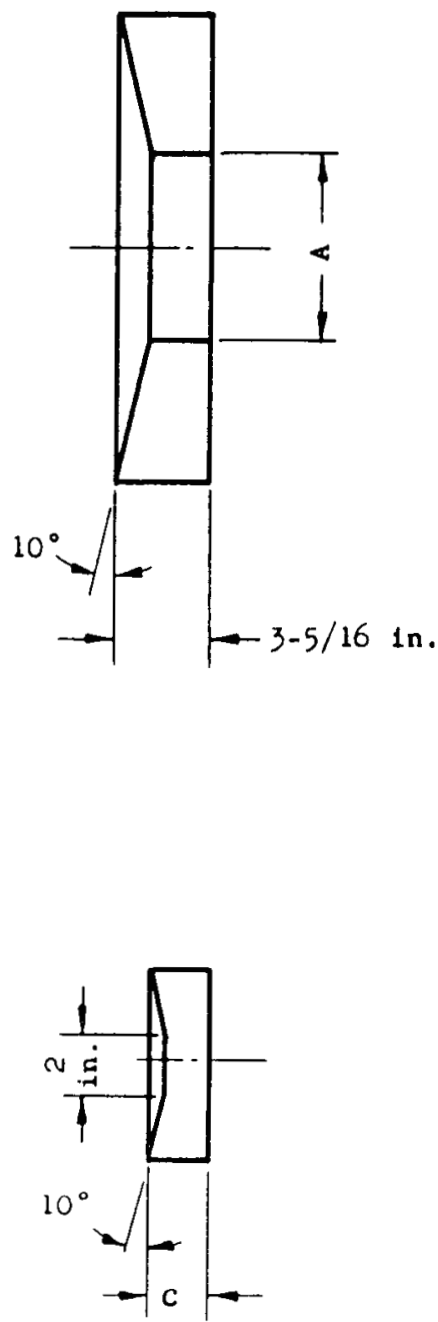

Dimension, in.

\begin{tabular}{|c|l|l|l|l|}
\hline Item & Part & A & B & C \\
\hline 1 & Fol. Block & $2-3 / 4$ & & \\
\hline 2 & Fol. Block & 7 & & \\
\hline 3 & Plug & & $2-3 / 4$ & $2-1 / 16$ \\
\hline 4 & Plug & & 7 & $2-7 / 16$ \\
\hline
\end{tabular}

Item 3 Must Be Slide Fit in Item 1

Item 4 Must Be Slide Fit in Item 2

FIGURE 8

POLLOWER BLOCXS IN PUNCHING EXPER IMENT

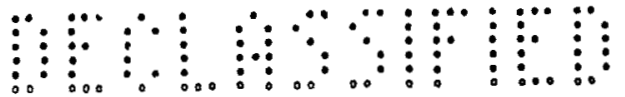


approximately 400 tons had been reached. The mandrel was held very tightly in the butt after each punching experiment.

The full capacity of the press was used on Billet 11 , since no study of yield was involved. The graphite follower block was crushed and the rod was freed from its butt without shearing.

A shear-type chrome carbide insert die was used for all billets except those used in the punching experiments; a steel die was used for these.

4. Rod Evaluation

Yields for all of the rods except Rods 9 and 11 were determined in the same manner as described for the seventh campaign. Rods 9 and 11 were cut into one-inch-thick transverse slices and these slices will be radiographed.

C. Experimental Results

Yields for the individual rods are listed in Table VIII. None of the copper or cast iron follower blocks extruded because they did not have sufficient flowability at the temperatures at which they were used. Also, since the temperatures of these follower blocks were considerably below those of the billets, the back ends of the billets were chilled and heavy butt losses were sustained. The uranium follower block was extruded, but did not separate from the rod. It was necessary to shear all of the rods except those which were punched and Rod 11 , which was extruded with the capacity of the press. 
Individual Rod Yields - Eighth Gamma Extrusion Campaign at Dow, Madison, Illinois

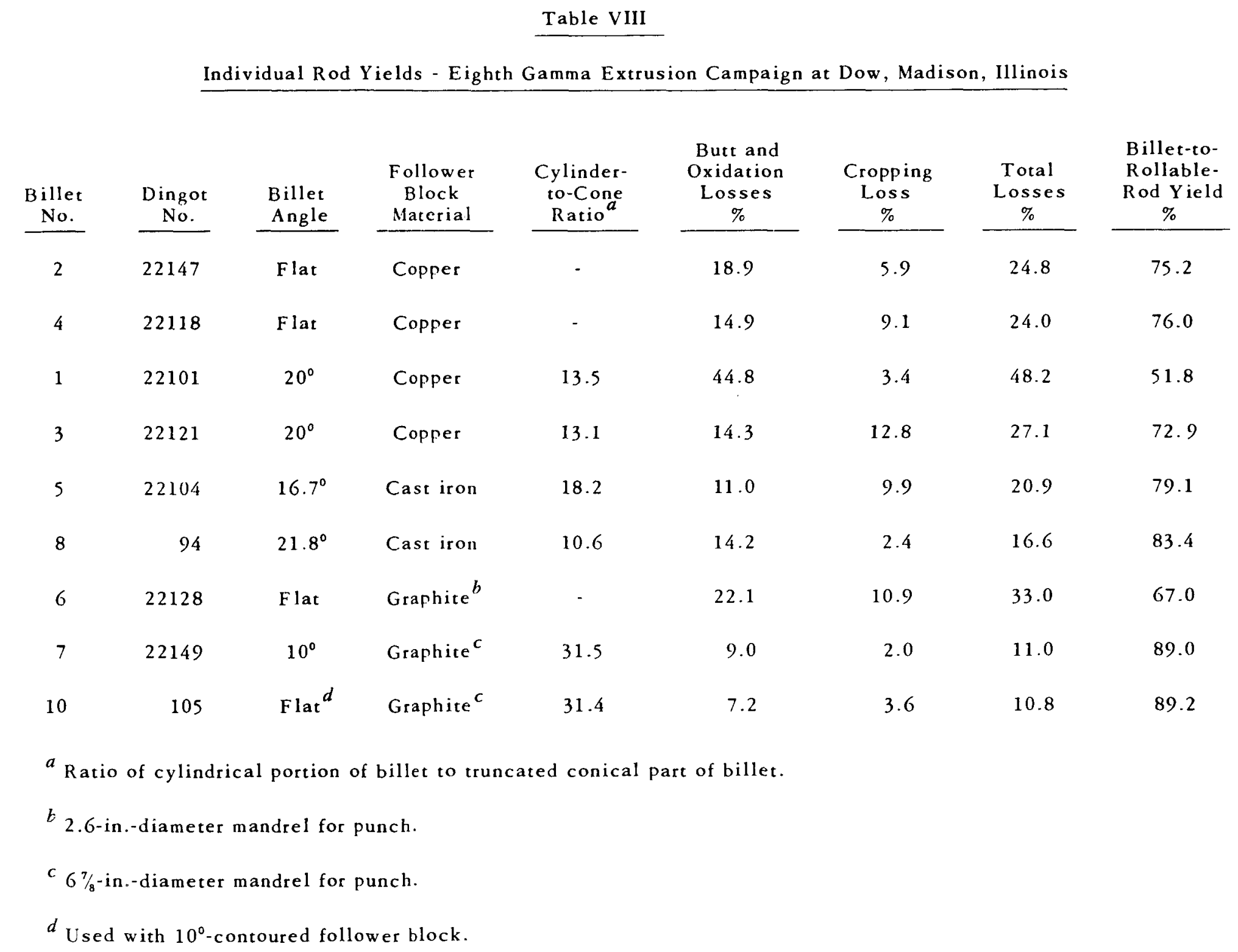


The 2.6-in:-diameter piercing mandrel, which was used to free Rod 6 from its butt, indented the back end of the rod to form a tube. Continuing pressure on the back end of the rod caused this tube to break in tension, with part of it remaining integral with the rod and part remaining attached to the butt. That part of the tube integral with the rod is included in the cropping loss for Rod 6 in Table VIII, and that part remaining attached to the butt is included in the corresponding butt and oxidation loss.

Radiographic inspection of Rods 9 and 11 is? not yet complete and will be reported later. The chrome carbide die was severely damaged during this campaign. The damage was quite obviously due to the action of the single-acting shear used.

D. Discussion of Results

It would be necessary to heat copper or cast iron follower blocks to considerably higher temperatures than those employed in this campaign in order to partially extrude them behind the rod.

The low yield for Rod 6 was partially due to the 2.6-in.-diameter mandrel indenting the back end of the rod and forming a tube. The back ends of Rods 7 and 10 were flat, and the yields were probably raised by inclusion of the center portion of the butt in the back end of the rod. No extrusion defect was revealed by cropping of Rod 7 and only about $2 \%$ of the $3.6 \%$ cropped from Rod 10 showed extrusion defect. Therefore, the yield for the se two rods actually was about $91 \%$. It is of interest to note that the yield for Billet 10, which had a flat back end but was extruded with a contoured follower block, was approximately the same as that for No. 7, which was a contoured billet. Refinement of the punch design is necessary to reduce the considerable amount of time consumed in removing the mandrels from the butts after punching.

E. Conclusion

Punching shows definite promise as a method for separating rods from their butts.

A considerable amount of work will be required on metal follower blocks if their use is to be made practicable for freeing rods from their butts. Also, their use would be economical only if the cleaner operation resulting were deemed highly desirable. 
VI. Ninth Campaign at Dow

\section{A. Purpose}

The purposes of this campaign were to investigate further methods of freeing rods from their butts, to investigate the flow of uranium in upsetting prior to extrusion, and to investigate the effect of billet taper, such as is contemplated for Weldon Spring, on heating and extrusion characteristics. Punching and the use of graphite follower blocks weakened by having grooves machined in them to promote controlled crushability, were the methods under consideration for freeing rods from their butts.

B. Experimental Work

1. General

Procedures were in general the same as for previous Dow campaigns. Extrusion conditions are listed in Tables $\mathrm{IX}$ and $\mathrm{X}$.

\section{Table IX}

Constant Extrusion Conditions - Ninth Gamma Extrusion Campaign at Dow, Madison, Illinois

Billet Temperature

Hot Follower Block Oven Temperature

Warm Follower Block Oven Temperature

Tool Oven Temperature

Container Temperature

Follower Block Material

Die Material

Die Design $1850^{\circ} \mathrm{F}$

$1850^{\circ} \mathrm{F}$

$890^{\circ} \mathrm{F}$

$890^{\circ} \mathrm{F}$

$880^{\circ} \mathrm{F}$

CS 312 Graphite

All. Lud. Grade CA815 Chrome Carbide Insert (in AISI H-13 Case, 50-54 $\mathrm{R}_{\mathrm{C}}$ )

Flow Type, $3 / 4$-in-inlet radius, $1 / 2$-in. and $1 / 16^{-i n}$. offser relief 
Extrusion Conditions for Individual Rods -

Ninth Gamma Extrusion Campaign at Dow, Madison, Illinois

$\therefore . . .:$

$\vdots \ldots .:$.

$\ldots . .:$ :

(n......

$\because \because$

$\because \because:$

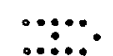

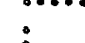

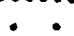

$\therefore .$.

$\therefore . . .:$

$\therefore \ldots$

\section{Heating}

Time

\begin{tabular}{cccc}
$\begin{array}{c}\text { Billet } \\
\text { No. }\end{array}$ & $\begin{array}{c}\text { Dingot } \\
\text { No. }\end{array}$ & $\begin{array}{c}\text { Time } \\
\text { (Including) } \\
\text { Soak } \\
\text { min }\end{array}$ \\
\hline 1 & 186 & 65 \\
2 & 188 & 49 \\
3 & 190 & 62 \\
4 & 192 & 59 \\
5 & 193 & 44 \\
6 & 198 & 46 \\
7 & 21982 & 53 \\
8 & 199 & 37 \\
9 & 212 & 47
\end{tabular}

10

201

\begin{tabular}{c}
$\begin{array}{c}\text { Transfer } \\
\text { Time } \\
\text { min }\end{array}$ \\
\hline 5.4 \\
4.5 \\
3.9 \\
5.7 \\
5.9 \\
4.8 \\
4.8 \\
3.4 \\
4.0
\end{tabular}

4.6

\begin{tabular}{c}
$\begin{array}{c}\text { Ram } \\
\text { Speed } \\
\text { in./min }\end{array}$ \\
\hline 54 \\
61 \\
60 \\
56 \\
69 \\
68 \\
Dud
\end{tabular}

64

67

43

83

\begin{tabular}{c}
$\begin{array}{c}\text { Final } \\
\text { Extrusion } \\
\text { Thrust } \\
\text { tons }\end{array}$ \\
\hline 1400 \\
1400 \\
1300 \\
1300 \\
1300 \\
1200 \\
- \\
1300 \\
1300
\end{tabular}

\begin{tabular}{c}
$\begin{array}{c}\text { Hot } \\
\text { Follower } \\
\text { Block }\end{array}$ \\
\hline $10^{\circ}$, Plugged \\
$10^{\circ}$, Plugged \\
$10^{\circ}$, Solid
\end{tabular}

(1)

\begin{tabular}{c}
$\begin{array}{c}\text { Warm } \\
\text { Follower } \\
\text { Block }\end{array}$ \\
\hline
\end{tabular}

2-in., Plugged

2-in., Plugged

$1 \frac{1}{2}$-in.; Solid

2-in., Plugged

$10^{\circ}$, Plugged

$10^{\circ}$, Solid

$10^{\circ}$, Solid

$20^{\circ}, 2$-in. $\min$. th., Solid

$10^{\circ}$, Grooved Solid

$10^{\circ}$, Plugged

1300

$10^{\circ}$, Grooved Solid

$1 \frac{1}{2}$-in., Solid

Punch

Diameter in.

4 
Billetshaving contours machined on one end were used in all cases. Billet 9 was machined as shown in Figure 9 to simulate the shape expected of Weldon Spring dingots.

2. Billet Heating

During heating of the first billet in the coil which had been damaged during the seventh campaign and subsequently repaired, the liner gap closed. The billet was partially melted in the vicinity of the gap, but extruded. The damage to the liner precluded further use of this coil and the balance of the billets for the campaign were all heated in the other coil.

The Rayotubes and recorders had been erroneously calibrated on a black body and therefore did not indicate true temperature on the first billets. Since the only reliable calibration method has been found to be calibration of the instruments at the phase transformation temperatures, it was necessary to heat several billets before reliable temperature readings were obtained.

Heating of the tapered billet, No.9, proceeded without incident. However, the temperature was estimated to be about $50^{\circ} \mathrm{F}$ lower at the small end than at the large end.

3. Extrusion

An articulated dummy block, bored and threaded to receive a mandrel, was used for all extrusions in this campaign. This was the same dummy block as the one used with a piercing mandrel attached to it in the eighth campaign for punching, but in the ninth campaign it was attached to the ram. A blank to protect the threaded hole shown in Figure 10 , was inserted before each extrusion. Only two turns of the threads were required to insert or remove this blank. Various combinations of the follower blocks shown in Figure 11 were used in conjunction with this blank for extrusion. The arrangement of follower blocks for the various billets is shown in Figure 12.

After extrusion of Billets 1-6 and 9, the ram was retracted and the blank was retroved from the dummy block. The bushing shown in Figure 13 was then inserted, also by only two turns of the threads, and a punch of the design shown in Figure 14 was inserted in the bushing. Punches having three front face diameters were used, as shown in Table $X$. The ram was advanced until the front of the punch was beyond the face of the die for Billets 1 and 2, but was stopped when the front of the punch was just short of the die face on Billets 3-6 and 9. The latter procedure required the graphite behind the billet to perform the shearing action through the die required to free the rod from its butt. Damage to the bushing during punching of the first two butts caused misalignment of the punch which resulted in breakage of the three punches and damage to the die. 

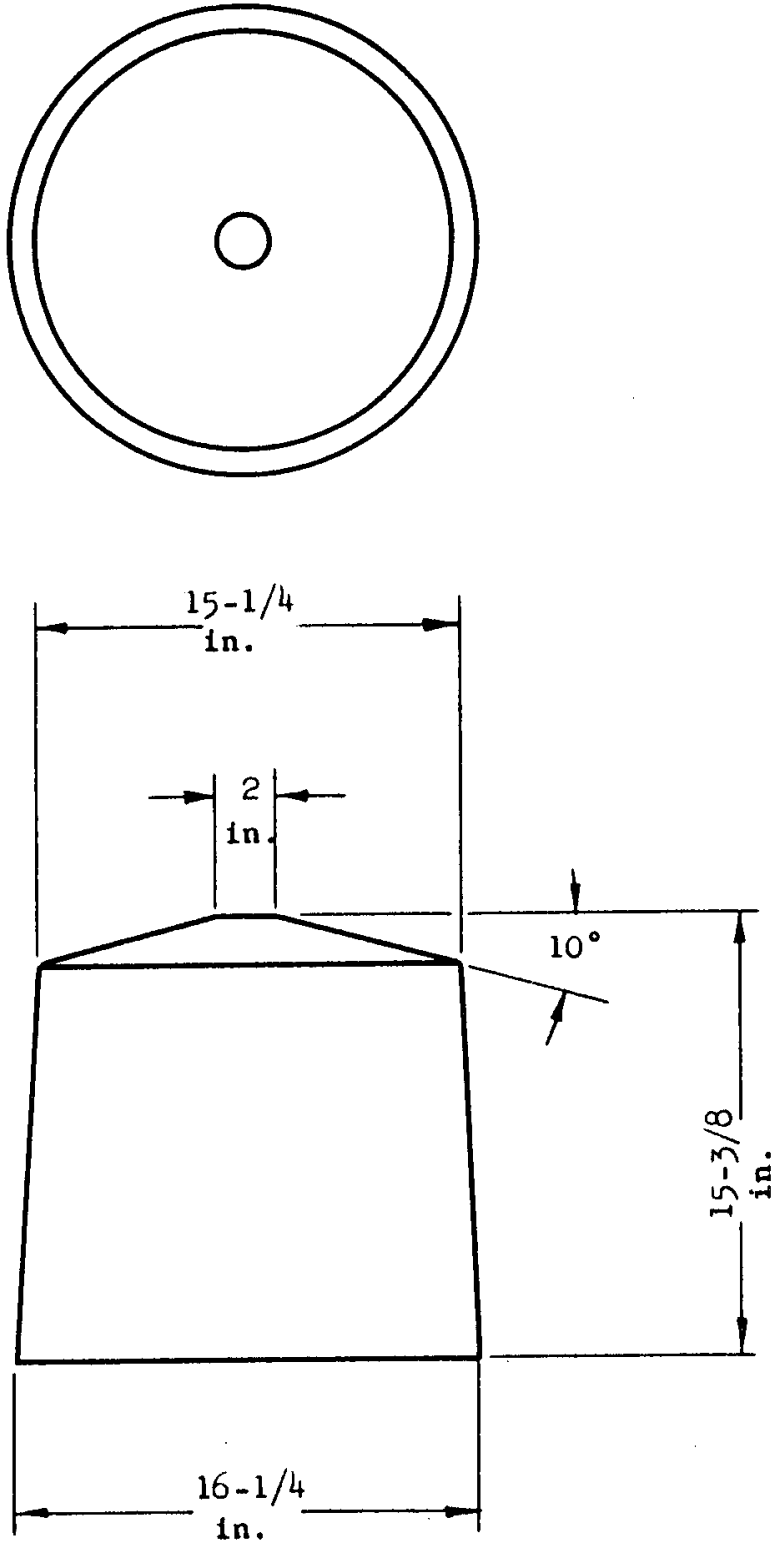

FIGURE 9

MACHINING OF DINGOT NO. 212

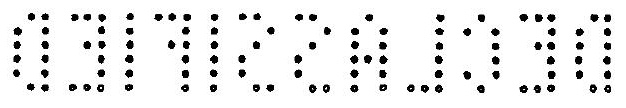


FIGURE 10

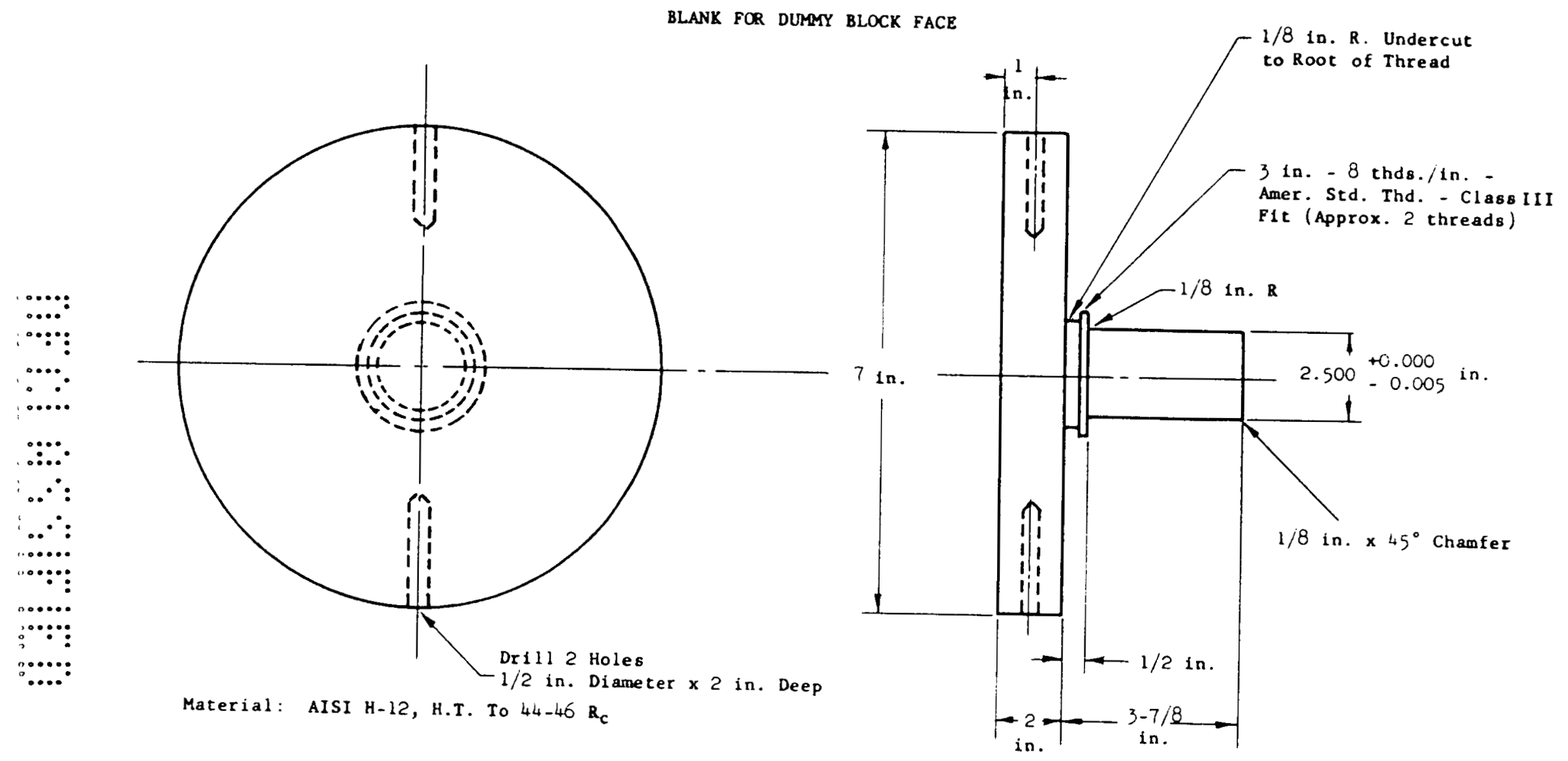




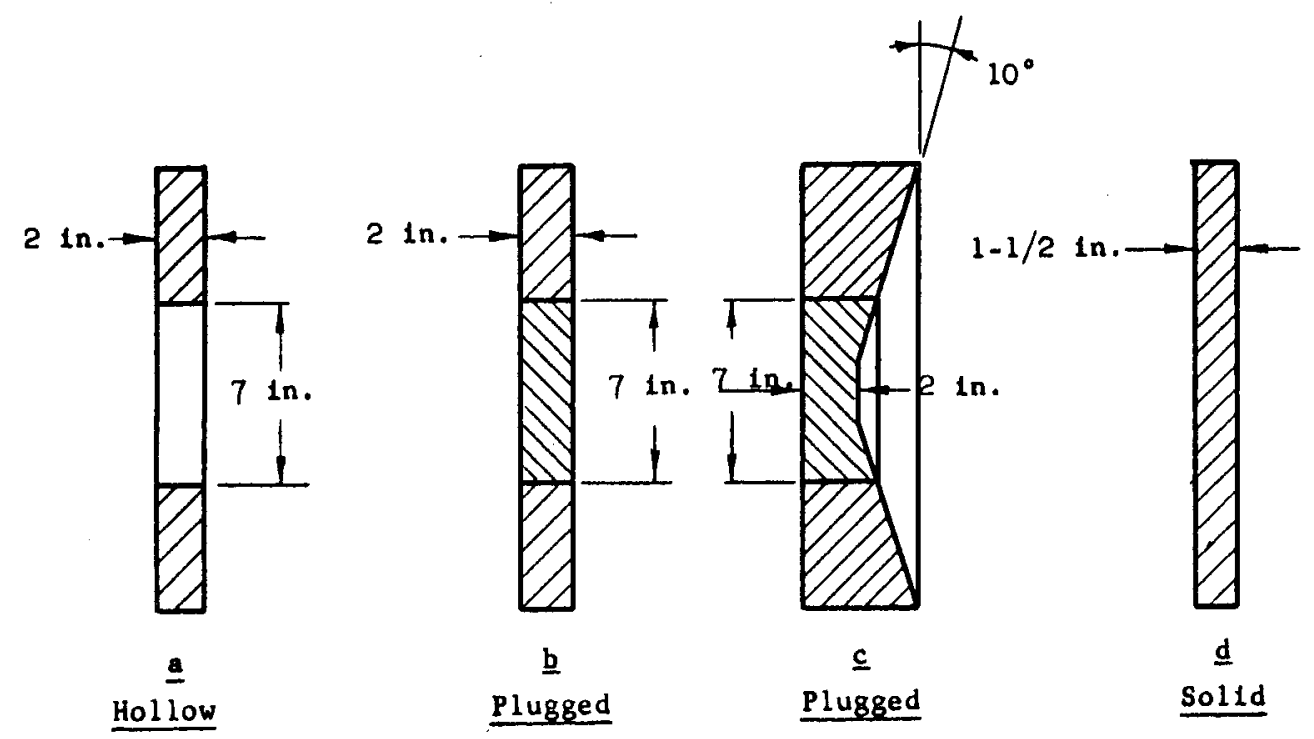

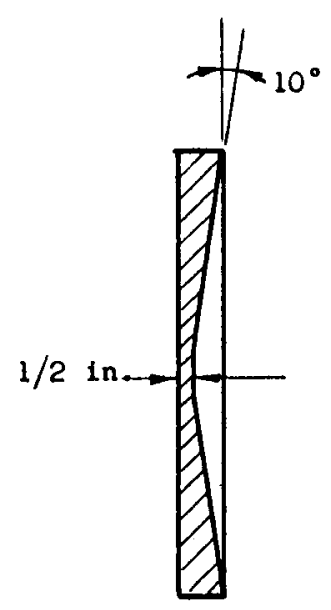

e

Sol1d

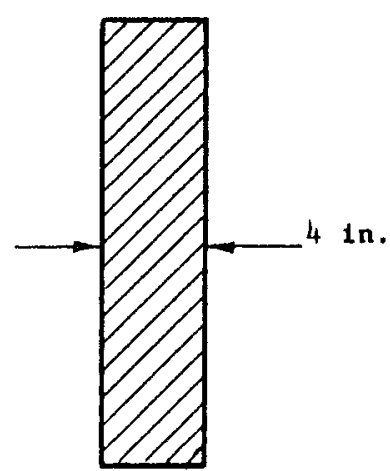

$\underline{f}$

Solid

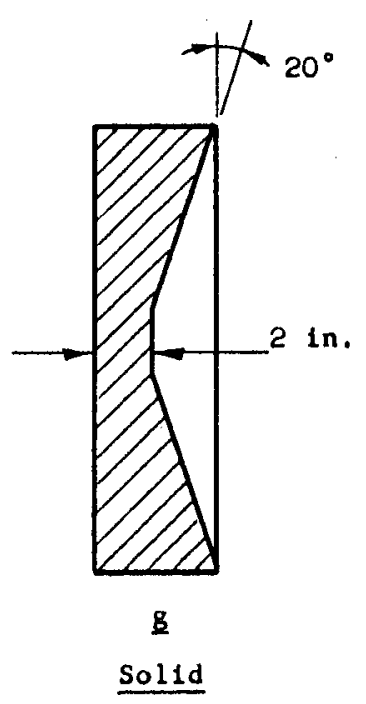

Al1 Follower Blocks 17 1n. Diameter 2-In.- Diameter F1at At Bottom of All Contours Plugs Slide Fit In Follower Blocks

FIGURE 11

GRAPHITE FOLLOWER BLOCKS, NINTH CAMPAION AT DOW 

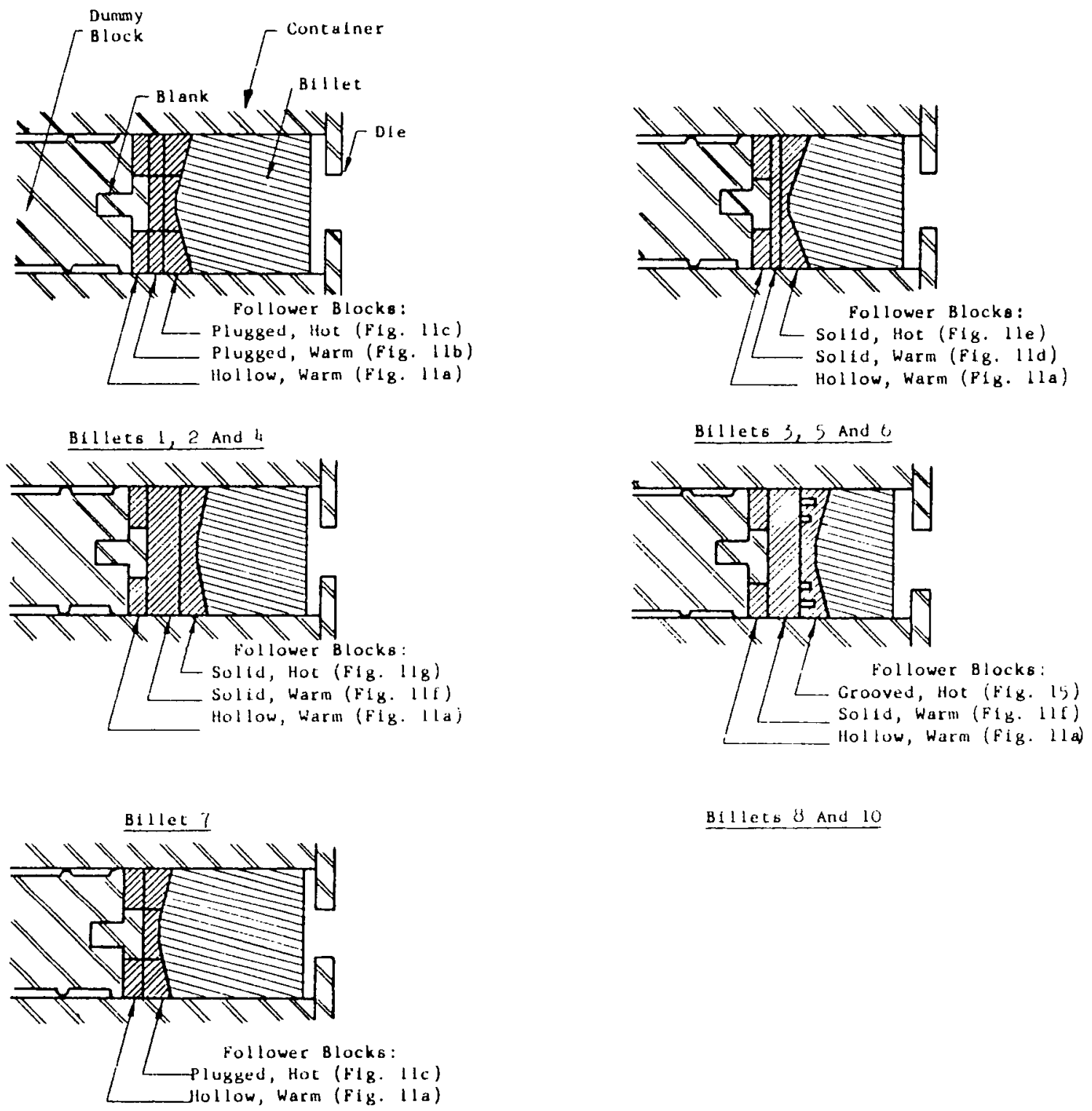

Billets of And 10

Billec 9

FIGURE 1\%?

ARKANCEMENT OP FOLLOWER BLOCKS FOR VAKIOUS BILLETS, NINTH CAMPAIGN AT DOW 
…:

:...:

.

…:.:

$\because \because$

$\because$

(

(a....

:..:

(n:..:

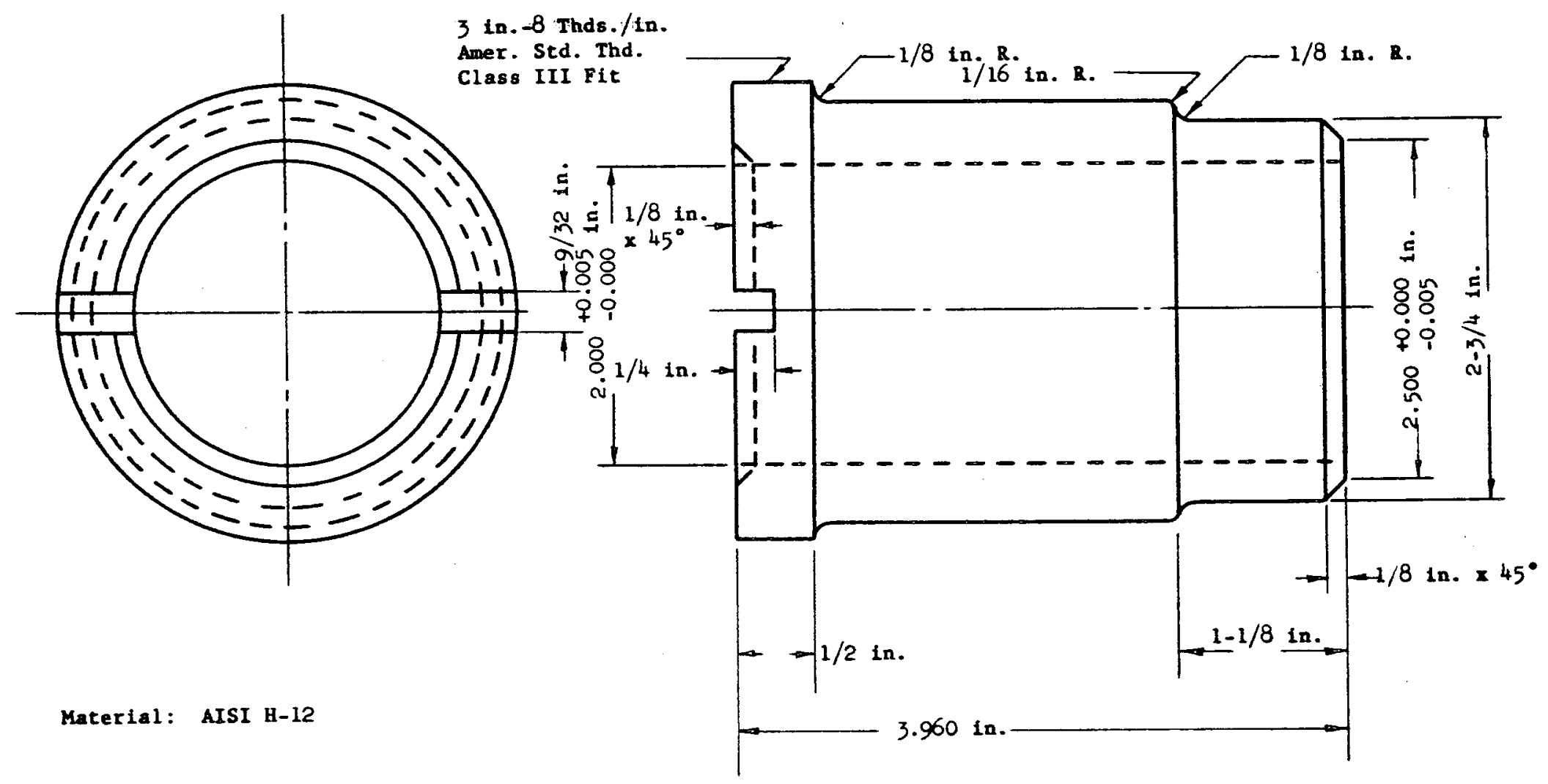

FIGURE 13

BUSHING 
FIGURE 14

PUNCH

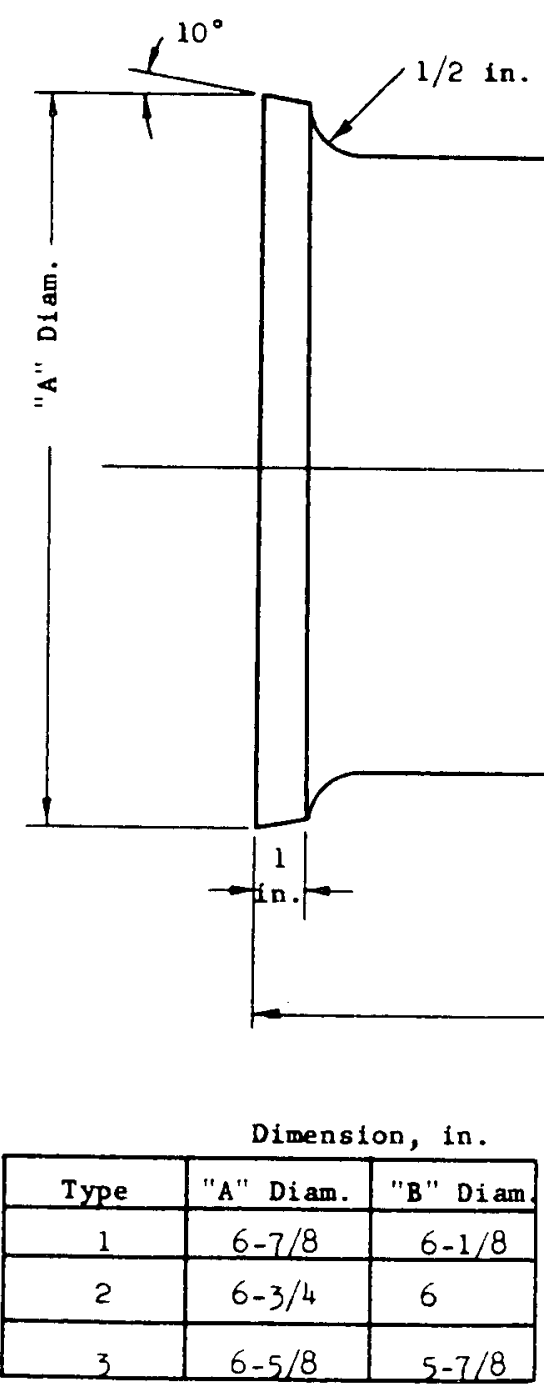

Material: AISI H-12, H.T. To $56-60 \mathrm{R}_{\mathrm{C}}$ 
Extrusion of the tapered billet, No. 9, was accomplished with no difficulties.

After inserting Billet 7 into the container with the follower block arrangement shown in Figure 12, the ram was advanced until pressure was indicated on the gauge and then one inch further. The upset billet with its 6 inches of rod projecting was then removed from the container in the box specially designed for this purpose, which was also used in the seventh campaign.

Billets 8 and 10 were extruded with grooved graphite follower blocks of the design shown in Figure 15. The design of these follower blocks was based on the expectation that the graphite near the edge would crush and flow into the groove cavities, allowing the uncrushed center portion to be forced through the die as a punch. These follower blocks did not crush in such a manner as to free the rods from their butts, so the rods were sheared.

4. Rod Evaluation

All rods except No. 7 were evaluated according to the procedure described for the seventh campaign above. The partially extruded billet, No. 7, will be sectioned, etched and radiographed for examination of the flow pattern in upsetting.

C. Experimental Results

$\mathrm{Yields}$ for the individual rods are listed in Table XI. 
Individual Rod Yields -

Ninth Gamma Extrusion Campaign at Dow, Madison, Illinois

$\cdots \cdots$

$\cdots \because$

$\because \because$

$\cdots$

$\because \because$

$\because$.

(n):

.....

$: \cdots:$

\begin{tabular}{|c|c|c|c|c|c|c|c|c|}
\hline $\begin{array}{c}\text { Billet } \\
\text { No. }\end{array}$ & $\begin{array}{c}\text { Dingot } \\
\text { No. }\end{array}$ & $\begin{array}{c}\text { Billet } \\
\text { Length } \\
\text { in. }\end{array}$ & $\begin{array}{l}\text { Billet } \\
\text { Angle }\end{array}$ & $\begin{array}{c}\text { Cylinder- } \\
\text { to-Cone } \\
\text { Ratio }^{a} \\
\end{array}$ & $\begin{array}{c}\text { Butt and } \\
\text { Oxidation } \\
\text { Losses } \\
\% \\
\end{array}$ & $\begin{array}{c}\text { Cropping } \\
\text { Loss } \\
\% \\
\end{array}$ & $\begin{array}{c}\text { Total } \\
\text { Losses } \\
\%\end{array}$ & $\begin{array}{c}\text { Billet-to- } \\
\text { Rollable- } \\
\text { Rod Yield } \\
\% \\
\end{array}$ \\
\hline 1 & 186 & $16 \frac{1}{8}$ & $10^{\circ}$ & 23.6 & 8.4 & 9.4 & 17.8 & $82.2^{b}$ \\
\hline 2 & 188 & $163 / 8$ & $10^{\circ}$ & 24.0 & 19.4 & 2.1 & 21.5 & 79.5 \\
\hline 3 & 190 & $15 \%$ & $10^{\circ}$ & 22.8 & 19.3 & 2.2 & 21.5 & 79.5 \\
\hline 4 & 192 & $151 / 16$ & $10^{\circ}$ & 22.0 & 12.8 & 1.4 & 14.2 & 85.8 \\
\hline 5 & 193 & $15 \% / 16$ & $10^{\circ}$ & 22.1 & 23.0 & 2.4 & 25.4 & 74.6 \\
\hline 6 & 198 & $15 \% / 16$ & $10^{\circ}$ & 22.7 & 21.9 & 3.0 & 24.9 & 75.1 \\
\hline 8 & 199 & $15 \%$ & $10^{\circ}$ & 23.2 & 30.9 & 3.8 & 34.7 & 65.3 \\
\hline 9 & 212 & $15 \frac{1}{2}$ & $10^{\circ}$ & 22.6 & 21.1 & 1.7 & 22.8 & 77.2 \\
\hline 10 & 201 & 15 & $10^{\circ}$ & 21.8 & 28.6 & 2.0 & 30.6 & 69.4 \\
\hline
\end{tabular}

${ }^{a}$ Ratio of cylindrical portion of billet to truncated conical portion of billet.

${ }^{b}$ Billet partially melted. 


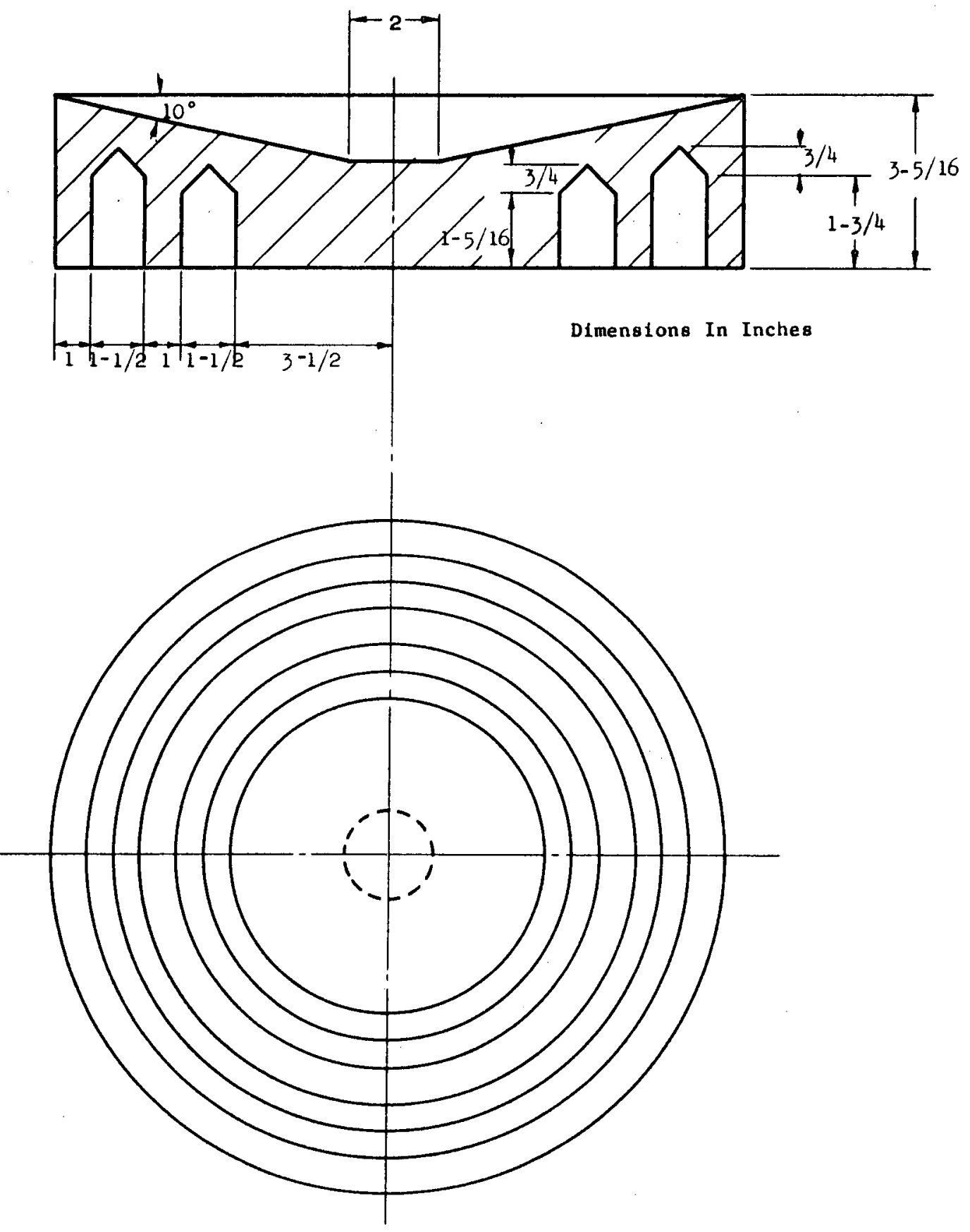

FIGURE 15

GROOVED, CONTOURED GRAPHITE FOLLOWER BLOCK

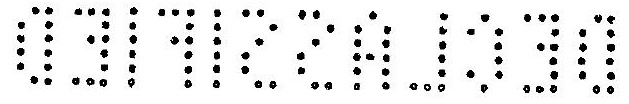


All rods except No. 9 were separated from their butts when the punching operation was used. No extrusion defect was revealed on cropping the back end of any of the rods except No. 1. The billet from which this rod was extruded was partially melted during heating, so an extrusion defect could be expected in this case. Cropping of a considerable amount of metal from the back end of Rod 6 was necessary, but this was not to remove extrusion defect and the metal removed was not included in the cropping loss. Apparently the graphite crushed during punching and was forced into the back end, expanding the periphery, and causing deep longitudinal cracks in the last 12 inches of the rod.

The grooved follower blocks used with Billets 9 and 10 did not crush sufficiently to free the rods from their butts. However, a flat impression about seven inches in diameter was made in the back side of the butts.

Billet 7 was completely upset and filled the container except for about one inch of its front corner.

D. Discussion of Results

The low yields were due to heavy butt losses, which are attributable to the relatively long transfer times and difficulty in calibrating the temperature recorder-controllers. The absence of extrusion defect on cropping a small amount from the back ends of the rods indicates that the $10^{\circ}$ angle on the follower block contour is near the optimum.

The punch diameter apparently has no effect on the effectiveness of the punching operation. In fact, it is not necessary to have the front of the punch pass into the die orifice, if there is sufficient thickness of graphite behind the butt. Billet 9 revealed that a minimum thickness of two inches of graphite at the center is required. Solid follower blocks worked equally as well as plugged. Alignment of the punch is an important requisite to success of the punching operation, to prevent punch breakage and die damage.

Although the rods extruded with grooved follower blocks were not separated from their butts as expected, the fact that the center portion of the butt was indented indicates that redesign of this type of follower block along the same lines would probably result in an acceptable process. 


\section{E. Conclusion}

Use of a punching procedure similar to that used in this campaign is planned in the Weldon Spring operation and should be satisfactory. Differential hardening of the punches, to give maximum hardness on the front end and a much lower hardness on the shank end, should decrease the danger of punch breakage.

No difficulties should be encountered in using the tapered billets contemplated for Weldon Spring. 
$W^{i} \cdot$ J. S. Smith

Summary

Approximately 2000 pounds of WAPD-grade $\mathrm{UO}_{2}$ has been ground to an average particle diameter of 0.8 microns in a fluid-jet grinding mill. There was no apparent correlation between the product particle diameter and the feed rate within the range of 20 to 50 pounds per hour.

Instability and unreliability of the vibratory feed mechanism resulted in considerable variation in the feed rates and numerous powder "blowbacks" through the feed system.

Introduction

Very finely ground materials are occasionally required for investigation of the processes employed in uranium production. This report is concerned with the development of operating technique and the evaluation of performance of a fluid-jet grinding machine, the Micronizer, manufactured by the Sturtevant Mill Company, Harrison Square, Boston 22, Massachusetts.

Experimental Equipment

The Micronizer (Figure 1) consists of a shallow, circular grinding chamber with such necessary connections as grinding fluid inlets, a feed introduction point and a product discharge line.

Grinding of materials in the Micronizer results from the action of high velocity gas streams emerging from nozzles spaced around the periphery of the grinding chamber in which there is a circulating load of the solid to be ground. The compressed gases issuing through these jets maintain a high speed of rotation in the grinding chamber. Solids fed into the grinding chamber are accelerated by the rotating gases and are thrown to the periphery where a portion coming into the zone of action of a nozzle is further accelerated tangentially and radially inward, causing violent impact between the particles thus accelerated and other particles circulating at a much lower velocity in a thin band near the periphery. The fines resulting from the continuing series of impacts are carried by the rotating gases in an in wardly spiraling path toward the central outlet. Thus, the mass is subjected to an intense classifying action and, as the fine particles approach the outlet, centrifugal force returns the oversize particles to the grinding zone.

The Micronizer installed in the pilot plant has a grinding chamber eight inches in diameter by $1 \frac{1}{4}$ inches deep. As shown in Figure 1 , all parts in contact with the product are lined with Linatex, a tough rubbery material highly resistant to abrasion. 


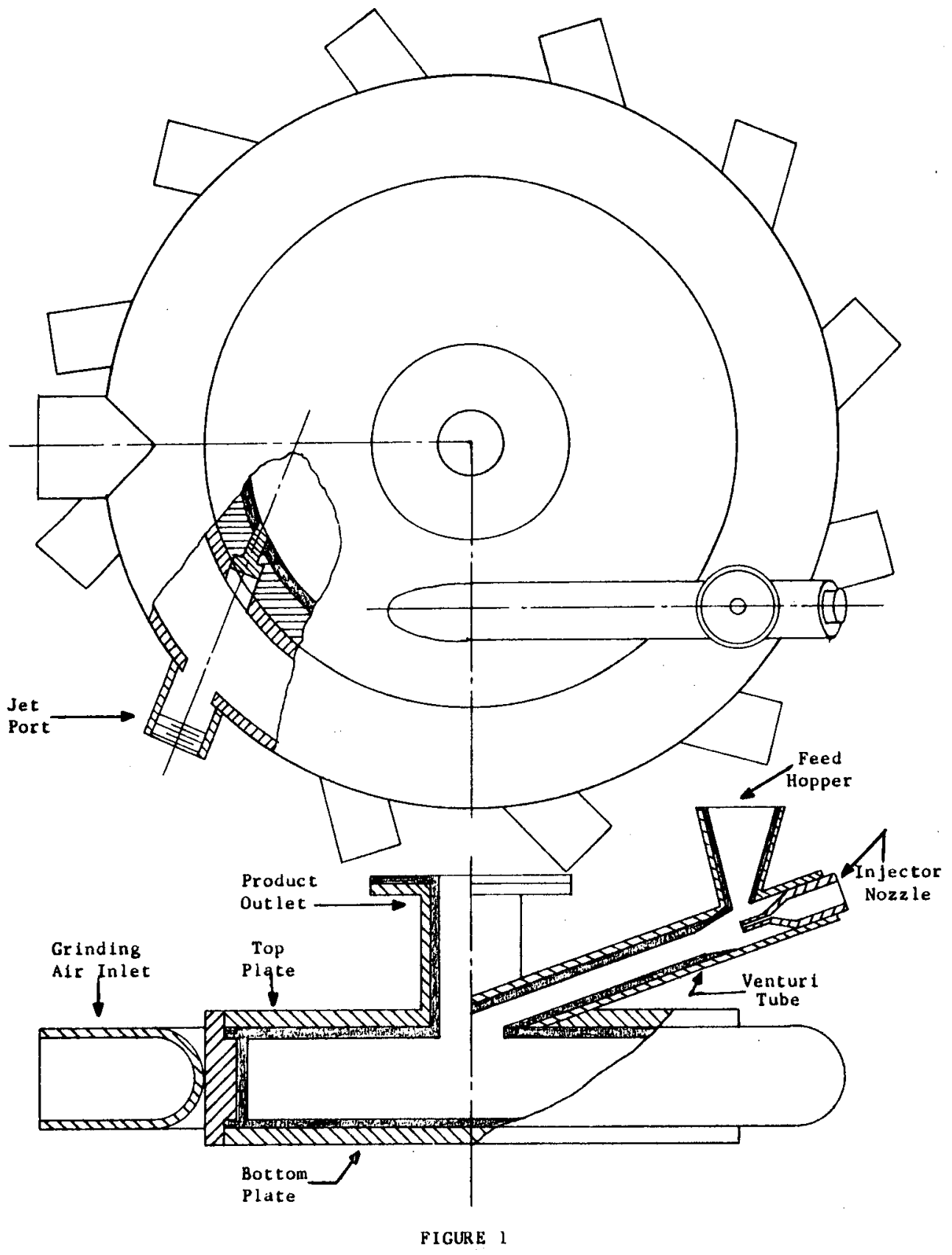

MICRONIZER DETAILS 
In a standard Micronizer of this size, there are six grinding jets set tangentially to a $5 \frac{1}{2}$-inch circle. The pilot plant unit has an additional six jets set tangentially to a $6 \frac{1}{2}$-inch circle.

The solids feed system consists of ane-eighth-inch nozzle discharging into a one-half-inch venturi tube directly under the Micronizer feed funnel.

Auxiliary equipment is shown in Figure 2 and includes an air compressor, an air receiver, a vibrator feeder:(Syntion), á product bag filter, a product rotary valve, ia product drum, and a dust collection system which includes a bag filter, rotary valve, and scrap drum. The compressor is a carbon ring machine with a maximum pressure rating of 135 psig and a capacity of 130 SCFM at 100 psig.

The Micronizer is fed by a Syntron, Model FM-0-10, vibratory feeder discharging into the feed funnel. Feed rate adjustments are made by changing the amplitude of the vibrations applied to the feed trough.

The grinding air passes from the Micronizer through a ten-square-foot, felt, product filter bag. The product is then discharged through a rotary valve to a packaging drum.

There is, in addition, a bag filter located outside the building which serves a hood in the Micronizer enclosure and collects extraneous dust.

\section{Experimental Procedure}

Materials micronized so far include fluid-bed-denitrated $\mathrm{UO}_{3}$, pot-denitrated $\mathrm{UO}_{3}, \mathrm{MCW}$-produced $\mathrm{UF}_{4}$, and WPD-grade $\mathrm{UO}_{2}$.

All operations have been made with all twelve grinding jets installed in an effort to attain finer grinding. Smaller jets are used in order to maintain the flow rate and pressure drop that would occur with six standard jets.

Grinding pressures have been in the range 90 to 100 psig, with most of the runs at the higher figure. Air flow rates at these pressures are about 120 cubic feet per minute. The solids feed injector air pressure is ordinarily set at the lowest value consistent with smooth operation and has ranged from 40 to 80 psig depending on the feed rate and grinding pressure. Feed rates have been varied from about twenty to fifty pounds per hour with the usual rate at about twentyfive pounds per hour. 
$\therefore \ldots:$

$\vdots \ldots .:$

$\ldots .$.

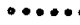

$\because \because$

$\because \because$

$\because \cdots$

$\therefore$

(...... n

$\therefore .$.

$\therefore . .$.

$\therefore \ldots:$

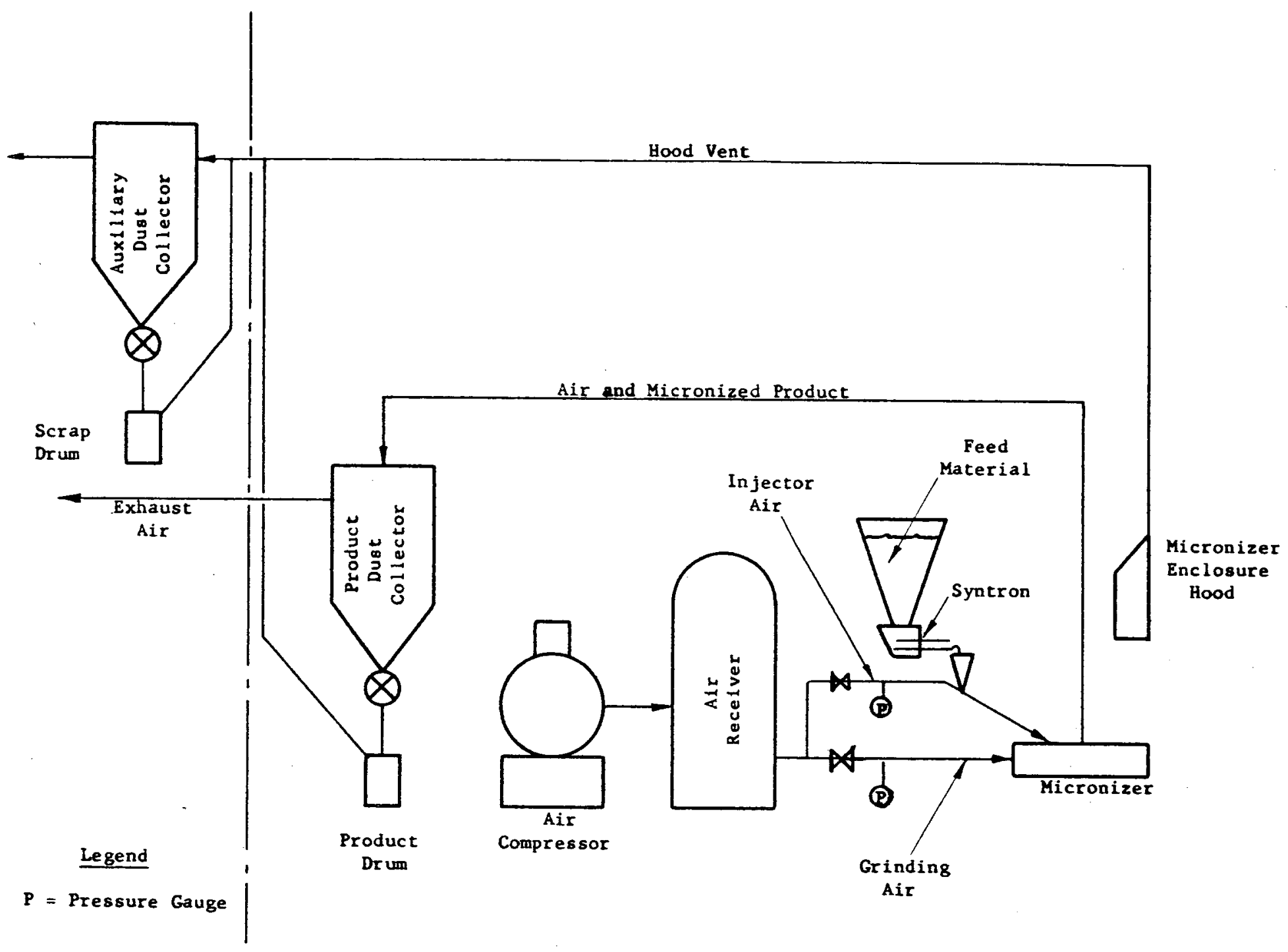

FIGURE 2

MICRONIZER EQUTPMENT FLOW DIAGRAM 


\section{Experimental Results}

The only material on which a significant number of runs has been made is WAPD-grade $\mathrm{UO}_{2}$. This material is fed as a finely divided, dense powder with a mean particle diameter of about four or five microns, $100 \%$ passing through a twenty-mesh sieve. A summary of operating conditions and results for the WAPD material is presented in Table I. These data are representative of runs made on all material with a mean particle diameter in the range below ten microns, including MCW plant-produced $\mathrm{UO}_{3}$ and $\mathrm{UF}_{4}$. The feed rate calibrating data for $\mathrm{UO}_{2}$ are listed in Table II and are plotted, with similar data from the production runs, in Figure 3 . Table III shows the Micronizer product particle diameter variation during Run 14. All particle diameters in the micron tange were determined on a Fisher Sub-Sieve Sizer.

\section{Table I}

Micronizer Operation for WAPD-Grade $\mathrm{UO}_{2}$

\begin{tabular}{|c|c|c|c|c|c|c|c|}
\hline $\begin{array}{l}\text { Run } \\
\text { No. }\end{array}$ & Date & $\begin{array}{c}\text { Run } \\
\text { Duration } \\
\text { hr:min }\end{array}$ & $\begin{array}{l}\text { Syntron } \\
\text { Setting } \\
\end{array}$ & $\begin{array}{c}\text { Production } \\
\text { Rate } \\
\mathrm{lb} / \mathrm{hr} \\
\end{array}$ & $\begin{array}{c}\text { Injector } \\
\text { Pressure } \\
\text { lb/in. } \\
\end{array}$ & $\begin{array}{c}\text { Product } \\
\text { Collector } \\
\text { Pressure } \\
\text { Drop } \\
\text { in. } \mathrm{H}_{2} \mathrm{O} \\
\end{array}$ & $\begin{array}{c}\text { Mean } \\
\text { Product } \\
\text { Diameter } \\
\text { micron }\end{array}$ \\
\hline 10 & $6 / 5$ & $6: 55$ & 75 & 45 & 50 & $1.5-2.0$ & $0.81-0.90$ \\
\hline 11 & $6 / 6$ & $6: 55$ & 75 & 35 & 60 & $0.6-1.7$ & $0.74-0.86$ \\
\hline 12 & $6 / 9$ & $6: 10$ & 70 & 21 & $65 \cdot 70$ & $1.5-2.2$ & $0.81-0.84$ \\
\hline 13 & $6 / 10$ & $6: 30$ & 70 & 30 & $65 \cdot 70$ & $2.2 \cdot 2.4$ & $0.72-0.81$ \\
\hline 14 & $6 / 11$ & $5: 15$ & 70 & 19 & $65-70$ & $2.3-2.8$ & $0.68-0.96$ \\
\hline 15 & $6 / 12$ & $7: 30$ & 70 & 19 & 70 & $2.4-3.0$ & $0.74-1.06$ \\
\hline 16 & $6 / 13$ & $7: 30$ & 70 & 20 & $65 \cdot 70$ & $2.9 \cdot 3.0$ & $0.81-0.89$ \\
\hline 17 & $7 / 2$ & $4: 20$ & 70 & 21 & 65 & $2.4 \cdot 3.0$ & 0.80 \\
\hline 18 & $7 / 3$ & $7: 35$ & 70 & 22 & 65 & $2.6-3.3$ & $0.81 \cdot 0.86$ \\
\hline 19 & $7 / 7$ & $8: 40$ & 70 & 23 & -65 & $2.6 \cdot 3.7$ & 0.78 \\
\hline 20 & $7 / 8$ & $7: 40$ & 70 & 24 & $65 \cdot 75$ & $3.0-4.0$ & $0.80-0.82$ \\
\hline 21 & $7 / 9$ & $7: 45$ & 70 & 17 & 75 & $0.6-2.0$ & $0.80-0.86$ \\
\hline
\end{tabular}


Table II

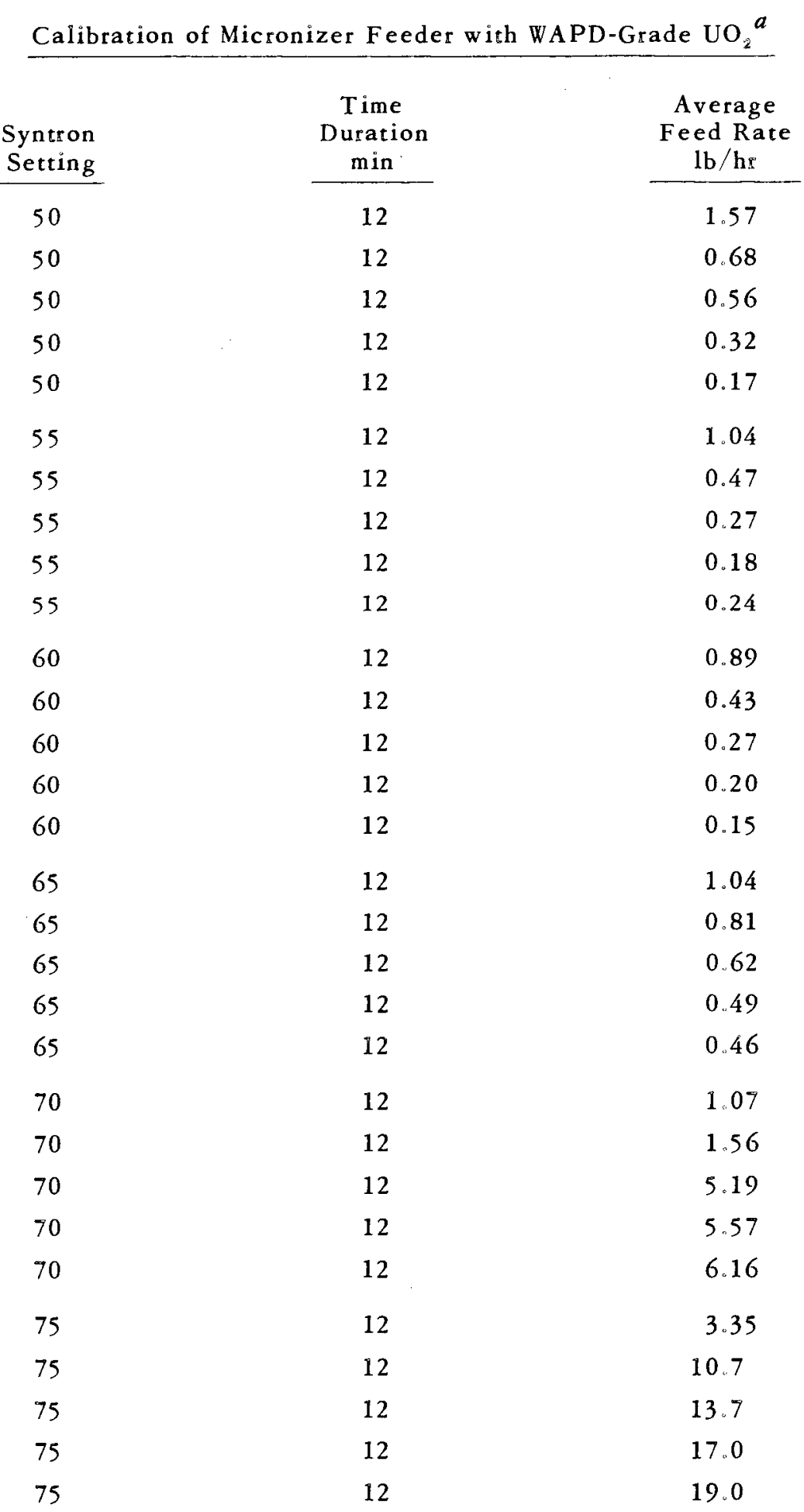

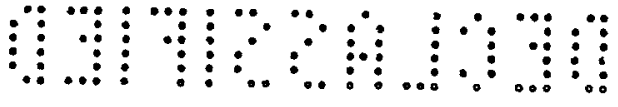


Table II (continued)

\begin{tabular}{|c|c|c|}
\hline $\begin{array}{l}\text { Syntron } \\
\text { Setting } \\
\end{array}$ & $\begin{array}{c}\text { Time } \\
\text { Duration } \\
\text { min }\end{array}$ & $\begin{array}{c}\text { Average } \\
\text { Feed Rate } \\
\text { lb/hr }\end{array}$ \\
\hline 80 & 6 & 35.3 \\
\hline 80 & 6 & 45.7 \\
\hline 80 & 6 & 33.2 \\
\hline 80 & 6 & 33.2 \\
\hline 80 & 6 & 42.6 \\
\hline 85 & 3 & 76.3 \\
\hline 85 & 3 & 73.6 \\
\hline 85 & 3 & 78.9 \\
\hline 85 & 3 & 82.7 \\
\hline 85 & 3 & 82.1 \\
\hline
\end{tabular}

a The runs were made consecutively in the order shown without shutdown.

Table III

Particle Diameter of Micronized $\mathrm{UO}_{2}$ from Run No. 14

\begin{tabular}{cc}
$\begin{array}{c}\text { Clock } \\
\text { Time }\end{array}$ & $\begin{array}{c}\text { Mean Particle Diamerer } \\
\text { micron }\end{array}$ \\
\cline { 2 - 2 } 1000 & 0.68 \\
1300 & .71 \\
1400 & .83 \\
1600 & .96
\end{tabular}


FICURB 3

WAPD -TYPE $\mathrm{UO}_{2}$ FEED RATE VERSUS SYNTRON SETTING

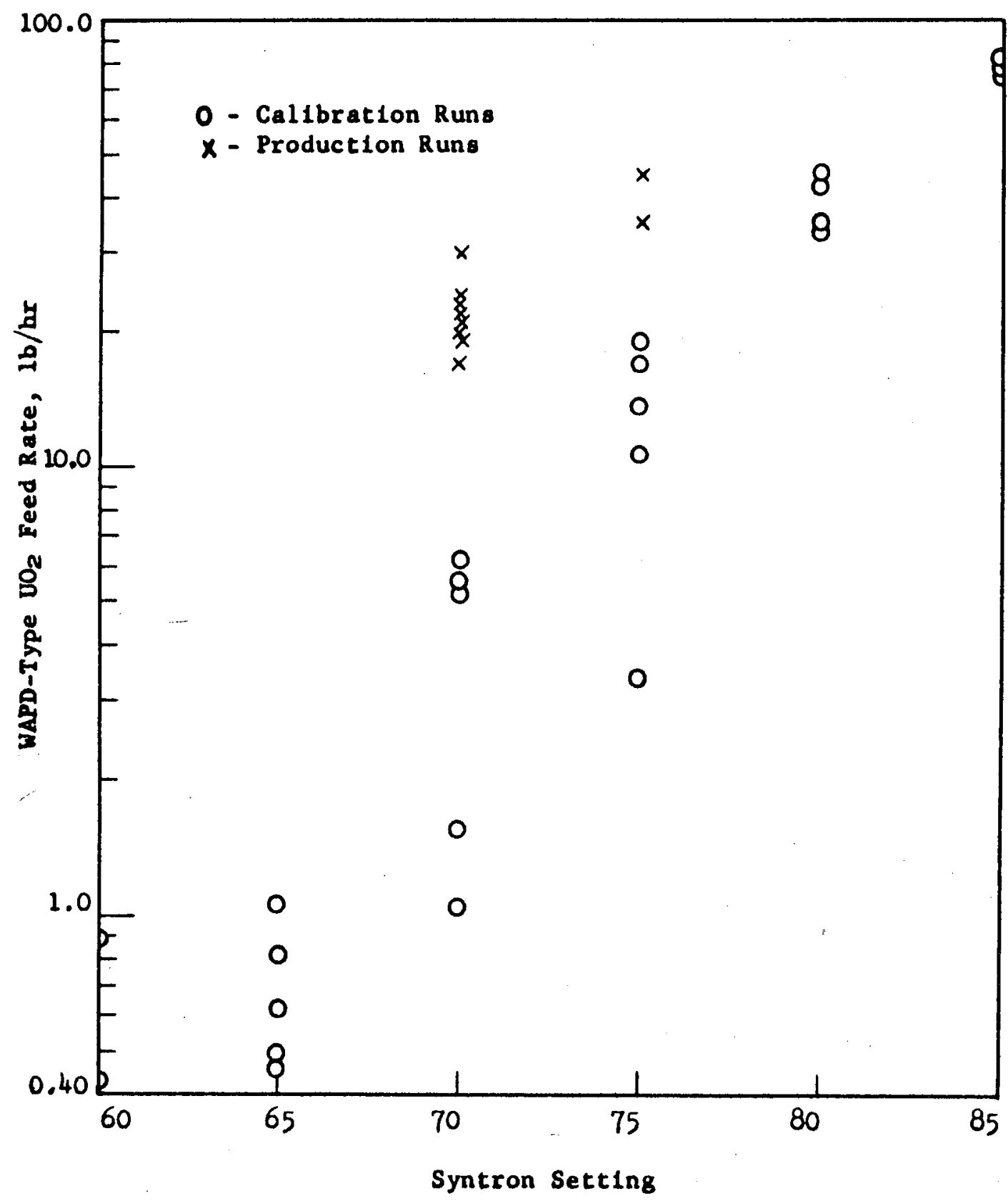

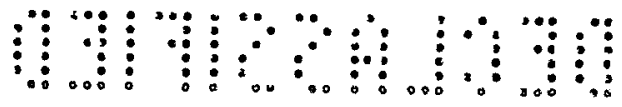


On a number of occasions, there has been severe blowing back through the Micronizer feed funnel at fairly frequent and regular time intervals. In some cases this problem has been bad enough to force continuous readjustment of operating conditions. At other times, only relatively minor puffing at the Micronizer feed funnel has been observed.

Contamination problems have stemmed from the difficulty of completely cleaning the equipment between runs of different material. There has been some contamination due to erosion of the liner material in the grinding chamber and possibly at the metal parts in the dust collection equipment. Figure 4 shows pictures of the top and bottom plate liners when new and after grinding 2500 pounds of material in an operating time of about 100 hours.

There was a constant increase in pressure drop through the product filter bag, with no noticeable effect on the particle diameter or the production rate, until a value of 4 inches of water was reached. At this point, feeding difficulties forced replacement of the bag. Figure 5 shows the pressure drop through a new, wool felt filter bag versus pounds of micronized product through the collector.

Discussion of Results

It appears that the principal cause of blowbacks is instability and unreliability of the vibratory feed mechanism. The Syntron FM-0-10 is a volumetric feeder whose capacity is too high to maintain the constant, low weight rates desired. It has been observed that high production rates permit injector air pressure to be lowered byt increase the tendency to blow back and that rates which are too low require an excessive injector air pressure to prevent puffing. An increase in injector air nozzle diameter would probably reduce feed problems but would also require more air capacity. A smaller diameter in the feed venturi cube would also help the feed situation, but might increase erosion of the venturi tube with consequent contamination of the product.

It is indicated in Table I that there was considerable variation in the feed rate for the same feed material at identical Syntron settings. Runs 10,11, and 13 should be noted in particular. The feed rate variation was even greater in the calibration runs as noted in Table II.

It is also indicated in Table $I$ that there is no apparent correlation between the feed rate and the final product particle diameter within the range tested. Table III indicates a wide variation in product particle diameter at a given feed rate. 


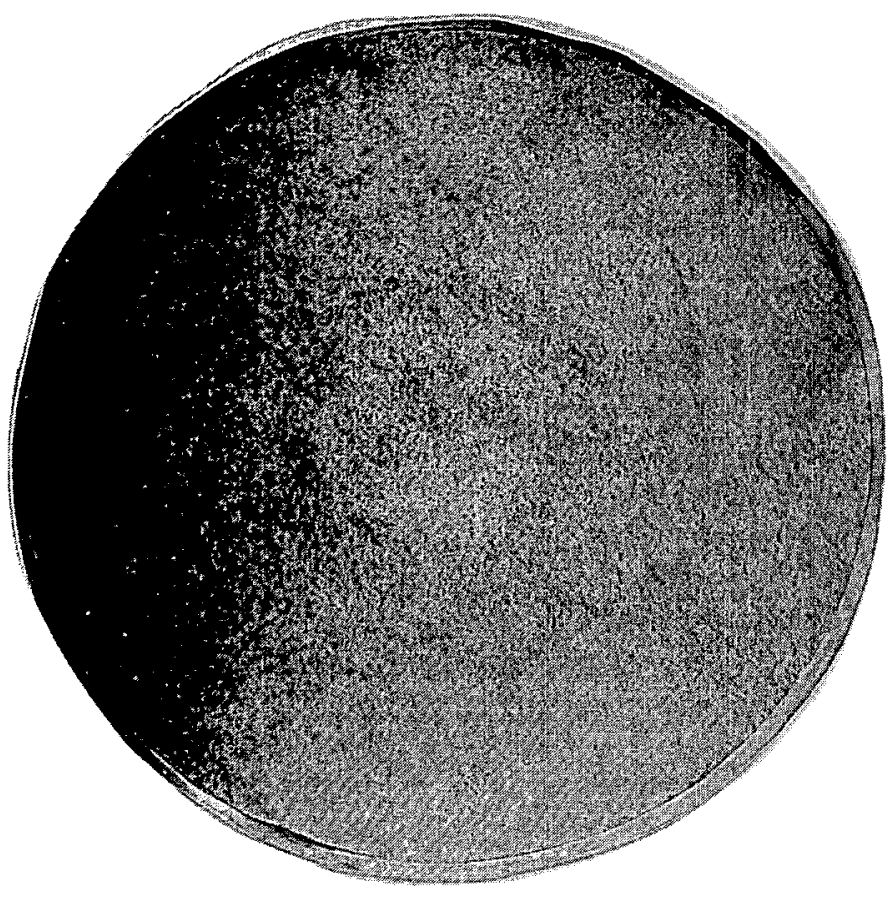

Bottom, New

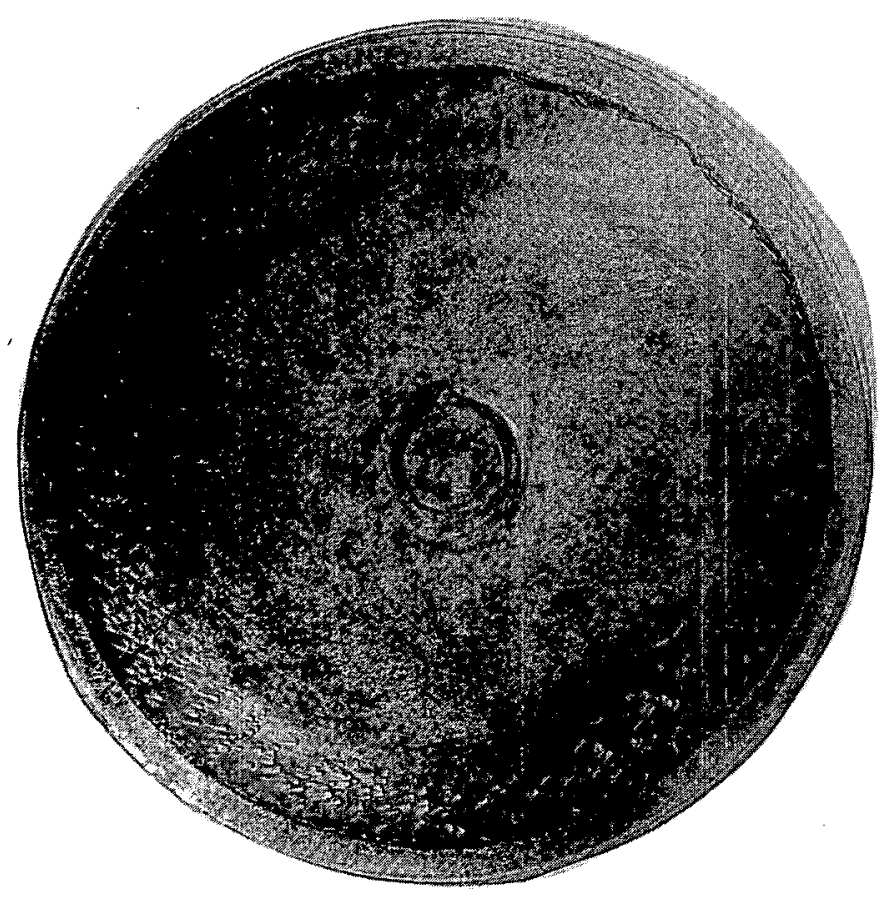

Bottom, Used

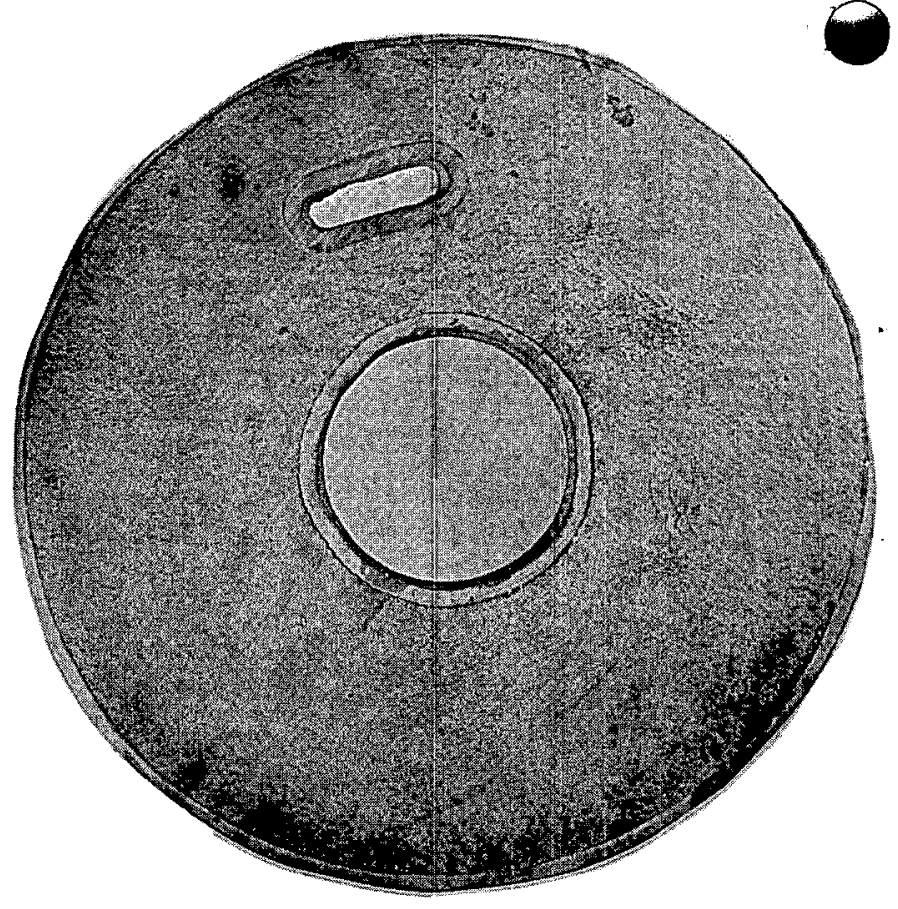

Top, New

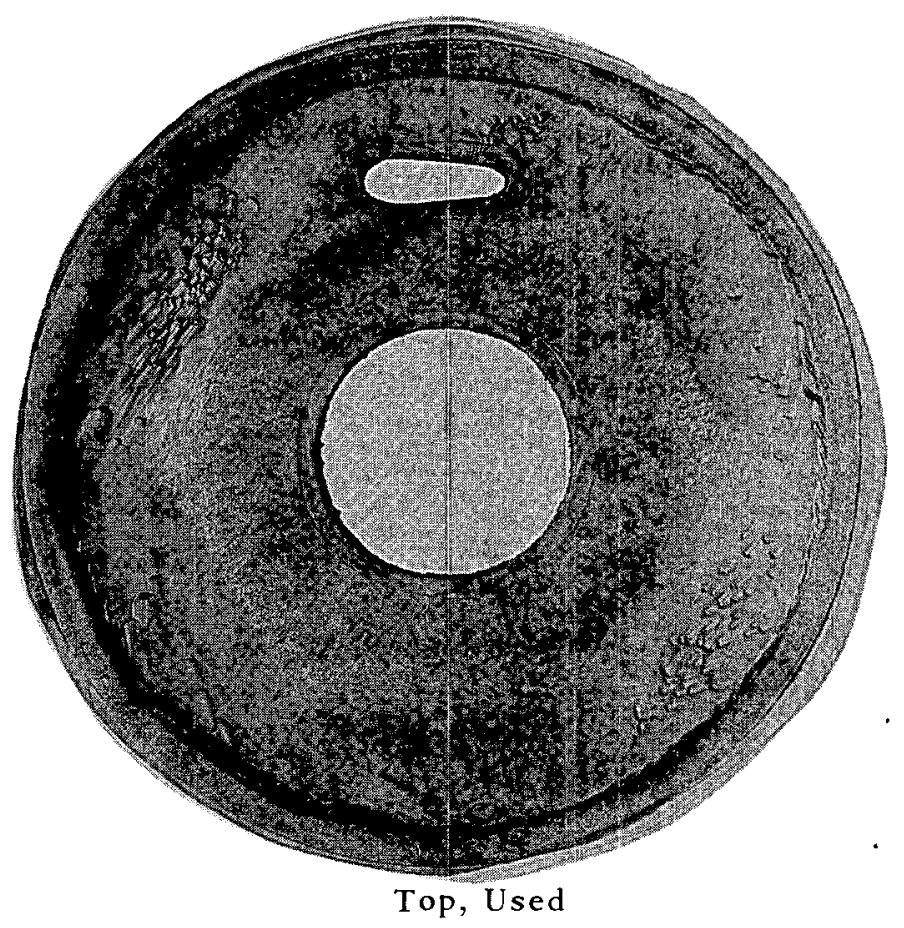

Figure 4

Micronizer Plate Liners, New and After Grinding

Approximately 2500 Pounds of $\mathrm{UO}_{2}$ in Approximately

100 Hours

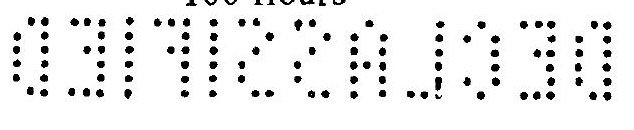


FIGURE 5

PRODUCT FILTER BAG PRESSURE DROP VERSUS CUMULATIVE PRODUCTION

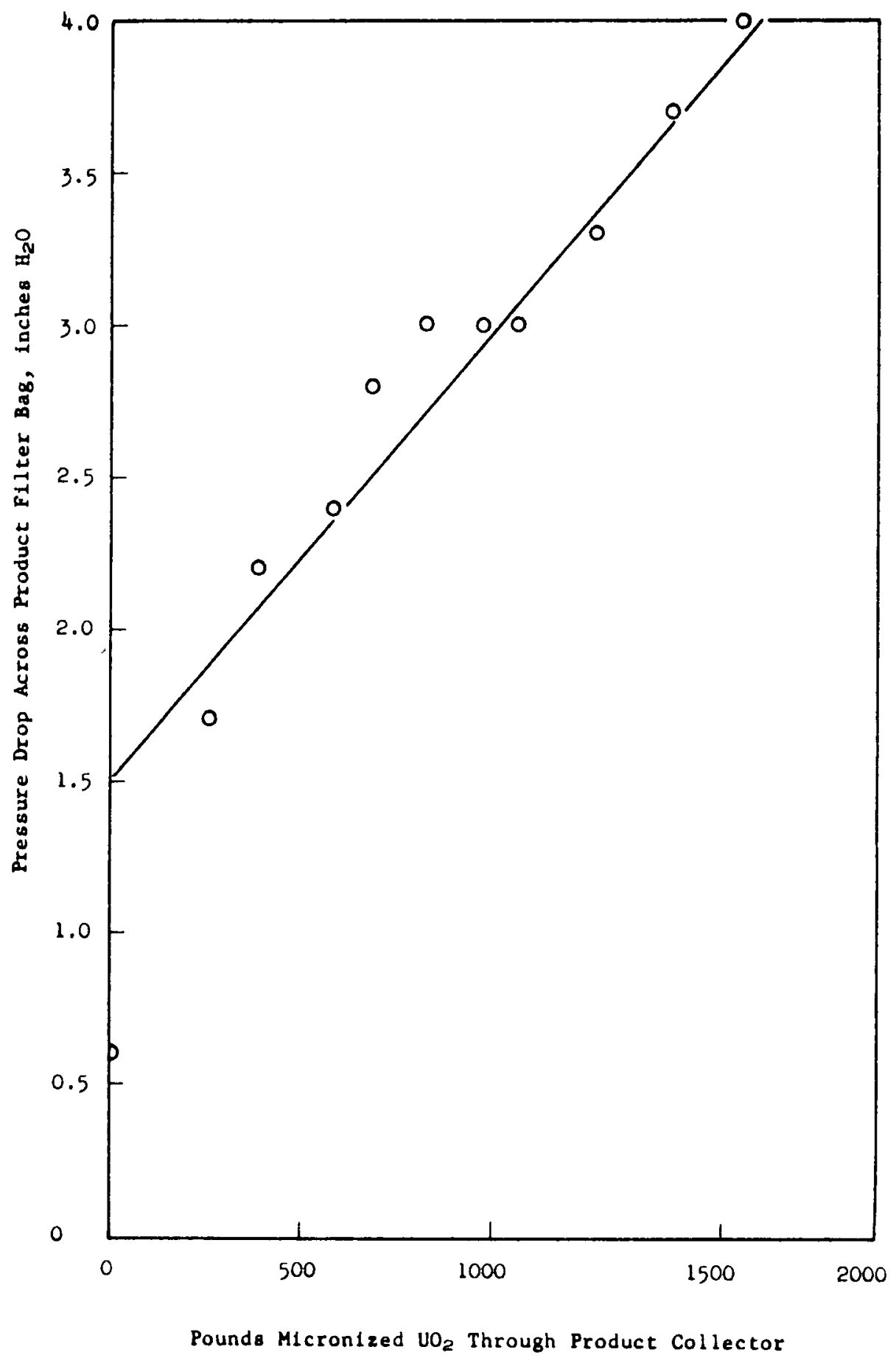

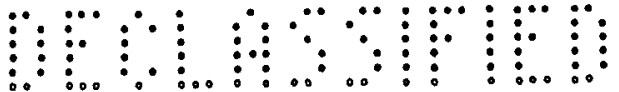




\section{Conclusions}

Approximately 2000 pounds of WAPD-type $\mathrm{UO}_{2}$ has been micronized to an average particle diameter of about 0.8 microns at production rates of about 20 pounds per hour at a grinding pressure of 100 psig. These values are of the same order of magnitude as those reported previously, ${ }^{92}$ the differences possibly being due to bias in the Sub-Sieve Sizers or to differences in sampling technique. Further work will be directed toward developing maximum capacity in the Micronizer while maintaining grinding efficiency.

In order to minimize contamination of material for which there are tight purity specifications, the equipment must be completely disassembled and thoroughly cleaned before grinding operations are begun.

The production rate has been limited by feeding problems. Attempts to solve these will be made by modification of the Syntron feeder and of the solids injection system.

\& Henderson, C. M., Wrinkle, R. B., Process Development Quarterly Report, Part II, Mallinckrodt Chemical Works, $M C W-1400$ (F ebruary 1, 1957), p 129

2 Wrinkle, R. B., Henderson, C. M., Process Development Quarterly Report, Part II, Mallinckrodt Chemical Works, MCW-1402 (May 1, 1957), p 151 


\title{
FLAME FUSION STUDIES
}

\author{
by \\ W. H. Hediey \\ R. J. Roehrs
}

Summary

The flame fusion technique has been used to grow specimens of $\mathrm{UO}_{2}$ up to $3 \frac{3}{8}$ inches long, weighing up to 83.5 grams, containing crystals up to one-eighth inch in diameter and having densities up to $98.1 \%$ of the theoretical maximum. Pure $\mathrm{UO}_{3}$ powder has also been converted into high purity $\mathrm{UO}_{2}$ boules by this technique.

Introduction

The purpose of this project is to produce monocrystalline pieces of $\mathrm{UO}_{2}$ having the maximum density theoretically possible (10.97 grams per cc). The flame fusion or Verneuil method" has been used in attempts to achieve this aim. It consists of progressively melting uranium oxide powder and solidifying it to form solid shapes known as boules.

Equipment and General Procedure

In recent work on this project an atomic hydrogen arc has been employed to attain the temperature necessary to melt $\mathrm{UO}_{2}$. Figure $1 \mathrm{~A}$ shows a seed rod supported on a rotating, water-cooled probe which positions it during the growth operation. The seed may be a pressed and sintered compact or a single crystal from a previous run. Approximately one-half of the top of the seed is kept molten (Figure 1B) by the hydrogen arc while fresh powder awaiting fusion is being deposited on the other half. Feed powder such as $\mathrm{UO}_{2}$ or $\mathrm{UO}_{3}$ is carried through a tube by entraining gases which exit above the seed directly opposite the hottest zone of the arc. As the probe is rotated, the feed powder continues to deposit on the top of the seed and then move into position directly under the arc where melting takes place (Figure 1C). The rotation of the probe spreads the powder evenly over the top of the seed. The surface tension of the molten liquid with the sharp thermal gradient between the molten top and the solidified edge below it tends to prevent the liquid from flowing down the sides of the seed rod. The probe is gradually lowered so that the top of the growing UO, rod remains in a fixed horizontal plane that is favorable for an equilibrium of heat transfer. Figures $1 \mathrm{D}$ and $1 \mathrm{E}$ show the formation of a $\mathrm{UO}_{2}$ boule by progressive melting and solidification. The seed is protected at all times from the atmosphere by a reducing gas envelope.

1 Verneuil, A., "Growing Synthetic Rubies by Fusion," Compt; Rend. 135, 791-794 (1902) 


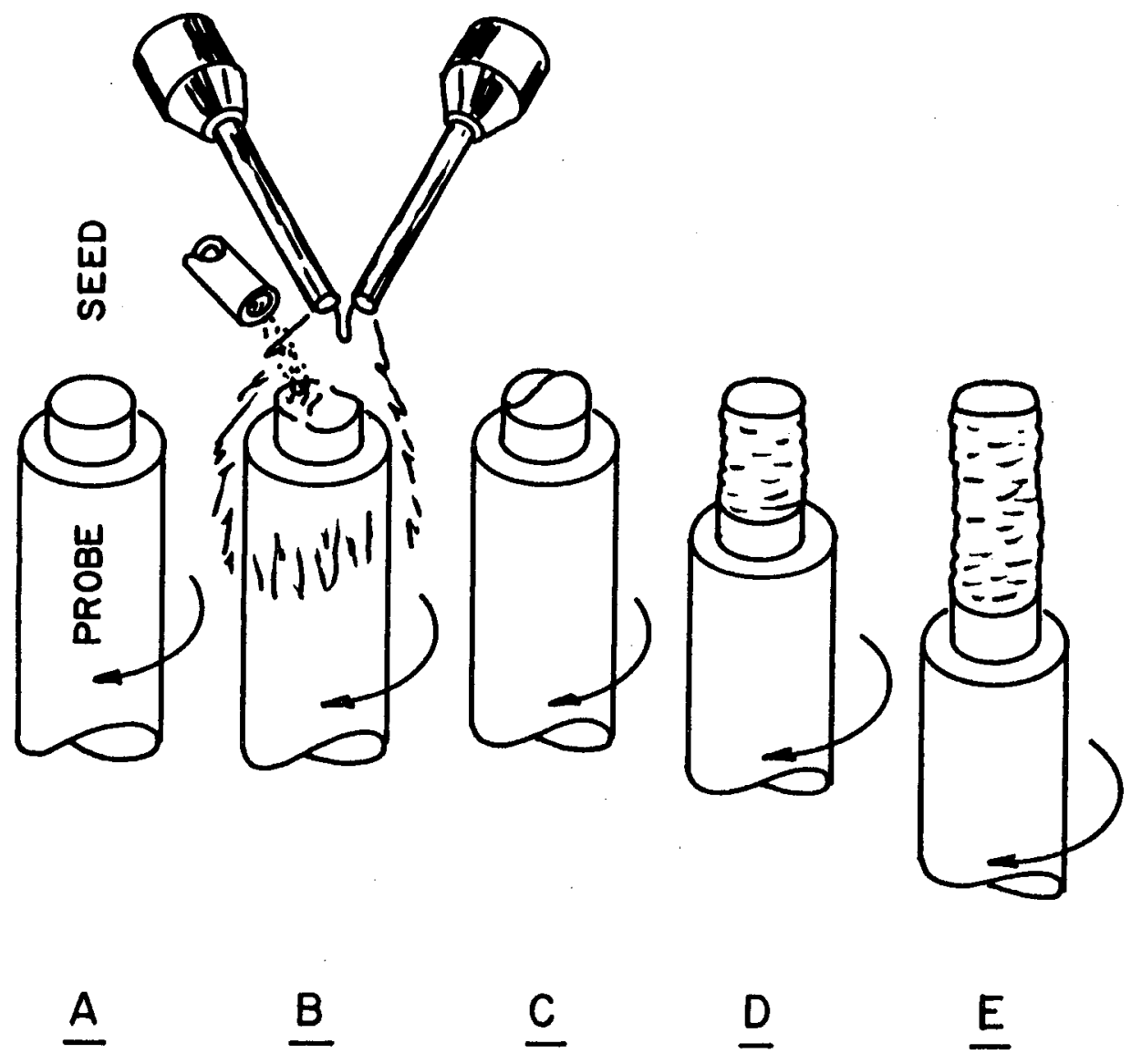

FIGURE 1

GROWING A URANIUM DIOXIDE BOULE BY THE FLAME FUSION PROCESS

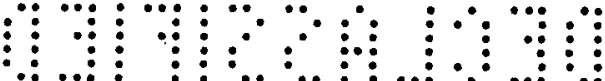


Figure 2 shows a general view of the flame fusion equipment. The flanged gas-tight chamber at the top of the unit houses a Syntron vibratory feeder. Variation of the vibration speed permits control of the rate at which the feeder discharges powder. The tube from the bottom of the chamber discharges the powder and entraining gas directly above the seed rod.

The positioning of the seed on its supporting probe in a fixed horizontal plane at the hottest zone of the arc, is achieved by continuously lowering the probe at a rate coninciding with the rate of crystal growth in the flame. The platform on which the probe is mounted is controlled by twin screws which are driven by a variable speed motor. The lowering rate may be set anywhere within the range of 0.001 to 1.25 inches per minute. Lateral adjustments of the probe and fusion chamber are also available to assist in obtaining the proper coordination of the feed, the seed, and the probe. The probe rotation speeds which have been used vary from 90 revolutions per hour up to several hundred revolutions per minute.

As the fused rod is lowered, it enters a cooling chamber which protects the UO from oxidation while it is being cooled. Inert or reducing gases flowing upward through the chamber serve as both protective and cooling media. The actual melting takes place within a refractory lined fusion chamber which is equipped with an off-gas removal vent. This minimizes operational hazards such as exposure to heat, ultraviolet light, and uranium oxide fumes.

Experimental Results and Discussion

A summary is given in Table $I$ of the weight, length, diameter, growth rate, and density of UO, boules grown since the last report. Figure 3 shows a photograph of Boules 16 and 18 . 


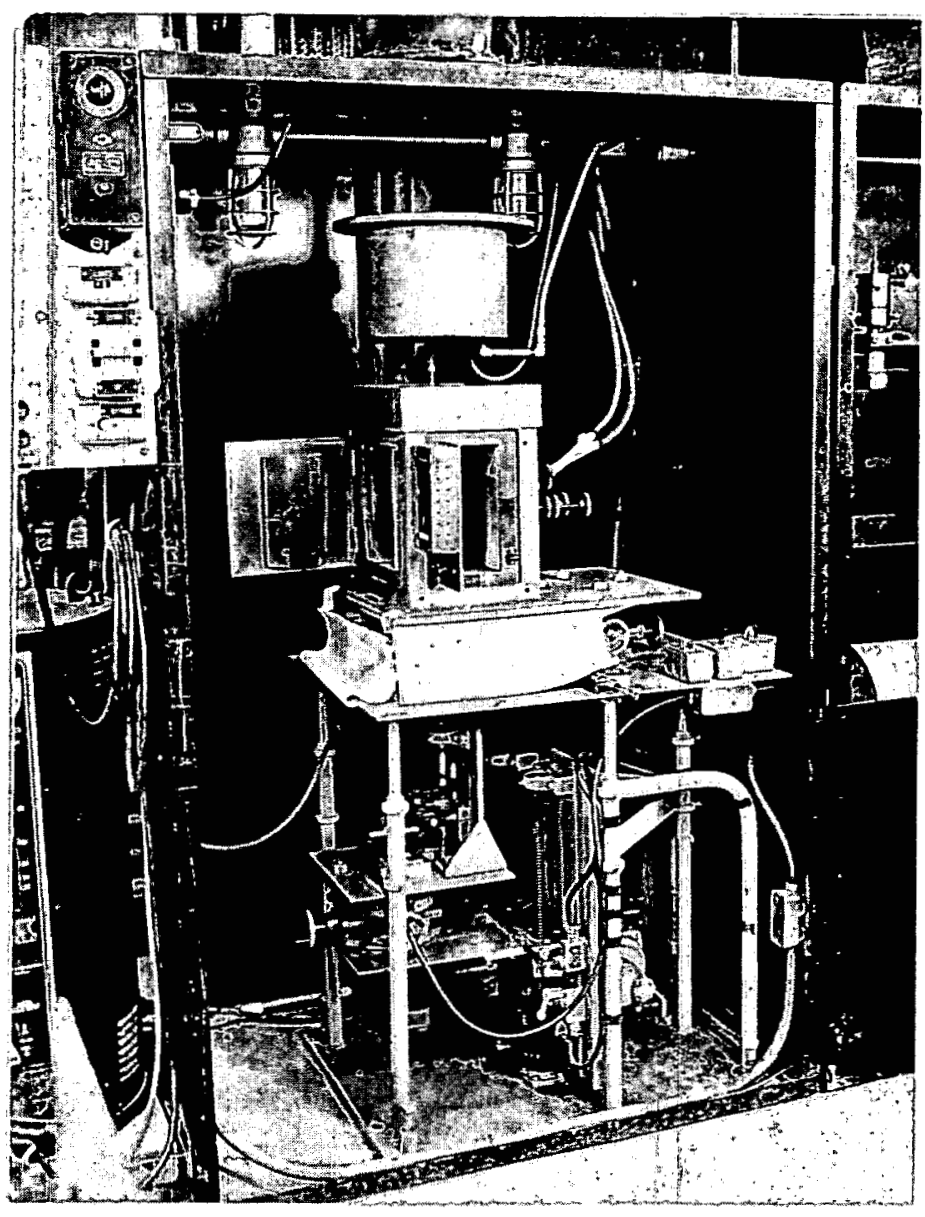

Figure 2

Flame Fusion Unit 

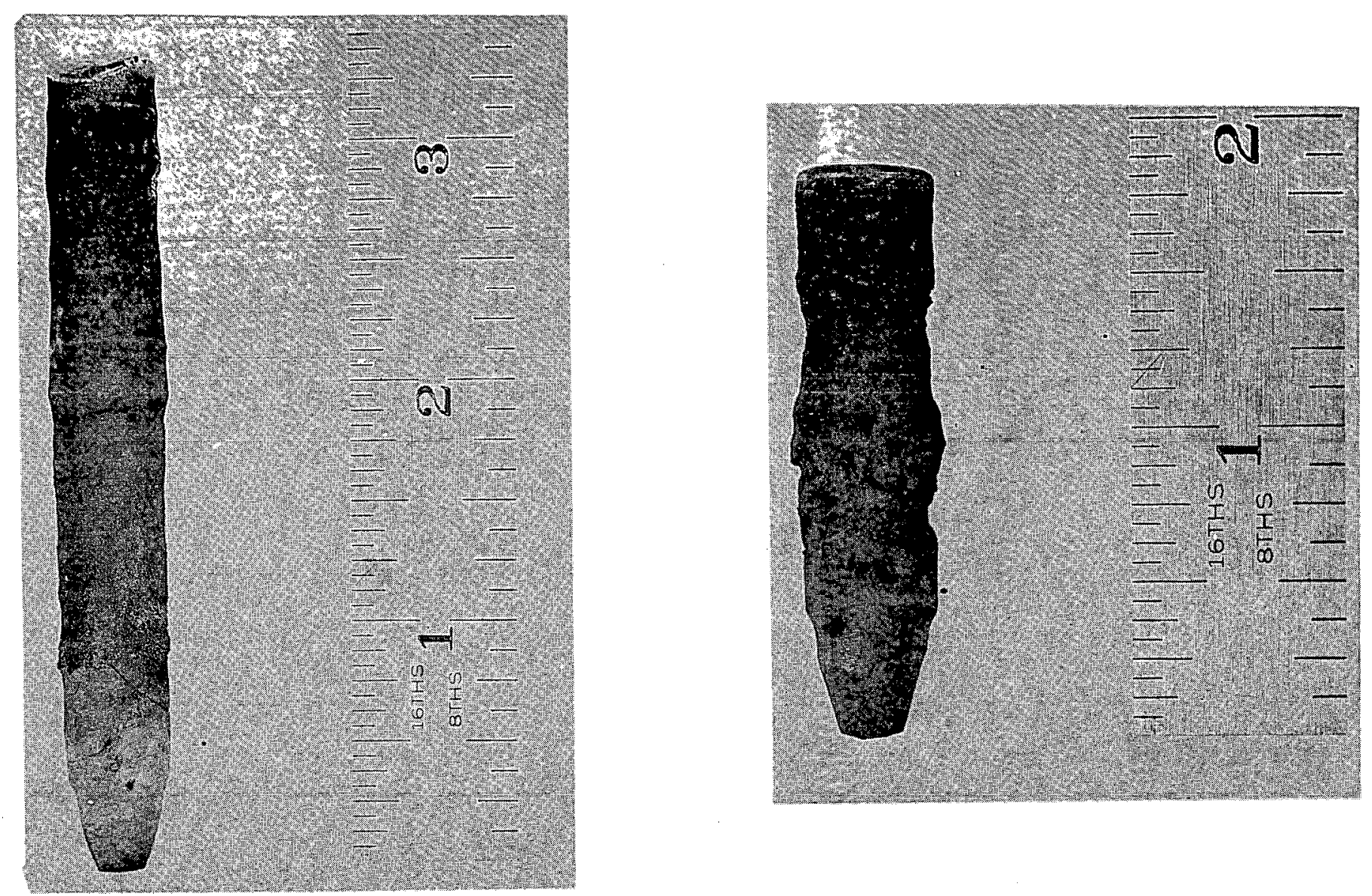

Figure 3

Boules 16 (left) and 18

…...

$\vdots \ldots .$.

$\ldots:$.

:०!:

: " :

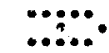

$\vdots \ldots .$.

$\therefore .$.

$\vdots \ldots+\therefore$

:......: 
The heaviest boule of pure $\mathrm{UO}_{2}$ grown to date is Boule 22. Boule 21 is the longest yet produced. Boule 18 was produced at the highest growth rate yet achieved. Boule 15 has the highest density yet achieved.

The largest pure $\mathrm{UO}_{2}$ boule reported previously was Boule $7,^{2}$ which weighed only 26 grams. It was one-half inch in diameter by five-eighths inch long and was produced at a rate of 26 grams of $\mathrm{UO}_{2}$ per hour. The density of Boule 7 , the highest previously reported for pure $\mathrm{UO}_{2}$, was only $86.0 \%$ of the theoretical maximum.

The density of the boules is measured by weighing them in air and then immersed in mercury. The previous low densities obtained appeared to be caused by occlusion of gas in the boules during the melting operation. Examination of the more recent boules which have higher densities indicates that much less gas was entrapped.

The improvements in size, growth rate, and density of the boules grown are due both to faster probe rotation and mechanical improvements in the apparatus such as the addition of the fusion chamber and to better electrode positioning control. Boules up through number 14 were grown with a probe rotation speed of $1.5 \mathrm{rpm}$. Boules 15 through 23 were grown with probe rotation speeds of $110 \mathrm{rpm}$ or more. Fast rotation helps prevent the formation of large piles of powder on top of the boule under which gas can be trapped. The use of very fast feed rates, however, such as were used in producing Boule 18, can still deposit piles of material which trap gas and cause lowered density.

Several boules have been polished and etched to determine the grain size. The specimens were 1) imbedded in thermoplastic, 2) polished with 180-grit silicon carbide, and 3) further polished with diamond dust. Then the sample was etched with $10 \mathrm{v} / \mathrm{o}$ concentrated $\mathrm{H}_{2} \mathrm{SO}_{4}-90 \mathrm{v} / \mathrm{o}$ hydrogen peroxide ( $30 \%$ solution) for approximately one minute. Microscopic examination showed that grain sizes up to one-eighth inch in diameter have been attained. Figure 4 shows the top of Boule 19 prior to polishing and etching. Some of the grains in this surface of last solidification are as large as one-sixteenth inch in diameter.

The polycrystallinity of the boules is evidently due to the manner in which the $\mathrm{UO}_{2}$ is solidified rather than to any influence of the polycrystalline nature of the seeds. Slivers were taken from Boule 19 and used as seeds for growing Boules 20 and 21. Figure 5 shows these silvers of $\mathrm{UO}_{\hat{3}}$ prior to their removal from the boule. The cross-sections of each sliverwere monocrystalline, but Boules 20 and 21, which were grown from them, were polycrystalline. Reducing the thermal gradients in the top of the boule as it is being grown may allow the growth of larger crystals.

2 Hedley, W. H., Process Development Quarterly Report, Part Il, Mallinckrodt Chemical Works, MCW-1404 (August 1, 1957), p 57.59 
Figure 5

Boule 19 , Side View

:.....

:...: :

(......

1...:

(......

:

: " :

$\because \ldots$

:

$\because \because$

$\cdots$

$\vdots \ldots . .:$

:....:
Figure 4

Boule 19, Top View

Magnification $2 \mathrm{X}$

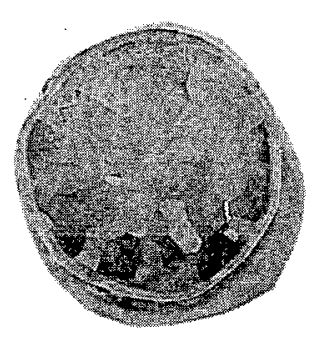

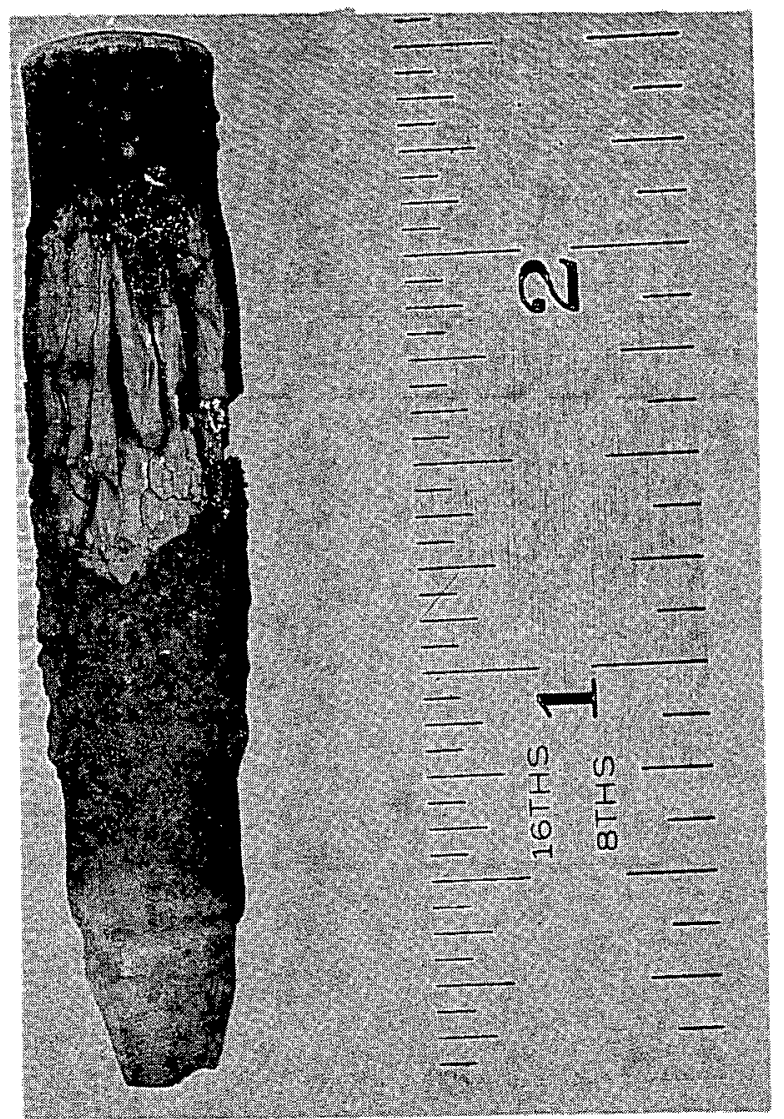


Boule 19 was grown from pure pot-denitrated $\mathrm{UO}_{3}$. X-ray analysis of the resulting boule showed that the composition of the product lay somewhere between $\mathrm{UO}_{2: 00}$ and $\mathrm{UO}_{2.03}$. This shows that the flame fusion process can be used to convert $\mathrm{UO}_{3}$ powder into a solid piece of high purity $\mathrm{UO}_{2}$ in one operation.

Work on this project will continue. 
AOI

billet

black oxide

brown oxide

derby

dingot

DMFL

$\mathrm{E}_{\mathrm{A}}^{0}$

ESU

green salt

I \& E slug

ingot

MFL

NOK

OK-liquor

orange oxide

$P$ - D

preignition time
- ammonium oxalate insoluble

- a bar of forged dingot uranium suitable for subsequent rolling

$-\mathrm{U}_{3} \mathrm{O}_{8}$

$-\mathrm{UO}_{2}$

- the uranium metal product of the nominal 300-, 100-, and 500-lb reduction bombs which is subsequently recast

- (direct ingot) the uranium metal product of 1400- and 3300-1b reduction bombs. This metal not recast.

- dingor magnesium fluoride liner

- distribution coefficient (organic to aqueous)

- easily soluble uranium

$-\mathrm{UF}_{4}$

- (hollow) internally and externally cooled slug

- recast uranium metal

- magnesium fluoride liner

- a uranyl nitrate solution obtained by stripping uranyl nitrate from tributyl phosphate-hexane solvent with water

- the uranyl nitrate liquor of highest purity used as a feed to the denitration pots

$-\mathrm{UO}_{3}$

- pumper-decanter

- time interval between placing bomb in hot furnace and initiation of reduction reaction 
Glossary (continued)

raffinate

RMF

rod

shotgun

slag

slug

soda-salt

UNH

U-Con

U-Mag

701-metal

C-701

- the aqueous residue remaining after tributyl phosphate extraction of a uranium concentrate previously digested with $\mathrm{HNO}_{3}$

- reject magnesium fluoride

- cylindrical length of uranium produced by rolling or extruding uranium billets or ingots

- a per cent increase of neutron absorption cross-section due to impurities in the product; pure $\mathrm{U}_{3} \mathrm{O}_{8}$ has a shotgun of zero

- magnesium fluoride, containing small quantities of uranium and magnesium formed in the thermite bomb reaction

- rods of uranium machined to specific diameter and lengths. Slugs, when canned, are used as fuel elements.

- sodium diuranate; usually applied to raw materials of that composition

- uranyl nitrate hexahydrate

- a product of the physical separations plant consisting of a mixture of fine metal particles, uranium oxides, and magnesium fluorides, screened to -10 mesh and as saying $70-75 \%$ uranium

- an intermediate product of the physical separations plant consisting of the $\$ 10$ mesh oversize from the screening of ground RMF. It is further separated to 701-metal and C-701.

- the metal concentrate product of the physical separations plant consisting of uranium metal particles ranging in size from +10 mesh to $1 / 2$ inch and assaying $95 \%$ uranium

- the reject product of the physical separations plant consisting chiefly of finely ground magnesium fluoride 